\title{
Persons at risk during interrogations in police custody
}

Citation for published version (APA):

Geijsen, K. (2018). Persons at risk during interrogations in police custody: Different perspectives on vulnerable suspects. [Doctoral Thesis, Maastricht University]. Ipskamp Printing BV. https://doi.org/10.26481/dis.20181101kg

Document status and date:

Published: 01/01/2018

DOI:

$10.26481 / \mathrm{dis} .20181101 \mathrm{~kg}$

Document Version:

Publisher's PDF, also known as Version of record

\section{Please check the document version of this publication:}

- A submitted manuscript is the version of the article upon submission and before peer-review. There can be important differences between the submitted version and the official published version of record.

People interested in the research are advised to contact the author for the final version of the publication, or visit the DOI to the publisher's website.

- The final author version and the galley proof are versions of the publication after peer review.

- The final published version features the final layout of the paper including the volume, issue and page numbers.

Link to publication

\footnotetext{
General rights rights.

- You may freely distribute the URL identifying the publication in the public portal. please follow below link for the End User Agreement:

www.umlib.nl/taverne-license

Take down policy

If you believe that this document breaches copyright please contact us at:

repository@maastrichtuniversity.nl

providing details and we will investigate your claim.
}

Copyright and moral rights for the publications made accessible in the public portal are retained by the authors and/or other copyright owners and it is a condition of accessing publications that users recognise and abide by the legal requirements associated with these

- Users may download and print one copy of any publication from the public portal for the purpose of private study or research.

- You may not further distribute the material or use it for any profit-making activity or commercial gain

If the publication is distributed under the terms of Article $25 \mathrm{fa}$ of the Dutch Copyright Act, indicated by the "Taverne" license above, 
Koen Geijsen

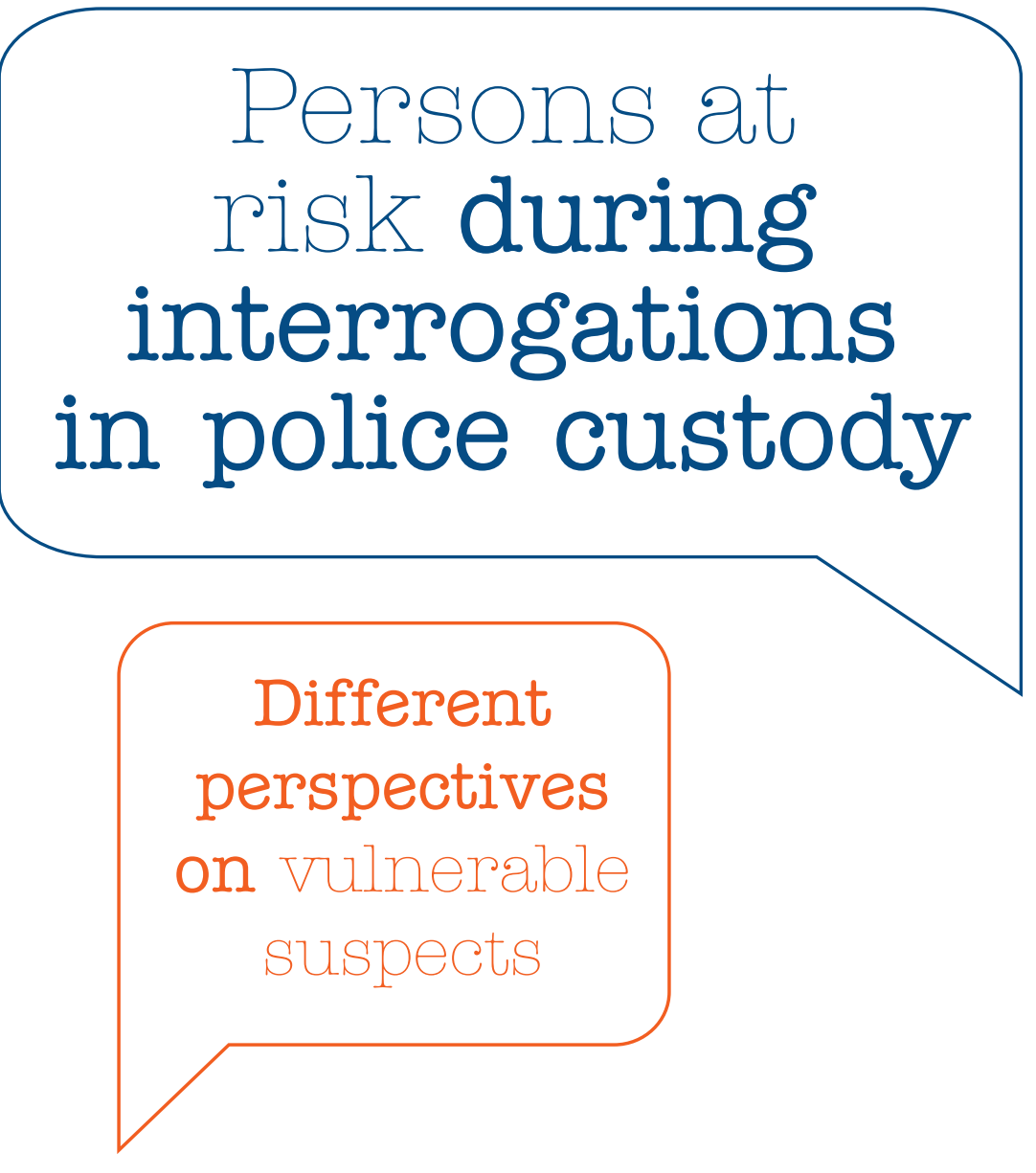



Koen Geijsen

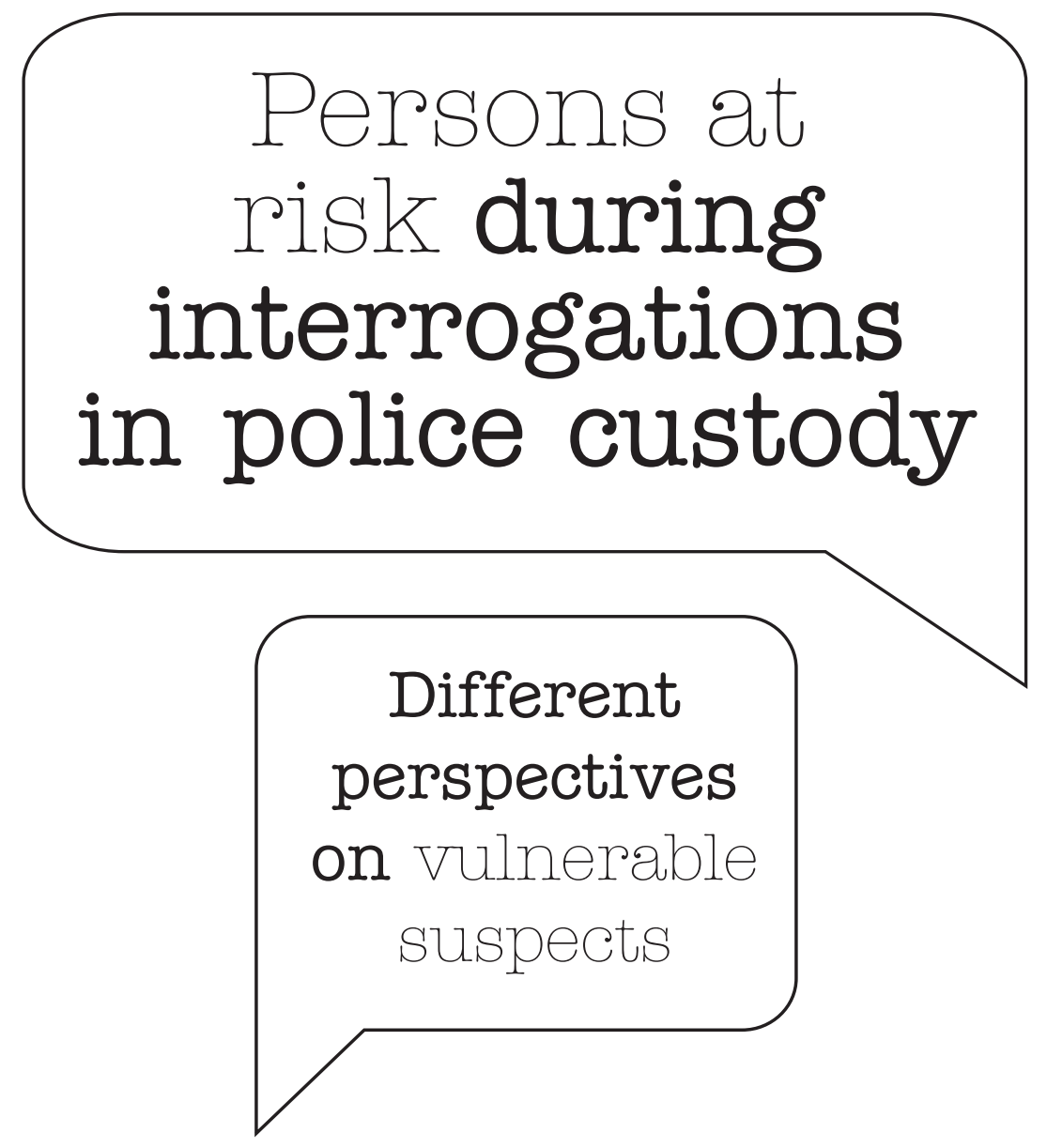


ISBN: 978-94-028-1204-6

Illustration \& cover design \& lay-out: Esther Beekman (www.estherontwerpt.nl).

Printed by: Ipskamp printing, Enschede

\section{(C) 2018 Koen Geijsen}

All rights reserved. No part of this dissertation may be reprinted, reproduced, or utilized in any form or by any electronic, mechanical, or other means, now known or hereafter invented, including photocopying and recording or any information storage or retrieval system, without prior written permission of the author. 


\section{Persons at risk during \\ interrogations in police custody \\ Different perspectives on vulnerable suspects}

\section{DISSERTATION}

to obtain the degree of Doctor at Maastricht University

on the authority of the Rector Magnificus Prof. dr. Rianne M. Letschert in accordance with the decision of the Board of Deans to be defended in public on Thursday 1 November 2018 at 12:00 hours

by

Koen Geijsen 


\section{Supervisor}

Prof. dr. Corine de Ruiter

\section{Co-Supervisor}

Dr. Nicolien Kop (Police Academy of the Netherlands)

\section{Assessment Committee}

Prof. dr. Marko Jelicic (Chair)

Dr. Robert Horselenberg

Prof. dr. Harald Merckelbach

Prof. dr. Christianne de Poot (Vrije Universiteit Amsterdam)

Prof. dr. Eric Rassin (Erasmus University Rotterdam) 



\section{CONTENTS}


Chapter One

Chapter Two

Chapter Three

Chapter Four

Chapter Five

Chapter Six

Chapter Seven
General introduction

Identifying psychological vulnerabilities

25

Studies on police suspects' mental health issues and police officers' views

Screening for intellectual disability

in Dutch police suspects

The interrogation of police suspects

65 in the Netherlands

Current practices

The interrogation of vulnerable suspects

75 in the Netherlands

An exploratory study

Staying overnight in a police cell

95

A study on suspects' psychological wellbeing

and sleep problems

General discussion

111

Summary

Samenvatting | Summary (in Dutch)

Valorisation Addendum

References

Dankwoord | Acknowledgements (in Dutch) 
I left the CUBT* because it was a factory.

Everything had to be done

in a hurry. There never was time to

interrogate someone properly and

appropriately. I did not agree with that,

I did not want to work like that.

But hey, the supervisors were forced

to do it that way, they are being

judged on statistics.

Police officer, District 1, Amsterdam Police Force

(2016)

*Dutch acronym for 'Calamiteiten Unit Basis Team':

a district criminal investigation unit within

the Amsterdam police force, which investigates

common violations and felonies. 
Chapter One

\section{General \\ introduction}




\section{Case 1: The Ina Post case}

In the evening of 22 August, 1986, the body of an 89-old lady was found in her apartment of a home for the elderly. In the beginning, the police had no clue about who committed the homicide. The only evidence was bank cheques of the old woman that were stolen at the time of the murder and found one day later in a shop where they had been cashed. All nurses of the elderly home were forced to complete a writing test, in order to be compared with the handwriting on the bank cheques. So did nurse Ina Post. The police noticed Ina Post was very nervous at the time of this test, and a number of resemblances between Ina's handwriting and the handwriting on the cheques were found. However, the handwriting of two of Ina's colleagues also resembled the handwriting on the cheques, but the police did not report this in the judicial file. From that moment on, Ina was regarded as the main suspect in this homicide case, and after being interrogated intensively for four days in a row, she confessed the murder. There were many inconsistencies in her statements, but because no recordings were made of the interrogations, no one will ever know what exactly happened in the interrogation room (Gosewehr \& Timmerman, 2007; Israëls, 2004). Subsequently, Ina Post stated that she just desperately wanted to escape the manipulative interrogation techniques and the tremendous amount of pressure put on her during the interrogations, yet this statement was ignored by the Court. In 1987 Ina Post was sentenced to six years imprisonment based on her confession - which was later deemed to be false - and on flawed Bayesian statistical argumentation. It took 24 years before the High Court of the Netherlands ruled that the case had to be reconsidered. On 6 October, 2010, Ina Post was found innocent by the Appeals Court of 's Hertogenbosch, the Netherlands, and was acquitted of all charges.

\section{Case 2: The Mohammed D. case}

On a Sunday morning in the autumn of 2001, the body of a young woman was found at a parking lot in Maastricht, the Netherlands. She had been killed. About 10 days later, Mohammed D., an inhabitant of Maastricht with Moroccan roots, was arrested for this homicide because he fit the description eyewitnesses had given to the police. After prolonged interrogations, Mohammed D. not only partially confessed to the murder, but he told the police detectives that he wanted to be treated for his problems and that he wanted to be punished for his bad deeds as well. Despite his strange and incoherent statements, the detectives did not consult a police psychologist and produced an extensive police file of more than 2000 pages. In a later stage of the investigation process, Mohammed D. was assessed by a psychiatrist and psychologist 
of the Netherlands Institute of Forensic Psychiatry and Psychology (NIFP) and was diagnosed with schizophrenia and intellectual disability. Still, the public prosecutor thought the defendant's incoherent statements were proof of guilt. The Appeals Court and the High Court of the Netherlands ruled that Mohammed D. falsely confessed the murder, thus rendering all the efforts of the police and the public prosecution service futile (De Ruiter, Peters, \& Smeets, 2010).

\section{Case 3: The Schiedam park murder case}

On June 22, 2000, in a park in Schiedam, the Netherlands, Nienke Kleiss (10) was sexually abused and murdered. Her friend Maikel (11) was stabbed in his neck but not critically injured, and by playing dead he survived the attack. He succeeded to escape and ran into Kees B. in the park, who immediately called the emergency number. Early in the police investigation, a police officer recalled that a few weeks earlier Kees B. had been a suspect in a sexual offence case, and as a result, Kees B. became the main suspect of the assault on Nienke and Maikel. After his arrest, Kees B. confessed the murder during one of the first interrogations, although he denied the crime the next day and in all subsequent interrogations. A lot of the other evidence exculpated him as the perpetrator as well, for example, the description of the perpetrator did not match the physical appearance of Kees B. at all, and DNA samples found at the crime scene did not match with Kees B.'s DNA profile. Furthermore, important evidence about other potential suspects was left out of the police file, and Kees B.'s statements did not match the statements of witnesses. Nevertheless, Kees B. was sentenced to 18 years imprisonment and mandatory psychiatric treatment under the TBS order (Van Koppen, 2003). Four years later, a DNA sample of a suspect in another crime case matched the DNA sample found on Nienke, and soon after this Kees B. was released from prison and the actual culprit was convicted. In the years afterwards, it became clear that from the moment Kees B. was arrested, the police had made serious mistakes during the investigative process due to tunnel vision and confirmation bias (Van Koppen, 2009). 


\section{General introduction}

Most people are convinced that a suspect who is not guilty will not confess a crime he or she did not commit (Appleby, Hasel, \& Kassin, 2013; Farrugia \& Milne, 2012), however, the previously described cases show otherwise. It is impossible to make an exact estimate of the prevalence of false confessions because if the innocence of a suspect is proven prior to trial, the case is dismissed (Kassin, 2017). However, a body of research has shown that false confessions occur quite frequently (Gudjonsson, 2010; Kassin, 2017), including in the Netherlands (Van Koppen, 2009). In the United States of America, false confession rates are believed to be around $13 \%$, and around 25\% in DNA exoneration cases (Bedau \& Radelet, 1987; Gross, Jacoby, Matheson, \& Montgomery, 2005; Kassin, 2017). ${ }^{1}$

The three cases also illustrate that a false confession has serious consequences. First and foremost, it results in serious ramifications for the suspect, such as prison time or mandatory admission to a forensic psychiatric hospital, which in turn results in lost years, trauma, and social stigma. In an interview immediately after her acquittal, Ina Post told an interviewer:

'It has affected almost half of my life. I was almost 30 at that time, I was about to make choices in life, which did not happen (...)' (EenVandaag, 2010).

Second, the three false confession cases illustrate that biases, such as confirmation bias and guilty bias, and inappropriate interrogation techniques, contribute to less effective police investigations. If police investigations had been properly executed and suspects had been interrogated in an appropriate manner, the police could have focussed on other evidence and other potential suspects, and, foremost, innocent suspects would not have been wrongly sent to prison.

Third, false confessions and their consequences may harm societal trust in the police, the public prosecution service, and the criminal justice system. Each time a false confession case is exposed, the general public loses trust in the legal system.

\footnotetext{
${ }^{1}$ For more information about (research on) false confessions and DNA exoneration cases, see:

(1) FalseConfessions.org: www.falseconfessions.org

(2) The Innocence Project: www.innocenceproject.org

(3) National Registry of Exonerations: www.law.umich.edu/special/exoneration/Pages/about.aspx

(4) Knoops' Innocence Project: www.knoops.info/nl/knoops-innocence-project
} 


\section{Types of false confessions}

In the past, several theoretical models have been proposed as to why suspects make false confessions (Kassin \& Wrightsman, 1985; Ofshe \& Leo, 1997). Gudjonsson (2003) refined these models because in his opinion little attention was paid to pressure used by police officers, the custodial environment, non-police coercion (being coerced by a peer or spouse to confess), and psychological vulnerabilities. Gudjonsson's model distinguishes between three types of false confessions. The first type is a voluntary false confession, supposedly caused by the desire to protect the real perpetrator, a pathological desire for notoriety, or because of an inability to distinguish facts from fantasy. The second type is a coerced-compliant false confession. In this case, the suspect gives a false confession in an attempt to escape the stressful interrogation situation, to gain a promised (or implied) reward, or to avoid punishment. The third type, an internalized false confession, occurs when suspects develop a profound distrust of their memory, for example, due to highly suggestive interrogation tactics, making them psychologically vulnerable to the influence of the interrogator. Suspects confabulate false memories during this process (Gudjonsson, 2003; Kassin, 2017).

\section{Why false confessions occur}

In the past, researchers have addressed the following questions to investigate the nature of false confessions: why do police target innocent individuals as suspects, what types of interrogation techniques increase the risk that persons falsely confess, and what types of suspects are more vulnerable to falsely confess during interrogation (Kassin, 2017).

The answer to the first question why police target innocent people for suspicion is that police officers often engage innocent suspects with a guilty bias and a confirmation bias (Hill, Memon, \& McGeorge, 2008; Leo \& Drizin, 2010). In the Netherlands - as in most western countries - police officers may only arrest suspects when facts or circumstances have resulted in a reasonable presumption of guilt of a crime (Code of Criminal Procedure, 2018; Davis \& Leo, 2012; Hill et al., 2008). After the arrest, the public prosecutor decides if the suspect is charged with a crime. In the Netherlands, immediately after the arrest suspects are led before a deputy public prosecutor, which is a trained and certified police officer with the rank of Inspecteur (Inspector, the first rank in Dutch police management) or higher, who decides whether there is enough evidence to justify placement of the suspect in police custody for further investigation. Thus, if a suspect is detained in a police station or police detention centre, obviously police officers have serious reasons to think that the suspect is actually involved in a 
crime. First impressions occur quickly and are difficult to drop (St-Yves, 2006). Police interrogators who presume the suspect is guilty focus on obtaining a confession and use a more accusatory style of interviewing (Mortimer, 1994). Furthermore, if a suspect already has a criminal record, police interrogators are less inclined to give suspects the benefit of the doubt and are more inclined to put the emphasis on obtaining a confession rather than getting at the facts, and they will act in a more prejudicial and stereotypical manner (Moston \& Stephenson, 1993).

The second question was what types of interrogation techniques make some suspects vulnerable for providing a false confession. A police interrogation is an exceptional social situation in which police officers try to obtain as much information from suspects as possible (Kassin, 2015, 2017). Sometimes manipulative interrogation methods are used, such as inappropriate questions (e.g., leading questions, suggestive questions, proposing a hypothetical scenario), emotional provocation (e.g., appeal to selfinterest or conscience, reducing fears, offering moral rationalizations, encouraging to take responsibility for the offence), and physical intimidation (e.g., slamming a fist on the table, raising the voice), to overcome resistance of presumably guilty suspects in order to obtain a confession (Kassin et al., 2010; Kelly, Miller, Kleinman, \& Redlich, 2013; Verhoeven \& Stevens, 2012). Especially if a case lacks technical evidence, police officers tend to put more pressure on the suspect by using more persuasive and/or suggestive tactics (Häkkänen, Ask, Kebbel, Alison, \& Granhag, 2009). In addition, being in police custody increases stress in suspects, due to loss of liberty, lack of contact with relatives, and uncertainty about the future. The answer to the second question is that a combination of these circumstances may cause suspects to falsely confess (Kassin, 2017; Kassin et al., 2010; Rassin \& Israëls, 2014).

The answer to the third question, about what types of suspects are more vulnerable to falsely confess during interrogation, is that certain suspects are psychologically more vulnerable to provide a false confession (Gudjonsson, 2003; Kassin, 2017). Gudjonsson (2003) defined a psychologically vulnerable suspect as 'a person whose psychological characteristics or mental states render a suspect prone, in certain circumstances, to providing information which is inaccurate, unreliable (or invalid), or misleading' (p. 316). Gudjonsson divided psychological vulnerabilities of suspects into four groups: mental health problems, an abnormal mental state, intellectual disability, and vulnerable personality traits (Gudjonsson, 2003, 2010). These psychological vulnerabilities of suspects form an important part of a complex and dynamic process during police interrogations (Gudjonsson, 2003; Herrington \& Roberts, 2012; Kassin, 2017). 
Mental health problems refer to mental disorders, such as schizophrenia, attention deficit hyperactivity disorder (ADHD), and depression. People suffering from mental disorders experience difficulties with reality monitoring, which might impair their ability to differentiate between reality and fantasy. Psychopathology is also often accompanied by impaired judgement, mood disturbance, anxiety, feelings of guilt, and poor self-control (Gudjonsson, 2003, 2010; Kassin et al., 2010).

Suspects' intellectual disabilities affect interrogations in different ways. First, people with intellectual disabilities may not understand their legal rights, even when carefully explained to them (Gudjonsson, 2003). Further, suspects with limited intellectual abilities have trouble understanding and answering questions, understanding consequences of their answers, and are more easily intimidated by police officers (Gudjonsson \& Joyce, 2011). Moreover, these suspects show higher levels of compliance, interrogative suggestibility, acquiescence, and fantasy proneness, as well as impaired memory capacity (Gudjonsson, 2003; Gudjonsson \& Joyce, 2011).

Suspects who find themselves in an abnormal mental state are not necessarily suffering from mental health problems, but are experiencing, for example, high levels of acute stress and/or anxiety, symptoms related to alcohol and/or drug abstinence, or sleep problems. Anxiety and stress can be induced by the fear of being in police custody, in view of the police investigation, and by phobic symptoms (e.g. claustrophobia). Individuals addicted to alcohol or drugs may experience high levels of stress and anxiety due to withdrawal symptoms (Gudjonsson, 2010; Kassin et al., 2010). Sleep problems increase the likelihood that police suspects falsely confess (Blagrove, 1989; Frenda, Berkowitz, Loftus, \& Fenn, 2016; Kassin et al., 2010).

Personality traits are specific characteristics of individuals. Gudjonsson $(2003,2010)$ identified three important traits which increase a suspect's vulnerability to falsely confess: interrogative suggestibility, compliance, and acquiescence. These traits can make a suspect give in to pressure or leading questions or to clues provided by the interrogators, which may result in a false confession (Gudjonsson, 2003; Smeets, Leppink, Jelicic, \& Merckelbach, 2009). Interrogative suggestibility and compliance show similarities in a number of aspects, such as eagerness to please, social desirability, anxiety, and an avoidant coping style, thus the two concepts are overlapping rather than completely distinct. However, compliance refers to the tendency to deliberately obey instructions and comply with requests for some immediate instrumental gain, while interrogative suggestibility concerns the private acceptance of suggestions. Acquiescence is the tendency to give affirmative answers to questions (Gudjonsson, 1989, 2003). 


\section{Research questions of the dissertation}

During the last two decades, it has become more widely recognised that psychologically vulnerable suspects are at risk during interrogations in police custody. Much has been learned about psychological vulnerabilities in police suspects (e.g., Baksheev, Thomas, \& Ogloff, 2012; Blaauw, Kerkhof, \& Vermunt, 1998; Dorn, Ceelen, Buster, \& Das, 2013; Dorn et al., 2014; Gudjonsson, 2010; Young, Goodwin, Sedgwick, \& Gudjonsson, 2013; Herrington \& Roberts, 2012), but in the Netherlands, this issue has not been tested in the context of actual interrogations during police custody. This dissertation aims to examine this issue.

The first two research questions are how often police officers engage psychologically vulnerable suspects during interrogations, and if police officers are able to make an adequate estimation of the prevalence of vulnerable suspects. The third research question is whether current Dutch interrogation techniques can, in theory, be considered appropriate for questioning vulnerable suspects. Subsequently, the fourth research question is how police suspects - and vulnerable suspects in particular - are interrogated in practice. The fifth and final research question is how police suspects experience their psychological wellbeing and sleep problems while being in police custody.

\section{Dissertation outline}

\section{Framework}

This dissertation follows the framework proposed by Gudjonsson and MacKeith (1988, 1997), later refined by Gudjonsson (2003). The aim of the framework is to assess the ability of suspects to cope with an interrogation situation during police custody and to provide a standard which psychologists and psychiatrists may use when giving expert testimony in court.

Gudjonsson and MacKeith published an article in 1988 on the assessment of cases where suspects retracted self-incriminating statements. Based on their experiences and relevant literature, they proposed a standard to assess defendants to assist in evaluations and writing court reports, which comprised an assessment of psychological variables (e.g., intellectual disabilities, neuropsychological status, personality disorders, and phobic symptoms), mental state (e.g., anxiety level, withdrawal symptoms because of alcohol, drugs or medication use), knowledge about relevant statements to provide background to the case and to circumstances in which the statements were made, as 
well as interrogation techniques, and circumstances in police detention (Gudjonsson \& MacKeith, 1988).

The framework is called CIPH, which is an acronym for Circumstances, Interactions, Personality, and Health. Circumstances refer to a variety of factors which influence attitudes and behaviour of the suspect and the police (Gudjonsson \& MacKeith, 1997). Suspects are affected by different circumstances, such as a violent arrest, timing and duration of the interrogation(s), and the physical circumstances in police custody (Gudjonsson, 2003). Interaction refers to the complex process of police officers interrogating suspects and covers a wide range of non-verbal and verbal communication aspects. In addition, interrogators' biases and interrogation style must be taken into account (Gudjonsson, 2003; Gudjonsson \& MacKeith, 1997). Personality is defined as suspects' enduring psychological qualities, while Health refers to a suspect's physical and mental health (Gudjonsson \& MacKeith, 1997). A suspect's mental and physical health may affect the reliability of statements, due to high stress levels, medication use, intoxication with drugs and/or alcohol, withdrawal symptoms, and/or a mental disorder (Gudjonsson, 2003). Gudjonsson and MacKeith (1997) emphasized 'the importance of not solely assessing psychological vulnerabilities in police suspects, but to interpreter these vulnerabilities within the context of all information available' (p. 16).

\section{Outline of the dissertation}

The outline of this dissertation follows the CIPH framework, albeit in reverse order. First, the prevalence of a number of psychological vulnerabilities in police suspects is examined, as well as the ability of police officers to estimate the prevalence of these vulnerabilities (Chapter Two). Second, one specific vulnerability, intellectual disability, is examined (Chapter Three). Next, police officers' interaction with vulnerable suspects is explored, by focussing on Dutch police interrogation practices in theory (Chapter Four) and in practice (Chapter Five). In addition, suspects' psychological wellbeing and sleep problems when detained in police detention centres are investigated (Chapter Six). Finally, the results of the set of studies are summarised and discussed (Chapter Seven). The studies reported in the chapters are described in more detail in the next paragraphs.

\section{Personality and Health: Psychological vulnerabilities}

Chapter Two is a close replication of prior research on vulnerable suspects conducted by Gudjonsson, Clare, Rutter, and Pearse (1993). The prevalence rate of several psychological vulnerabilities in police suspects in the Netherlands is explored, namely mental disorders, an abnormal mental state, and specific personality characteristics 
of suspects. In addition, the views of Dutch police detectives on the identification of vulnerable suspects are examined, to estimate to what extent they are aware of psychological vulnerabilities among police suspects.

Chapter Three addresses a specific vulnerability in police suspects: intellectual disability. Many people suffering from intellectual disability are quite apt at disguising their disability and thus may appear to possess normal intellectual capacities. However, in interrogation situations intellectually disabled suspects may face problems with understanding questions and estimating the consequences of their answers. In addition, the predictive accuracy of a recently developed Dutch screening instrument for mild intellectual disability (SCIL; Kaal, Nijman, \& Moonen, 2013) is examined, to explore if the SCIL is a usable screener for the police to screen for intellectual disability in police suspects. The research questions are whether the SCIL is a valid instrument for the police to screen for intellectual disability in police suspects, and what the prevalence rate of intellectual disabilities in police suspects is.

\section{Interaction: Interrogation}

Chapter Four discusses concerns about a number of contentious aspects of an important Dutch interrogation method termed the General Interrogation Strategy (GIS; in Dutch: Standaard Verhoorstrategie, SVS), commonly used by police officers, and described in the Interrogation Manual (Handleiding Verhoor; Van Amelsvoort, Rispens, \& Grolman, 2015). This Manual is currently in its seventh edition, in which the GIS is renamed the Scenarios Investigative Method (Scenario's Onderzoekende Methode, SOM; Van Amelsvoort \& Rispens, 2017), but essentially the interrogation strategy has remained unchanged. A major problem with the GIS/SOM is that its effectiveness has never been empirically tested. This contrasts with police interviewing practices in other countries, for example, the United Kingdom, Australia, Canada, New Zealand, and Norway (Bull \& Soukara, 2009; Oxburgh, Myklebust, \& Grant, 2010; Walsh \& Bull, 2015). Chapter Four discusses the question whether the current Dutch police interrogation method is in line with the empirical evidence regarding optimal investigative interviewing (Farrugia \& Milne, 2012; O’Mahony, Milne, \& Grant, 2012), particularly in view of the psychological vulnerabilities suspects may present (Herrington \& Roberts, 2012).

Chapter Five focuses on the actual execution of police interrogations, and especially those with vulnerable suspects. After the assessment of a number of psychological vulnerabilities in police suspects, interrogations of these suspects were analysed in 
terms of appropriateness. Although the goal of a police interrogation should be factfinding into what exactly happened during the alleged crime (Van Amelsvoort, Rispens, \& Grolman, 2017; Vrij, 2010), most police officers will admit that a confession of a suspect is the crowning glory of every interrogation (Blom, 2011; Hill, Memon, \& McGeorge, 2008; Kortlever, 2011; Rassin \& Israëls, 2014). This is because a confession is generally seen as an important and powerful piece of evidence in a criminal investigation, while people tend to believe a suspect who is not guilty will not confess (Appleby, Hasel, \& Kassin, 2013; Beune, 2009; Farrugia \& Milne, 2012). To date, what exactly happens in Dutch police interrogation rooms is largely unknown. The research question examined in Chapter Five is whether vulnerable suspects are interrogated appropriately.

\section{Circumstances: Police detention centre environments}

Chapter Six concerns how an overnight stay in a police cell may impact suspects' experiences of mental wellbeing and sleep problems. In the Netherlands, police detention centres vary to a great extent in terms of interior design (e.g., colour, space, amount of daylight), services, and number of staff. The interiors are mostly designed to foster safety of suspects and staff and to serve efficiency (e.g., hygiene, cleaning, routing). They are not specifically designed in view of suspects' comfort and wellbeing. Prior research has addressed the effects of prison environments on inmate behaviour, wellbeing of detainees and prison staff (Hancock \& Jewkes, 2011; Morris \& Worrall, 2010; Nurse, Woodcock, \& Ormsby, 2003). However, only few studies have addressed circumstances in Dutch police detention centres in relation to mental health problems of suspects (Blaauw, Kerkhof, \& Vermunt, 1998). The research question is to what extend staying in a police detention centre affects suspects' psychological wellbeing and sleep problems.

\section{Data collection}

Between June 24, 2014, and May 7, 2015, suspects in six different police detention centres across the Netherlands were invited to participate in a psychological assessment. All suspects were 18 years or older and placed in continued custody (inverzekeringstelling), meaning they were suspected of an offence for which they could be sentenced to a prison term for a minimum of four years, or they were suspected of a specific offence (e.g., assault, embezzlement, demolition, or the possession of certain drugs or weapons), or they were suspected of an offence in combination with homelessness - yet only if facts or circumstances indicate that the charge is substantiated, and that continued detention is absolutely necessary for the police investigation (Article 67 of the Code of Criminal Procedure, 2018). Before inviting suspects for the psychological 
assessment, the police detective department was contacted to ensure not to interfere with the investigative process in any way, in order not to harm suspects' legal rights. Suspects placed in an observation cell because of serious mental or physical health problems were not invited to participate, nor were suspects about to be released.

The assessments took place at the police detention centres located in Amsterdam $(n=37)$, Breda $(n=35)$, Eindhoven $(n=31)$, Heerlen $(n=26)$, Tilburg $(n=8)$, and Maastricht $(n=41)$. The assessors were able to invite 431 suspects for this study, and 275 suspects accepted the invitation. Eventually, 178 suspects completed the assessment. Hence, 97 suspects did not complete the assessment procedure for various reasons, such as major language problems, an unexpected immediate release, a lawyer visit, or because the suspect mentioned that he or she was suffering from a serious mental disorder. Figure 1.1 provides an overview of the recruitment process. The participants' age ranged from 18 to 63 years $\left(M_{\text {age }}=31.7, S D_{\text {age }}=11.2, M d n_{\text {age }}=\right.$ 27.5). Table 1.1 gives detailed demographic information on the 178 participants. The duration of the assessments was between 60 and 90 minutes.

The assessments were performed by the author of this dissertation and three Forensic Psychology Master's students of Maastricht University, the Netherlands. At the time of the assessments, the dissertation author held a Master's degree in Clinical Psychology and had obtained the Basic Qualification Psychodiagnostics (Basisaantekening Psychodiagnostiek; BAPD) ${ }^{2}$ of the Dutch Association of Psychologists (Nederlands Instituut van Psychologen; NIP), ${ }^{3}$ was a member of the NIP, and was not employed at

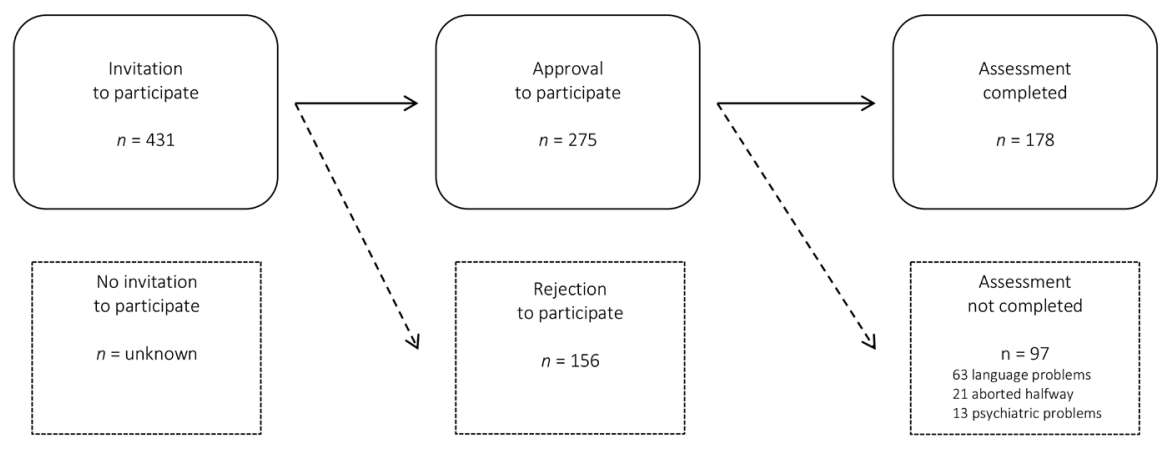

Figure 1.1. Recruitment of the participants for this study.

\footnotetext{
${ }^{2}$ https://www.psynip.nl/registraties/overige-registraties/basisaantekening-psychodiagnostiek-bapd/

${ }^{3}$ https://www.psynip.nl/en/
} 
the Dutch police. The three Master's students were screened by the Police Academy of the Netherlands before the start of the assessments. They had to sign a confidentiality agreement concerning all obtained information and observations during their presence in the police detention centres and the psychological assessments. They were closely supervised by the author of this dissertation during the data collection period.

The psychological assessment battery was designed to assess the previously mentioned four categories of psychological vulnerability (i.e., mental disorders, intellectual disability, abnormal mental state, and vulnerable personality characteristics). Yet, time constraints had to be taken into consideration, both in view of suspects' capabilities and the police investigation process, and therefore, the ultimate assessment battery consisted of a mix of complete instruments, screeners, and short forms. Table 1.2 shows the composition of the psychological assessment battery for this study.

Table 1.1. Demographic characteristics of the sample $(N=178)$.

\begin{tabular}{lrr}
\hline & $n$ & Percentage \\
\hline Gender & 162 & 91.0 \\
Male & 16 & 9.0 \\
Female & 57 & 31.5 \\
Education & 103 & 57.9 \\
Elementary school/ Special education & 18 & 10.1 \\
Low and intermediate level secondary school & 1 & .5 \\
High level secondary school / College / University degree & & \\
Missing & 133 & 74.7 \\
Nationality & 29 & 16.3 \\
Dutch & 16 & 9.0 \\
Dutch and other nationality & & \\
Other nationality than Dutch & 68 & 38.2 \\
Employment status & 110 & 61.8 \\
Employed or self-employed & & \\
Unemployed &
\end{tabular}


The instruments were administered in this order to ensure variation in terms of interview questions asked by the assessor, performance-based tasks, and questionnaires the participants had to fill out themselves.

The mBias (instrument 4) was dropped from the analyses because recent research showed that the mBias was not a reliable tool to screen for symptom exaggeration (Lange, Brickell, \& French, 2015; Lippa, Axelrod, \& Lange, 2016).

Additionally, police detectives of different subdivisions (e.g., departments of criminal investigation, sexual offences, and financial crimes) in seven (former) police regions of the Netherlands (i.e., Amsterdam, Limburg, Midden-Nederland, Oost-Brabant, Oost- Nederland, Rotterdam, and Zeeland West-Brabant) were invited by email to fill in an online questionnaire on the identification of vulnerable suspects. Eventually, 103 police detectives completed the questionnaire (Chapter Two).

\section{Fthical approval}

Before its start, approval for this study was given by the Ethical Review Committee Psychology and Neuroscience of Maastricht University (ERCPN number: 03_10_2014), the Office of the Attorney General of the Netherlands (College van ProcureursGeneraal), and the Chief Constable of the Police of the Netherlands (Korpschef). 
Table 1.2. Composition of the psychological assessment battery.

\begin{tabular}{|c|c|c|}
\hline \multicolumn{2}{|c|}{ Instrument } & \multirow{2}{*}{$\begin{array}{l}\text { Reference } \\
\text { (this dissertation) }\end{array}$} \\
\hline & $\begin{array}{l}\text { Questions concerning: } \\
\text { - Demographic data } \\
\text { - Sleep problems } \\
\text { - Use of alcohol, drugs, and medicines }\end{array}$ & \\
\hline 2. & WAIS-III-NL - Dutch short form & $\begin{array}{l}\text { Uterwijk, 2000; Velthorst } \\
\text { et al., } 2012\end{array}$ \\
\hline 3. & $\begin{array}{l}\text { Depression Anxiety and Stress Scale - } \\
\text { Dutch } 21 \text {-items version }\end{array}$ & De Beurs et al., 2001 \\
\hline 4. & $\begin{array}{l}\text { Mild Brain Injury Atypical Symptoms Scale } \\
\text { (mBias) }\end{array}$ & $\begin{array}{l}\text { Lange, Edmed, Sullivan, } \\
\text { French, \& Cooper, } 2013\end{array}$ \\
\hline 5. & $\begin{array}{l}\text { Mini Mental State Exam (MMSE) - } \\
\text { Dutch version }\end{array}$ & Kok \& Verhey, 2002 \\
\hline 6. & Brief Jail Mental Health State (BJMHS) & $\begin{array}{l}\text { Steadman, Scott, Osher, } \\
\text { Agnese, \& Clark Robbins, } \\
2005\end{array}$ \\
\hline 7. & Ultra Short ADHD questionnaire for adults & Kooij, 2009 \\
\hline 8. & $\begin{array}{l}\text { Gudjonsson Suggestibility Scale (GSS) - } \\
\text { Dutch 20-items short form }\end{array}$ & $\begin{array}{l}\text { Smeets, Leppink, Jelicic, } \\
\text { \& Merckelbach, } 2009\end{array}$ \\
\hline 9. & $\begin{array}{l}\text { Gudjonsson Compliance Scale (GCS) - } \\
\text { Dutch version }\end{array}$ & Smeets, 2008 \\
\hline 10. & $\begin{array}{l}\text { Wildman Symptom Checklist (WSC) - } \\
\text { Dutch short form }\end{array}$ & $\begin{array}{l}\text { Merckelbach, Smeets, \& } \\
\text { Jelicic, 2008; Merckelbach, } \\
\text { Langeland, De Vries, } \\
\text { \& Draijer, } 2014\end{array}$ \\
\hline 11. & $\begin{array}{l}\text { Screener for Intelligence and Learning } \\
\text { Disabilities (SCIL) }\end{array}$ & $\begin{array}{l}\text { Kaal, Nijman, \& Moonen, } \\
2013\end{array}$ \\
\hline 12. & Symptom Checklist 90-NL (SCL-90-NL) & Arrindell \& Ettema, 2005 \\
\hline
\end{tabular}


I have seen new colleagues perform interrogations as they have learned at the Police Academy.

These interrogations are unnecessarily long due to ridiculous reflection questions about feelings, which asked continually during the interrogation.

This irritates suspects and leads nowhere.

I have done murder case interrogations in the normal, old-fashioned way, and with result. Sometimes getting angry, sometimes raising your voice, sometimes letting the suspect know he is an asshole, or just rewarding the suspect for his honesty, is still the proper way to interrogate suspects.

Dutch senior police detective (2015) 


\section{Chapter Two}

\section{Identifying \\ psychological \\ vulnerabilities}

Studies on police suspects' mental health issues and police officers' views

This chapter is a modified version of the published paper:

Geijsen, K., De Ruiter, C., \& Kop, N. (2018). Identifying psychological vulnerabilities: Studies on police suspects' mental health issues and police officers' views. Cogent Psychology 5(1), 1462133. Published online 19 April 2018. DOI: 10.1080/23311908.2018.1462133. 


\section{Introduction}

In the last decades, there has been an increased interest in psychological vulnerabilities among police suspects. These vulnerabilities are 'psychological characteristics or mental states which render a suspect prone, in certain circumstances, to providing information which is inaccurate, unreliable (or invalid) or misleading' (Gudjonsson, 2003, p. 316). Several studies have demonstrated that psychological vulnerabilities in police suspects could interfere with the demand characteristics of an interrogation, for example with understanding the consequences of answers, and with giving a reliable, accurate and coherent statement (Gudjonsson, 2010; Gudjonsson \& Joyce, 2011; O’Mahony, Milne, \& Grant, 2012). Gudjonsson (2003) divides psychological vulnerabilities into four categories: mental disorders, intellectual disabilities, abnormal mental states, and personality characteristics. Mental disorders (e.g., schizophrenia, depression) and abnormal mental states (e.g., distress, alcohol or drug withdrawal) impact reality monitoring, perception, judgement, self-control, anxiety level, and mood, which may affect the accuracy of statements of suspects (Gudjonsson, 2010; Kassin et al., 2010). Police suspects who suffer from intellectual disabilities have trouble understanding their legal rights and the questions of the interrogators, and to oversee the implications of their answers (Gudjonsson, 2010; Gudjonsson \& Joyce, 2011). They also tend to confabulate more and face problems with memory capacity (Gudjonsson \& Joyce, 2011). It has been demonstrated that in numerous cases suspects falsely confessed due to a failure of police officers to identify psychological vulnerabilities in suspects (Applebye, Hasel, \& Kassin, 2013; Gudjonsson, 2010; Kassin, 2017; Kassin et al., 2010). Thus, it is important that police officers provide proper safeguards for a fair and effective police interview, for example, by adjusting interrogation methods, seeking assistance of a police psychologist, videotaping the interrogation, or ensuring a lawyer is present during the interrogations (Herrington \& Roberts, 2012; Kassin, 2017).

Yet, police officers have difficulty detecting vulnerabilities among police suspects (Gudjonsson, 2010; Kassin, 2012). This is partly because many people who suffer from mental disorders or intellectual disabilities are used to masking their vulnerabilities, because of social stigma (Herrington \& Roberts, 2012). There are several screening tools suitable for use by non-clinicians, but police officers must have an idea when to assess a specific vulnerability in order to select an appropriate screener (Herrington \& Roberts, 2012). Furthermore, police officers often lack time, skills, and/or inclination to conduct a screening (Herrington \& Roberts, 2012; Steadman, Scott, Osher, Agnese, \& Clark Robbins, 2005).

To the authors' knowledge, no research has yet examined the prevalence of 
psychological vulnerabilities in police suspects in the Netherlands, and it is unknown to what extent Dutch police officers are able to identify vulnerable suspects as well. This paper addresses these issues. In line with the research by Gudjonsson (e.g., Gudjonsson, 1993; 2003; 2010), Study 1 explores the prevalence of a number of important vulnerabilities in police suspects. For this purpose, 178 unselected police suspects, detained in six police detention centres across the Netherlands, were psychologically assessed. The rates of mental health problems, abnormal mental states, interrogative suggestibility, and compliance in police suspects will be compared with rates found in previous studies of general Dutch population samples. Study 2 aims to explore to what extent police officers believe they are able to note psychological vulnerabilities in suspects. For Study 2, 103 Dutch police detectives completed an online questionnaire about their police experience and training, their views on identifying vulnerable suspects, and the precautions they take when interrogating these suspects.

\section{Study 1}

\section{Introduction}

Gudjonsson, Clare, Rutter, and Pearse (1993) were the first to explore psychological vulnerabilities in police suspects prior to police interrogations. They assessed 156 police suspects detained in two London police stations over a period of six months, and examined suspects' mental states, psychological distress, intellectual functioning, reading ability, interrogative suggestibility, anxiety proneness, and understanding of legal rights. This was done by the use of a structured interview with questions about education, use of alcohol and drugs, medication, prior criminal convictions, mental disorders, detention circumstances and legal rights, and four additional psychometric tests, i.e., three subtests of the Wechsler Adult Intelligence Scale (WAIS-R; Wechsler, 1981), the Schonell Grades Word Reading Test (Schonell \& Goodacre, 1974), the Gudjonsson Suggestibility Scale (GSS-2; Gudjonsson, 1984), and the State-Trait Anxiety Inventory (Spielberger, Gorsuch, \& Lushene, 1970).

The assessment battery used in Study 1 was not an exact copy of the Gudjonsson et al. (1993) instruments but was adjusted in line with subsequent research on vulnerabilities in police suspects. Three instruments on vulnerabilities discovered in subsequent research (Gudjonsson, Hannesdottir, Petursson, \& Bjornsson, 2002a; Gudjonsson, Sigurdsson, Brynjolfsdottir, \& Hreinsdottir, 2002b; Gudjonsson, Sigurdsson, Sigfusdottir, \& Young, 2011) were added to the assessment battery in order to explore depression, attention deficit hyperactivity disorder (ADHD), and 
compliance. In addition, a test for malingering was included, because we assumed that some suspects during interrogation could feign problems with their mental health in order to be released more quickly or to be interrogated less intensively (Merckelbach, Langeland, De Vries, \& Draijer, 2014; Wildman \& Wildman, 1999).

\section{Method}

\section{Participants}

Between June, 2014 and May, 2015, 178 suspects placed in continued police custody participated in Study 1. The mean age of the participants was $M=31.7, S D=11.2, M d n$ $=28.0$, range $=18-60$. Participants were recruited in six different police detention centres across the Netherlands: Amsterdam $(n=37)$, Breda $(n=35)$, Eindhoven $(n=31)$, Heerlen $(n=26)$, Tilburg $(n=8)$, and Maastricht $(n=41)$. Demographic characteristics of the sample are shown in Table 2.1.

Table 2.1. Demographic data of the sample of Study $1(N=149)$.

\begin{tabular}{lrc}
\hline & $n$ & Percentage \\
\hline Gender & 13 & 8.7 \\
Female & 136 & 91.3 \\
Male & & \\
Education & 49 & 32.9 \\
Elementary / Special education & 83 & 55.7 \\
Low / Intermediate level secondary school & 17 & 11.4 \\
High level secondary school / University degree & & \\
Nationality & 136 & 91.3 \\
Dutch & 25 & 16.8 \\
Dutch and second nationality & 13 & 8.7 \\
$\quad$ Not the Dutch nationality & & \\
Employment status & 90 & 60.4 \\
Unemployed & 59 & 39.6 \\
$\quad$ Employed or self-employed & & \\
\hline
\end{tabular}


The recruiters invited available police suspects of at least 18 years of age to participate. Suspects who were about to be seen by a physician or psychiatrist because of urgent physical and/or psychiatric problems were excluded from participation. Over the course of Study 1, 21 assessments were interrupted and subsequently terminated due to unforeseen developments in the criminal investigation process (e.g., unexpected interrogations, visits of lawyers, or immediate release of the suspect); 63 assessments were terminated early on because of a lack of proficiency in the Dutch language, which led to misunderstanding of instructions and questions; and, 13 participants stated or implied shortly after the start of the assessments that they were suffering from a serious mental disorder. Ultimately, 178 suspects completed the assessment procedure.

\section{Procedure}

The assessments were conducted by a M.Sc. psychologist (first author), and three second-year Master's students in Forensic Psychology of Maastricht University who had previously followed several assessment skills training courses and were closely supervised. To not harm suspects' legal rights, it was assured that (1) suspects would be staying in continued detention at the police detention centre for at least the next few hours, and (2) that the assessment would not interfere with any planned investigation procedures.

The assessors approached prospective participants in their cells and briefly introduced the purpose of the study. When he or she agreed to consider participation, the suspect was taken to another room, where the details of the study procedure and the informed consent were explained. Participation was anonymous and suspects were informed that the researchers were bound by professional confidentiality. Participants were free to stop the assessment at any moment. After the explanation, a brief moment was given to consider participating. All participants signed the informed consent before starting the assessment.

Permission for this study was granted by the standing Ethical Review Committee Psychology and Neuroscience of Maastricht University (ERCPN number 03_10_2014), the Attorney General Office of the Netherlands, and the Chief Constable of the National Police of the Netherlands.

\section{Measures}

The instruments for Study 1 were part of a larger battery of tests to assess different psychological vulnerabilities in police suspects. First, the assessment contained four items to screen for malingering. Second, tests 2 to 6 assessed psychological vulnerabilities, namely serious mental health problems, the misuse of alcohol and 
drugs, ADHD, depression, anxiety, and stress, and symptoms of psychopathology. Third, tests 7 and 8 assessed two personality characteristics, namely interrogative suggestibility and compliance. Findings regarding intellectual disabilities in this sample are presented in Chapter Three of this dissertation.

(1) Four items of the Wildman Symptom Checklist (WSC; Wildman \& Wildman, 1999; Merckelbach, Smeets \& Jelicic, 2008; Merckelbach et al., 2014), which addresses non-credible, disturbing, cognitive symptoms (e.g., 'I have headaches that are so severe my feet hurt', and 'The buzzing in my ears keeps switching from the left to the right'). The total score of the WCS is the sum of the scores of all items (range $=0$ - 16), and a score of 4 or higher serves as an indication for malingering (Merckelbach et al., 2014). The Cronbach's alpha of the four items of the WCS in previous studies ranged from .56 to .73 (Deetman et al., 2011), in the present study the Cronbach's alpha was .73.

(2) Brief Jail Mental Health Screen (BJMHS; Steadman, Clark Robbins, Islam, \& Osher, 2007). The BJMHS was developed as a jail intake screen, which prison staff can use as a screening tool for inmates who need additional mental health evaluation. The BJMHS contains eight questions (e.g., 'Do you currently believe that someone can control your mind by putting thoughts into your head or taking thoughts out of your head?', 'Are you currently taking any medication prescribed for you by a physician for any emotional or mental health problems?', and 'Have you ever been in a hospital for emotional or mental health problems?'). Further mental health evaluation is advised if at least two of the items 1 through 6 are answered positively, or items 7 and/or 8 (i.e., the latter two questions mentioned above) receive an affirmative response (Steadman, Clark Robbins, Islam, \& Osher, 2007). Previous validation studies compared the BJMHS and the Structural Clinical Interview for DSM-IV (SCID; First, Spitzer, Miriam, \& Williams, 2002), and showed that the BJMHS is a reliable and valid mental health screener in custody settings (Baksheev, Ogloff, \& Thomas, 2012; Steadman, Scott, Osher, Agnese, \& Clark Robbins, 2005). For the purpose of this study, the BJMHS was translated into Dutch by the first and third author.

(3) Self-report questions about the use of alcohol and drugs: 'Do you use alcohol/ drugs?', if replied with 'yes', followed by a probing question about the frequency and amount of alcohol/drug use.

(4) Ultra Brief Questionnaire for ADHD in Adults (Ultrakorte Vragenlijst voor ADHD bij Volwassenen; Kooij, 2009). This screener contains four questions, which consists of three questions about hyperactivity, impulsivity, and problems with concentration and attention, and a fourth question about the persistence of these symptoms 
across the lifetime. The screener has proven to provide a good estimation of ADHD in clinical practice: 70 - 90\% of the subjects with a positive screening score was diagnosed with ADHD upon further examination (Kooij, 2009).

(5) Depression Anxiety and Stress Scale (DASS; Lovibond \& Lovibond, 1995). The DASS was developed over a period of 11 years and discriminates between depression, stress and anxiety - concepts that show overlap in other instruments (De Beurs et al., 2001). For this study, the 21 -items Dutch version (De Beurs et al., 2001) was used, which contains 7 items on depression, 7 items on anxiety, and 7 items on stress. The reliability of this 21 -items DASS short form is similar to the original 42-items version. (De Beurs et al., 2001).

(6) Symptom Checklist (SCL-90; Derogatis, 1977; Dutch version SCL-90-NL, Ettema \& Arrindell, 2005). The SCL-90 is widely used to screen for mental and physical problems related to psychopathology. The Dutch version contains 90 items, which refer to eight domains: Depression, Anxiety, Hostility, Agoraphobia, Interpersonal sensitivity, Somatization, Obsessive-Compulsive, and Sleeping Problems. Furthermore, the total score provides a global severity index of psychological distress (Psychoneurotisicm).

(7) A short form of the Gudjonsson Suggestibility Scale (GSS; Gudjonsson, 1997) including 20 items on interrogative suggestibility (Smeets, Leppink, Jelicic, \& Merckelbach, 2009). This short form of the GSS starts with a story of a mock crime, followed by 15 misleading questions and five cued recall memory questions. After answering the 20 items, the participants are told they made quite a few errors and are asked to answer all 20 questions a second time. Four suggestibility parameters were calculated to measure interrogative suggestibility: (1) the tendency to go along with misleading questions immediately (Yield 1); (2) the tendency to accept misleading cues after negative feedback (Yield 2); (3) the tendency to change an answer after negative feedback (Shift), (4) and the total interrogative suggestibility score, which provides an indication of susceptibility to suggestion (Gudjonsson, 1997; Smeets et al., 2009). Previous research showed that this GSS short form (without a retention interval) does not affect total or subscale scores of the original GSS (Smeets et al., 2009).

(8) Gudjonsson Compliance Scale (GCS; 1989; Smeets, 2008). The concept of compliance is based on studies of Milgram (1974) on obedience. Some people act compliant when they are put under pressure by authority figures (Gudjonsson, Sigurdsson, Brynjolfsdottir, \& Hreinsdottir, 2002). The GCS has been found to discriminate between suspects who are able to resist pressure, and those who conform to requests during interrogations in order to avoid confrontation and 
conflict (Gudjonsson et al., 2002). The GCS contains 20 items with true-false statements, which provide an indication of how suspects tend to cope with the demand characteristics of police interrogations (Gudjonsson, 1989). A higher score on the GCS reflects a higher level of compliance.

\section{Statistical Analyses}

IBM SPSS v24 was used to analyse the data. The scores obtained in the present sample were compared to data from previous studies using one-way ANOVAs, and Tukey HSD post-hoc tests.

\section{Results}

Before performing the analyses, participants were screened for possible malingering using a Dutch short form of the WCS (Merckelbach et al., 2008; Merckelbach et al, 2014). Test results showed that 14 participants (7.9\%) scored positive on possible feigning. In addition, 15 participants (8.4\%) had missing WCS data. These participants were excluded from the analyses described below, resulting in a total sample of $N=$ 149.

The BJMHS (Steadman et al., 2007) indicated that for 90 (60.4\%) participants serious concerns were raised about their mental health, requiring further evaluation.

Six participants (4.0\%) stated they drank alcohol on a daily basis, and 32 participants (21.5\%) stated they used drugs (e.g., marihuana, cocaine, GHB) on a daily basis.

The ADHD screener (Kooij, 2009) indicated that for 57 participants (38.3\%) further examination regarding possible ADHD was deemed necessary.

Mean scores on the Depression, Anxiety and Stress subscales of the DASS (De Beurs et al., 2001) are presented in Table 2.2, and compared to mean scores of a general population and a clinical sample (De Beurs et al., 2001). The general population sample comprised 289 undergraduate psychology students $\left(M_{\text {age }}=23, S D_{\text {age }}=5.6\right.$, age range $=18-53 ; 65$ male, 224 female). The clinical sample comprised 173 outpatients of a psychiatric hospital $\left(M_{\text {age }}=39, S D_{\text {age }}=9.1\right.$, age range $=21-73 ; 63$ male, 110 female), suffering from a variety of psychiatric problems (e.g., panic disorder, obsessive compulsive disorder, depression). We found significant differences between groups for Depression, $F(2,608)=41.50, p=.000$, Anxiety, $F(2,608)=56.27, p=.000$, and Stress, $F(2,608)=39.50, p=.000$. Tukey post-hoc tests showed that the means of the three subscales differed significantly between all three samples, all p's $<.01$, except for the mean of the Depression scale found in this study, which did not differ significantly from the mean in a clinical sample $(p=.21)$ but was significantly higher than the mean in a general sample $(p=.000)$. 
Table 2.2. Means and standard deviations of the DASS subscales found in this study, in a clinical population, and in a general population.

\begin{tabular}{|c|c|c|c|}
\hline & $\begin{array}{c}\text { Police suspects }^{a} \\
N=149 \\
M(S D)\end{array}$ & $\begin{array}{c}\text { Clinical population }^{b} \\
N=173 \\
M(S D)\end{array}$ & $\begin{array}{c}\text { General population }^{b} \\
N=289 \\
M(S D)\end{array}$ \\
\hline Depression & $11.6(9.4)$ & $13.4(11.9)$ & $5.7(7.7)$ \\
\hline Anxiety & $9.2(7.4)$ & $11.7(10.1)$ & $4.2(5.9)$ \\
\hline Stress & $12.3(7.9)$ & 15.7 (10.2) & $8.4(8.0)$ \\
\hline
\end{tabular}

a This study.

${ }^{b}$ De Beurs et al. (2001).

Participants' scores on the SCL-90-R-NL are shown in Table 2.3 and compared to scores of a Dutch prison sample and a general population sample (Arrindell \& Ettema, 2005). The prison sample comprised 257 men (no women) detained in regular prisons $\left(M_{\text {age }}=31.6, S D_{\text {age }}=9.8\right.$, range $\left.=18-66\right)$, the general population sample comprised 2394 Dutch inhabitants (50\% male, 50\% female; $M_{\text {age }}=41.1, S D_{\text {age }}=14.5$, range $=17$ - 88). Significant differences between groups were found for Depression, $F(2,1432)$ $=146.24, p=.000$, Somatization, $F(2,1432)=48.64, p=.000$, Hostility, $F(2,1432)=$ 88.66, $p=.000$, Anxiety, $F(2,1432)=86.20, p=.000$, Agoraphobia, $F(2,1432)=27.73$, $p=.000$, Obsessive-Compulsive, $F(2,1432)=62.00, p=.000$, Interpersonal Sensitivity, $F(2,1432)=45.50, p=.000$, Sleep Problems, $F(2,1432)=122.56, p=.000$, and overall Psychological distress, $F(2,1432)=114.83, p=.000$. Tukey post-hoc tests showed that the scores of the subscales did not significantly differ between our police suspects and prisoners, all p's $>.05$, however, the scores of both police suspects and prisoners were significantly higher than those of the general population sample, all p's $=.000$.

The mean scores on the GSS (short form) are shown in Table 2.4 and compared to scores obtained in two previous studies in Dutch general population samples who used the same GSS short form (Hansen et al., 2010; Smeets et al., 2009). Hansen et al. (2010) tested 90 undergraduate students $\left(M_{\text {age }}=21, S D_{\text {age }}=3.54\right.$, range $=18-45 ; 29$ male, 61 female), and Smeets et al. (2009) tested 80 undergraduate students $\left(M_{\text {age }}=21\right.$, $S D_{\text {age }}=2.79$, range unspecified; 19 male, 61 female). There were significant differences between groups for Yield 1, $F(2,191)=7.67, p<.01$, Yield 2, $F(2,191)=28.96, p=.000$, Shift, $F(2,191)=22.31, p=.000$, and the Total score, $F(2,191)=26.37, p=.000$. Tukey post-hoc tests revealed that the GSS scores of our sample were higher compared to scores obtained in the two previous studies, all p's $<.01$, except for the score on Yield 1 
Table 2.3. Means and standard deviations on the SCL-90-R-NL found in this study compared to previous research among Dutch police suspects, Dutch prisoners, and the general population.

\begin{tabular}{|c|c|c|c|}
\hline Measure & $\begin{array}{l}\text { Dutch police } \\
\text { suspects }^{\mathrm{a}} \\
N=149 \\
M(S D)\end{array}$ & $\begin{array}{c}\text { Dutch prisoners }^{b} \\
N=250 \\
M(S D)\end{array}$ & $\begin{array}{c}\text { Dutch general } \\
\text { population }^{\mathrm{b}} \\
N=1036 \\
M(S D)\end{array}$ \\
\hline Depression & $30.4(13.7)$ & $31.7(13.23)$ & $21.6 \quad(7.6)$ \\
\hline Somatization & $20.3(7.1)$ & $20.3 \quad(8.6)$ & $16.7 \quad(5.3)$ \\
\hline Hostility & 9.3 (3.4) & $9.3 \quad(4.0)$ & $7.2 \quad(2.1)$ \\
\hline Anxiety & $16.6(6.3)$ & $17.1 \quad(7.7)$ & $12.8 \quad(4.4)$ \\
\hline Agoraphobia & $8.9(2.8)$ & $9.1 \quad(3.4)$ & $7.9 \quad(2.3)$ \\
\hline Insufficiency of thinking and acting & $16.4(6.2)$ & $15.3 \quad(5.9)$ & $12.6 \quad(4.3)$ \\
\hline Interpersonal sensitivity & $29.4(10.3)$ & $28.7(11.4)$ & $24.1 \quad(7.6)$ \\
\hline Sleeping problems & $6.6(3.0)$ & $7.1 \quad(3.8)$ & $4.5 \quad(2.2)$ \\
\hline Psychoneuroticism & $151.2(47.2)$ & $153.1(52.0)$ & $118.3(32.4)$ \\
\hline
\end{tabular}

a This study.

b Arrindell \& Ettema, 2005 (SCL-90-R-NL Manual).

Table 2.4. Means and standard deviations on the Gudjonsson Suggestibility Scale found in this study and two previous Dutch studies.

\begin{tabular}{lccc}
\hline & This study & General & General \\
& $N=144$ & population & \\
& $M(S D)$ & $N=20$ & $\begin{array}{c}\text { population } \\
\text { p }\end{array}$ \\
& & $M(S D)$ & $M(S D)$ \\
\hline Yield 1 & $6.42(3.34)$ & $4.80(2.76)$ & $4.17(2.38)$ \\
Yield 2 & $9.42(3.60)$ & $5.40(3.59)$ & $4.93(2.46)$ \\
Shift & $5.65(2.87)$ & $3.65(1.79)$ & $2.33(1.75)$ \\
Total & $12.07(4.44)$ & $8.45(3.32)$ & $6.47(2.93)$ \\
\hline
\end{tabular}

${ }^{a}$ Results of the 'no delay/no recall' group (Smeets et al., 2009).

${ }^{b}$ Results of the group who received standard instructions for answering the questions (Hansen et al., 2010). 
Table 2.5. Means and standard deviations on the GCS found in this study and in two previous Dutch studies.

\begin{tabular}{lccc}
\hline & N & Mean & SD \\
\hline Police suspects $^{\mathrm{a}}$ & 149 & 10.1 & 3.6 \\
General population $^{\mathrm{b}}$ & 120 & 9.5 & 3.6 \\
University students $^{\mathrm{c}}$ & 30 & 10.0 & 2.8 \\
\hline
\end{tabular}

a This study.

b Smeets (2008).

${ }^{c}$ Hansen et al. (2010).

found in our sample, which did not differ from the score found in a general population sample, $p>.05$ (Smeets et al., 2009).

The scores on the GCS are shown in Table 2.5 and compared to those from two previous studies (Hansen et al., 2010; Smeets, 2008), who used the same version of the GCS in the same Dutch general population samples. There were no significant differences found between the three samples, $F(2,296)=.99, p=.37$.

\section{Discussion}

Study 1 examined a number of key psychological vulnerabilities in Dutch police suspects, that is, mental health problems, an abnormal mental state, and the personality characteristics interrogative suggestibility and compliance.

We found that $60.4 \%$ of police suspects screened positively for further mental health examination, based on the BJMHS. Baksheev, Ogloff, and Thomas (2012) assessed 150 suspects $\left(M_{\text {age }}=30.4, S D_{\text {age }}=9.0 ; 90.7 \%\right.$ male, $9.3 \%$ female) detained in two police stations in Melbourne, Australia, and found that $58.3 \%$ screened positively on the BJMHS. Dorn et al. (2013) assessed 248 suspects $\left(M_{\text {age }}=32.4, S D_{\text {age }}=11.9 ; 92 \%\right.$ male, $8 \%$ female) in Amsterdam police detention centres, and found that the BJMHS screened $40 \%$ suspects as in need of further mental health examination. Both samples are fairly comparable to our sample in terms of age and gender composition.

Results showed that $21.5 \%$ of our police suspects used illegal drugs on a daily basis, which seems to be a lot higher than the general Dutch population (18 - 64 years) in which a lifetime prevalence of $3.8 \%$ and a 12 -month prevalence of $0.9 \%$ was found (De Graaf, Ten Have, Gool, \& Van Dorsselaer, 2012). Only 4\% of police suspects reported they used alcohol on a daily basis in combination with drinking more than 15 glasses of 
alcohol per week, which seems to be comparable to the 12- month prevalence of $3.7 \%$ found in the Dutch population (De Graaf et al., 2012).

In our sample, 38.3\% scored positive on a screener for ADHD. The prevalence of ADHD among Dutch police suspects has not been subject of previous research. Yet compared to the prevalence of ADHD among adults from the Dutch general population, which is 2.1\% (Tuithof, Ten Have, Van Dorsselaer, \& De Graaf, 2014), ADHD seems to be (much) more common in police detainees.

On the DASS, police suspects scored significantly higher than a general population sample, and quite similar to a psychiatric out-patients sample, except for the Depression scale (De Beurs et al., 2001). The clinical sample was quite comparable with the present sample in terms of age.

The scores on the SCL-90-R-NL in our sample were also higher in comparison to a Dutch general population sample but did not differ significantly from scores of a Dutch prison sample (both samples provided in the Dutch SCL-90-R-NL test manual; Arrindell \& Ettema, 2005). Age and gender composition of our sample and the Dutch prison sample were fairly similar.

The scores on interrogative suggestibility were significantly higher compared to previous studies in general population samples (Hansen et al., 2010; Smeets et al., 2009), which could be due the fact that research (Gudjonsson, 2003) has revealed higher levels of interrogative suggestibility in individuals with intellectual disabilities and mental health problems (e.g., anxiety, personality disorders). In contrast, compliance scores did not differ significantly from Dutch general population samples (Hansen et al., 2010; Smeets, 2008). Again, it must be noted that these samples only included (mostly female) undergraduate students.

In sum, our findings indicate that $38.3 \%$ of police suspects needed further assessment for ADHD, and $60.4 \%$ needed a more comprehensive mental health examination. Levels of self-reported psychopathology, depression, anxiety, stress, drug use, and interrogative suggestibility were significantly higher compared to general Dutch population samples. In line with previous studies (Dorn et al., 2013; Gudjonsson, 2003; Herrington \& Roberts, 2012; Kassin et al., 2010), these findings demonstrate that police officers will frequently meet psychologically vulnerable suspects in their interrogation room - with the associated risks. 


\section{Study z}

\section{Introduction}

The findings of Study 1 confirm the high prevalence of psychological vulnerabilities among Dutch police suspects, echoing findings of previous studies (Baksheev et al., 2012; Blaauw, Kerkhof, \& Vermunt, 1998; Gudjonsson, 1993). With such high base rates of psychological vulnerability, the question to what extent police detectives are able to identify vulnerable suspects becomes even more pertinent. We hypothesize that police officers who received specialized training in interrogation methods would have a more realistic view of the base rate of vulnerable suspects, compared to those who did not receive specialized training (Angermeyer \& Dietrich, 2006; Herrington \& Roberts, 2012; Lamb, Weinberger, \& DeCuir, 2002; Ogloff et al., 2012). We are also interested in exploring what type of precautions police detectives take when they encounter vulnerable suspects in the interrogation room. To examine these research questions, we conducted an online survey among police detectives working at different divisions of the Dutch National Police.

\section{Method}

\section{Participants and procedure}

Police detectives of different subdivisions (e.g., departments of criminal investigation, sexual offences, and financial crime) in seven different police regions of the Netherlands (i.e., Amsterdam, Limburg, Midden-Nederland, Oost-Brabant, Oost-Nederland, Rotterdam, and Zeeland West-Brabant) were invited by email in May 2016. They were asked to participate anonymously in a study on vulnerable suspects by completing an online questionnaire. The invitation email was sent to the manager of the division, with the request to forward the email, after his or her approval, to his or her team members, and to managers of other detective subdivisions. Repeated invitation requests were sent after three and five weeks. Because of a major reorganisation of the Dutch National Police at the time of Study 2, and the snowball method used, it was not feasible to keep a record of exactly how many police detectives were invited to participate. Eventually, 141 police detectives filled out the questionnaire.

\section{Questionnaire}

The questionnaire developed for Study 2 comprised 16 items. It started with a brief introduction to the study. Next, 10 questions were asked about demographic characteristics, such as age, gender, level of experience as a police officer/detective, education, and enrolment in specialized criminal investigation courses and advanced 
interrogation courses. Further, participants were asked with open-ended questions how many interrogations they usually perform during one week (item 11), how many vulnerable suspects they had encountered during the past year (item 12), how they had recognised these vulnerable suspects (item 13), if they took any precautions when interrogating these suspects (item 14), and if so, what type of precautions they took (item 15), or if not, why they did not take precautions (item 16). After completing the questionnaire, a short briefing about the study was provided.

\section{Data Analysis}

Out of the total sample ( $N=141), 38$ questionnaires were incomplete and dropped from the analyses, which resulted in a total $N$ of 103. The analyses for Study 2 were performed with IBM SPSS v24. First, means, standard deviations, and percentages were calculated for the descriptive variables, and second, the effect of the number of completed advanced detective courses on the number of identified vulnerable suspects was explored with a Kruskal Wallis test.

\section{Results}

The age of the police detectives $(N=103)$ ranged from 23 to $63\left(M_{\text {age }}=44.74 ; S D_{\text {age }}\right.$ $\left.=11.95, M d n_{\text {age }}=45.00\right)$. The sample was predominantly male $(n=69 ; 70 \%)$. They had worked an average of 21 years in the police force $(M=21.39$; $S D=12.92)$, and about 11 years at an investigative unit $(M=11.42 ; S D=9.09)$. About half of the police detectives ( $n=51 ; 49.5 \%$ ) had followed one or two advanced level criminal investigation courses (e.g., courses on specific procedures or complex police investigations, for example in regard to severe, financial or sexual crimes), about onethird ( $n=29 ; 28.3 \%$ ) had followed three or more advanced level criminal investigation courses, yet 23 (22.3\%) police detectives had not completed any advanced training. On average, police detectives performed 2.54 interrogations per week (SD $=3.13$, range $=0$ - 15). Their estimate of how many vulnerable suspects they saw during the past 12 months ranged from 0 to $90(M=4.63, S D=12.13, M d n=0.00)$. Most police detectives ( $n=57 ; 55.3 \%$ ) answered they had not seen a vulnerable suspect during the past 12 months. Furthermore, 78 (75.7\%) police detectives had not received any advanced interrogation training, and 22 (21.4\%) police detectives had completed one advanced interrogation training. Only three (2.9\%) police detectives received two or more advanced interrogation training courses and a specific training on interrogating vulnerable witnesses and suspects. These three detectives gave somewhat different answers. The first detective answered that he/she performed 152 interrogations in the past 12 months, and that he/she identified only five vulnerable suspects $(3.3 \%$ 
of the interrogations) - without any further explanation. The second detective stated he/she interrogated 52 suspects himself/herself but was only called in for assistance during one interrogation (1.9\%) of a known vulnerable suspect (a suspect with a mental illness). The third detective stated he/she had interrogated 52 suspects in the past 12 months, and to have seen 52 vulnerable suspects as well (100\% of the interrogations).

Next, we explored whether police officers are able to identify vulnerable suspects. We did not provide a definition of a vulnerable suspect in order not to influence the answers of the detectives, yet we asked them: 'How did you recognise a vulnerable suspect?' Only 46 police detectives answered this question. Fifteen police detectives (14.6\%) stated they knew beforehand they were going to interrogate a vulnerable suspect (because of a known mental illness or substance use disorder or because the suspect had previously been admitted to a psychiatric institution), and 17 police detectives (16.5\%) observed abnormal behaviours during the interrogation (i.e., the suspect acted strangely, did not understand questions, or did not respond adequately to questions). A combination of the latter two situations was mentioned by 13 (12.6\%) police detectives. One detective stated that all suspects are potentially vulnerable.

In addition, police detectives were asked if they took any precautions when they thought a suspect might be a vulnerable suspect. About half ( $n=57 ; 55.3 \%$ ) stated they did not take any special precautions. A probing question to describe which precautions they took in case they met a vulnerable suspect during interrogation was answered by 43 police officers, who mentioned the following options: seeking the assistance of a police psychologist ( $n=17 ; 39.5 \%$ ), contacting the public prosecutor or their supervisor before they started the interrogation $(n=4 ; 9.3 \%)$, enlisting the help of a specialised police detective to perform the interrogation ( $n=3 ; 7.0 \%)$, adjustment of interrogation techniques ( $n=2 ; 4.7 \%$ ), audio recording the interrogation $(n=2$; $4.7 \%)$, or a combination of any of these ( $n=15 ; 34.6 \%)$. Contrary to our hypothesis, we did not find a significant association between the number of advanced level criminal investigation courses taken (none vs. 1 - 2 vs. $\geq 3$ ) and the number of identified vulnerable suspects reported over a period of 12 months, $H(2)=4.94, p=.09$, with a mean rank of 56.91 for none $(n=23), 52.40$ for $1-2(n=51)$, and 47.40 for $\geq 3$ ( $n=$ 29) advanced level criminal investigation courses. We also did not find a significant association between the number of specific interrogation courses taken (none vs. 1 vs. $\geq 2$ ) and the number of identified vulnerable suspects, $H(2)=5.60, p=.06$, with a mean rank of 55.21 for none $(n=78), 40.50$ for $1(n=22)$, and 53.00 for $\geq 2(n=3)$ specialized interrogation courses. 


\section{Discussion}

Study 2 explored the views of police detectives on the identification of vulnerable suspects. We hypothesized that most police detectives do not recognize vulnerable suspects and therefore underestimate the base rate of vulnerability in suspects; we also hypothesized that specialized interrogation training would result in more realistic base rate estimations ability to detect vulnerable suspects (Angermeyer \& Ditrich, 2006; Herrington \& Roberts, 2012; Lamb et al., 2002). In addition, we asked police detectives about the precautions they take when they encounter vulnerable suspects.

Our participants $(N=103)$ had an average of 21 years' experience working in the police force, and 11 years as a police detective in a criminal investigation unit. Most police detectives (about 78\%) had completed advanced criminal investigation courses, yet, despite the high number of years of police and detective experience, most of them (about 74\%) had never taken an specialized interrogation course. Police detectives reported they had encountered an average of five vulnerable suspects during the past 12 months, while they reported an average of 2.5 interrogations per week. About $55 \%$ of detectives stated they had not interrogated any vulnerable suspects in the past 12 months.

The number of completed courses on criminal investigation was unrelated to the number of vulnerable suspects police detectives reported to have seen during the previous 12 months. Successfully completing a specialized interrogation course seemed unrelated to a more realistic base rate expectation regarding vulnerable suspects. Even the three detectives who received the most advanced training in interrogating vulnerable suspects currently available in the Netherlands (Politieacademie, 2017) gave quite different answers to the question how many vulnerable suspects they had seen during the past year $(2 \%, 34 \%$ and $100 \%$ of the interrogations, respectively). About half of all detectives (55\%) stated they did not take special precautions when they knew they were interrogating a vulnerable suspect. About 42\% responded they would request the assistance of a police psychologist, public prosecutor, supervisor, or a specialized police interrogator, adjust their interrogation techniques, and/or audiotape the interview when interrogating a vulnerable suspect. 


\section{General discussion}

The findings of Study 1 indicate that a majority (60\%) of police suspects $(N=149)$ has mental health problems, which concurs with previous studies (Blaauw et al., 1998; Ceelen et al., 2012; Ogloff et al., 2012). Study 2 reveals that police detectives ( $N=103)$ on average reported 4.63 vulnerable suspects over the course of 132 interrogations in a year's time, resulting in an estimated prevalence of $3.5 \%$, which is obviously a grave underestimation compared to the actual prevalence rate of $60 \%$ as determined by means of psychological assessment.

The combined findings of Study 1 and 2 suggest that base rate neglect (a form of selective attention to pertinent information whereby base-rate information is ignored; Case, Fantino, \& Goodie, 1999) regarding psychological vulnerabilities in suspects is a problem among police detectives. Many police detectives appear to hold inaccurate beliefs regarding vulnerabilities in suspects, and these beliefs may have implications for their professional conduct and decision making, for instance, in terms of not taking precautions when interrogating vulnerable people. Without accurate knowledge of the high prevalence of psychological vulnerabilities in police suspects, detectives are less likely to notice these vulnerabilities and to take them into account, as the findings of Study 2 demonstrate.

Second, about three-quarters of our police detectives stated they had not received specialized interrogation training. This is worrisome because interrogating suspects is core businesses of detective work (Farrugia \& Milne, 2012; Gudjonsson, 2003). Previous research has shown that training and repeated feedback is pivotal for effective interrogation (Clark, Milne, \& Bull, 2011; Farrugia \& Milne, 2012; Vrij, 2003). It has been previously shown that even after extensive, three-weeks interrogation training, interviewing skills deteriorate over time (Griffiths \& Milne, 2006), suggesting that basic training alone is not enough. Continued coaching and supervision of interrogations is essential because police officers find it difficult to maintain complex social and communication skills after basic training (Clark et al., 2011).

\section{Strengths and limitations}

Astrong point of Study 1 is that the assessments took place in the real-world environment of police detention centres, which not necessarily offer optimal conditions for mental health. Gudjonsson et al. (1993) and Baksheev et al. (2012) also conducted their studies in police detention centres and these conditions obviously increase the ecological validity of the findings. We used both self-report (e.g., SCL-90-R-NL, DASS) methods and an assessor-administered rating tool (BJMHS) to assess mental health problems, 
with both revealing high prevalence rates, adding to the robustness of our findings. Another strong point of Study 1, compared to prior ones on the same topic, is that we included a measure of positive malingering in our test battery and excluded suspects who screened positive on this measure. Thus, we made sure our (high) prevalence rate would not be due to over-reporting. An important limitation of Study 1 -yet one which could not be prevented - is that an unknown number of suspects could not be included in the study, for different reasons (e.g., unwillingness to participate, being aggressive, poor language proficiency, or alcohol or drug intoxication). Another limitation is that we were unable to control the exact circumstances in which the assessments took place. The rooms in the six police detention centres slightly differed in terms of colour, and the presence of a window and daylight, which could be a subject for further research.

A strength of Study 2 is that it provides insight in the views of Dutch police officers about their ability to estimate how often they engage vulnerable suspects, and how they execute interrogations of these suspects. An important limitation of Study 2 is that we were unable to control the recruitment process, due to the extensive reorganisation of the Dutch police at the time of the study. An online questionnaire was chosen instead of another research method in order to invite as many police detectives as possible, and because a qualitative research method would have taken a substantially longer time. In addition, we were not able to send an email to all Dutch police detectives because we did not have access to email addresses of all detective subdivisions of the (former) 26 police forces. Therefore, known contacts from different detective subdivisions in seven police forces were approached and asked to forward the invitation email to members of their teams and other detective subdivisions. This snowball method to recruit the detectives may have resulted in selection bias. Because we only know in which police region (for reasons of anonymity) the detectives worked, it is unknown to what extent the 103 participants are representative for all Dutch police detectives. A second limitation is that the questionnaire did not contain a definition of a vulnerable suspect. This was done on purpose in order not to influence the answers of the police detectives about their knowledge of psychological vulnerabilities in police suspects, yet in hindsight, a definition could perhaps have provided more insight. 


\section{Conclusion}

Psychological vulnerabilities are highly prevalent among police suspects. Compounded by the serious underestimation of the base rate of psychological vulnerability by police detectives and their tendency to not take special precautions during interrogations, vulnerable suspects may face risks in Dutch interrogation rooms. Important first steps are raising awareness of the high base rate of different psychological vulnerabilities in suspects and appealing to police officers to take precautions when interrogating vulnerable suspects. Subsequent steps need to include special training in advanced interrogation techniques, especially for detectives who are involved in more complex cases, as well as continued supervision and feedback regarding interrogation style. 
If I were you, I would rather confess, otherwise they probably will postpone your case until after Christmas, and you will be detained during Christmas!

Police officer to a suspect at the Mijkenbroek Police Detention Centre, Breda, the Netherlands. (Christmas Eve, 2014) 


\section{Chapter Three}

\section{Screening for intellectual disability in Dutch police suspects}

This chapter is a modified version of the published paper:

Geijsen, K., Kop, N., \& De Ruiter, C. (2018). Screening for intellectual disability in Dutch police suspects. Journal of Investigative Psychology and Offender Profiling, 1-15. Published online 14 April 2018. DOI: 10.1002/jip.1502. 


\section{Introduction}

On 28 October, 2009, a 21-year old man was summoned to a Dutch police station for interrogation. He was suspected of having seduced a 16-year old girl to perform sexual acts in front of a webcam, but in the invitation letter the police did not mention he was a suspect in a sexual offence case. The man came to the police station and agreed to participate in the interrogation voluntarily without being arrested. Early on, the young man stated that he received special education in the past, and that he resided in an assisted living residence, yet despite this information, the police interrogators did not notify the man he could have access to a lawyer, and they proceeded to interrogate him about the alleged sexual offence. In the subsequent verdict, the court recognized it had been obvious the suspect was suffering from intellectual disability and that he was not able to oversee his situation and to determine his position during the police investigation, hence, the court blamed the police officers for not having informed the suspect he had access to a lawyer and ruled that his statement was deemed inadmissible because of violation of the principle of a fair trial (Arnhem Court, 2011).

The above is an example of recent Dutch jurisprudence, which illustrates that it is important that police officers take certain vulnerabilities of suspects (e.g., intellectual disability) into account during interrogation in order to obtain accurate statements (Gudjonsson \& Joyce, 2011). The level of intellectual functioning, generally determined by means of IQ (Intelligence Quotient) tests, can be described as 'the aggregate or global capacity of the individual to act purposefully, to think rationally and to deal effectively with his environment' (Wechsler, 1944, p. 3), or as 'the ability to understand complex ideas, to learn from experience, to engage in various forms of reasoning, and to overcome obstacles by taking thought' (Neisser et al., 1996, p. 77). At present, the fifth edition of the Diagnostic and Statistical Manual of Mental Disorders (DSM5; American Psychiatric Association, 2013) defines intellectual disability as a disorder that includes both intellectual and adaptive functioning deficits in conceptual, social, and practical areas, with an onset during the developmental period. The conceptual area refers to skills in knowledge, memory, reading, writing, math, reasoning, and language. The social area includes, for example, empathy, communication skills, and social judgement. The practical area refers to self-management in, for example, personal care, organizing school and work, and financial matters. The classification of intellectual disability across the three areas must be based on both clinical assessment and standardized intelligence testing (American Psychiatric Association, 2013).

Research has demonstrated that suspects who suffer from intellectual disability face problems understanding their legal rights and interrogation questions, overseeing 
consequences of answers, and giving a reliable, accurate and coherent statement during police interrogations (Gudjonsson, 2010; Kassin, 2012; Scheyett, Vaughn, Taylor, \& Parish, 2009). Intellectually disabled suspects are more vulnerable to give in to leading questions (interrogative suggestibility), react more compliant to authority figures (compliance), and produce more memories that are imagined or distorted (confabulation) (Gudjonsson \& Joyce, 2011; Scheyett et al., 2009). Hence, police officers must take precautions when interrogating suspects with intellectual disability (Gudjonsson, 2003; Kassin et al., 2010; O’Mahony, Milne, \& Grant, 2012) by, for example, asking questions in a simple and clear way, using short sentences and speaking more slowly, and avoiding leading questions and interruptions (Gudjonsson \& Joyce, 2011; Herrington \& Roberts, 2012). Police officers, however, are not particularly apt at detecting individuals with intellectual disabilities (Gudjonsson, 2003; Parton, Day, \& White, 2004). Furthermore, many intellectually disabled individuals develop strategies to disguise their cognitive and social limitations in trying to cope with the demand characteristics of their surroundings (Gudjonsson, 2003; Hayes, Shackell, Mottram, \& Lancaster, 2007; Scheyett et al., 2009), making it even harder to notice their disability.

Kaal, Nijman, and Moonen (2013) recently introduced the Screener for Intelligence and Learning Disabilities (SCIL), a screener for mild intellectual disability among persons older than 18 years. While an assessment with the Wechsler Adult Intelligent Scale (WAIS; Wechsler, 1997) or the Kaufman Adolescent and Adult Intelligence Test (KAIT; Kaufman \& Kaufman, 2004) is not always possible because of time constraints, the SCIL contains only 14 items and can be administered in about 10 minutes. The DSM-5 (American Psychological Association, 2013) defines intellectual disability by an IO lower than 70. However, people with an IO between 70 and 85, a so-called borderline $1 Q$, possess cognitive and learning characteristics, which are comparable to those of people with an 10 between 50 and 70 (Parton, Day, \& White, 2004; Roos, 2014). Hence, there is a fine line between people with a borderline $I Q$ and people with more severe intellectual disabilities (Hayes, 2007). For this reason, in the Netherlands mild intellectual disability is defined by an 10 score between 50 and 85, which provides the person access to certain psychological and social services (Roos, 2014). In view of this, the Dutch SCIL defines mild intellectual disability as an IQ lower than 85 (Kaal et al., 2013).

The SCIL was constructed on the basis of four sources. The first source was the Hayes Ability Screening Index (HASI; Hayes, 2002), which includes self-report questions, backwards spelling of a five-letter word, a trail-making test, and a clock-drawing test. The HASI was validated on the basis of the Kaufman Brief Intelligence Test (KBIT; Kaufman \& Kaufman, 2004) and the Vineland Adaptive Behaviour Scale (VABS; Sparrow, 
Balla, \& Cicchetti, 1984), and screens for an 10 below 70. The second source was the Learning Disability in the Probation Service (LIPS; Mason \& Murphy, 2002). This test contains items about demographic characteristics, a clock-drawing test, items about social-adaptive abilities and self-report questions relating to identity, education and mental health needs. The LIPS was validated against the WAIS-R (Wechsler, 1981) and screens for an $1 Q$ below 75 (Mason \& Murphy, 2002). The third source was the Learning Disability Screening Questionnaire (LDSQ; McKenzie, Michie, Murray, \& Hales, 2012) that contains items about telling time, educational history, healthcare, personal circumstances, and reading and writing abilities. The LDSQ was validated by means of the WAIS-III (Wechsler, 1997) and screens for an IO below 70 (McKenzie et al., 2012). Next, the developers of the SCIL consulted a fourth source, namely experts from the Dutch institution De Borg specializing in the care for clients with intellectual disability in combination with severe behavioural problems. These experts advised focussing on education, social abilities, arithmetic, reading and writing abilities, and language comprehension. Based on a validation study in a sample of 318 subjects recruited from various educational and mental health institutions, 14 items were selected (out of a test version with 48 items) which correlated strongly with intellectual capacity (based on WAIS-III-NL IQ scores) (Kaal et al., 2013).

To date, little is known about intellectual disability among suspects in police custody (McKinnon \& Grubin, 2010), which applies to the Netherlands as well (Kaal, 2014). Furthermore, the SCIL has not been tested as a screener in a sample of suspects in police custody. Therefore, the present study has two goals. The first and main goal is an examination of the predictive validity of the SCIL for mild intellectual disability $(\mathrm{IQ}<85)$ among suspects who are taken into police custody on a charge of a criminal offence. A previously validated 15 minutes short form (SF) of the WAIS-III scales, which contains four subtests (Arithmetic, Block Design, Digit Symbol Coding, and Information; Velthorst et al., 2013), is used as the criterion measure. Velthorst et al. (2013) showed that this method provided a valid full IQ score approximation in research and clinical settings (overall $R=.95 ; R^{2}=91, \mathrm{Cl}=.87-.95$ ). A principal component analysis (PCA) will be used to examine the interrelations among the SCIL items and to gain more insight into its factor structure. In addition, we will explore correlations between the four subtests of the WAIS-III and the 14 items of the SCIL. Our hypothesis is that the SCIL has adequate predictive validity to screen for individuals who suffer from mild intellectual disability (IQ below 85; Kaal et al., 2013) in a sample of Dutch police suspects.

The second goal of our study is to provide an estimate of the prevalence of intellectual disability among police suspects in The Netherlands. We expect this 
prevalence will be comparable with a previous study on police suspects in the United Kingdom, that is, that about $42 \%$ of police suspects have an 10 score between 70 and 79 , and that about $8 \%$ of police suspects have an 10 score below 70 (Gudjonsson, Clare, Rutter, \& Pearse, 1993). We will compare our obtained rate to prevalence rates previously found in police suspects (Young, Goodwin, Sedgwick, \& Gudjonsson, 2013) and detainees in regular prisons (Hayes et al., 2007; Parton et al., 2004; Søndenaa, Rasmussen, Palmstierna, \& Nøttestad, 2008) from other Western countries.

\section{Method}

\section{Participants}

The sample of police suspects in this study is the same sample as described in Chapter Two. The participants were suspects placed in continued police custody $(N=178)$. Their age ranged from 18 to 63 years $\left(M_{\text {age }}=31.7, S D_{\text {age }}=11.2, M d n_{\text {age }}=27.5\right)$. They were recruited from six different police detention centres across the Netherlands between June 24, 2014 and May 7, 2015. The sample distribution across the different police detention centres was: Amsterdam $(n=37)$, Breda $(n=35)$, Eindhoven $(n=31)$, Heerlen ( $n=26)$, Tilburg $(n=8)$, and Maastricht $(n=41)$.

Only police suspects who were not clearly under the influence of alcohol or drugs, able to speak the Dutch language, and at least 18 years of age, were invited to participate. Suspects who were thought to suffer from a major mental disorder (e.g., when a subject was placed in a police cell with permanent video surveillance due to known mental illness or medical condition, or when a subject was about to be presented to a medical doctor or psychiatrist because of urgent physical and/or mental health problems), were neither able nor allowed by the police to participate and hence excluded from participation.

Over the course of the study, 63 assessments had to be terminated due to major language problems (poor Dutch language proficiency) that led to, for example, misunderstanding of instructions and questions. Twenty-one assessments were interrupted and subsequently terminated because of unforeseen developments in the criminal investigation process (e.g., unexpected interrogations, visits of lawyers, or immediate release of the suspect). Directly after the start of the assessment, 13 participants stated or implied that they were suffering from a serious mental disorder. Ultimately, 178 police suspects voluntarily agreed to participate and completed the assessment procedure. One of the 178 participants did not complete the SCIL (this case was coded as missing). 
Unfortunately, it was not feasible to keep record of all suspects who were detained in the detention centres during the period of data collection. A number of suspects were released within six hours after being placed in police custody and, consequently, could not be asked to participate. Another set of suspects was placed in police custody for a rather brief period, for example, in association with unpaid fines, refugee detention, or awaiting transit to prison. In addition, a significant number of detainees could not be assessed due to serious mental health problems, the abuse of drugs or alcohol, or withdrawal symptoms. Official police registration systems could not be used to compensate for the lack of information on the total number of suspects in the detention centres, for privacy reasons.

\section{Procedure}

The psychological assessments were carried out by a M.Sc. psychologist (first author), and three psychologists-in-training. The latter were second year Master's students in Forensic Psychology from Maastricht University, who were trained in different clinical assessment skills, and were closely supervised during the assessments for this study. Police suspects were approached by the assessors in their cells, where they were briefly informed about the purpose of the study. If a suspect responded positively to the invitation to participate, he or she was taken to a separate room where details of the study, the procedures, and the informed consent were explained. All potential participants were told that participation would be completely anonymous, that the assessors were bound by professional confidentiality, and that the assessment results could not be used in a police investigation in any way. Potential participants were also assured they were free to withdraw from the assessment at any moment. Finally, all participants were asked to sign an informed consent before starting the assessment.

Three precautions were taken in order to assure the assessment would not harm suspects' legal rights. First, according to article 67 of the Code of Criminal Procedure (2018), only suspects placed in continued detention (inverzekeringstelling) were invited to participate. In the Netherlands, suspects may be placed in continued detention when (1) they are suspected of having committed a criminal offence for which they could be sentenced to imprisonment for four years or more, or (2) when they are suspected of a number of specifically described criminal offences (e.g., theft, assault, fraud), or (3) when they are suspected of a criminal offence in combination with being homeless. Second, before inviting suspects to participate, it was determined that the suspect would stay in continued detention for the next few hours and that the assessment would not interfere with any planned investigative activities. Third, the assessment was limited in duration to one to one-and-a-half hours. 
This study was approved by the standing Ethical Review Committee Psychology and Neuroscience of Maastricht University (ERCPN number: 03_10_2014), the Office of the Attorney General of the Netherlands, and the Chief Constable of the National Police of the Netherlands.

\section{Measures}

The instruments mentioned below were part of a larger battery of psychological instruments, in order to assess different psychological vulnerabilities.

\section{Screener for Intelligence and Learning Disabilities (SCIL)}

The SCIL (Kaal et al., 2013; Moonen, Kaal, \& Nijman, 2012) comprises 14 items that provide an indication for mild intellectual disability, defined by a full-scale IQ score below 85 (Kaal et al., 2013). Items 1 to 3 refer to educational background (i.e., special education, type of school diploma, and professional assistance in regard to possible intellectual disability). Kaal et al. (2013) argued that a low educational level or special needs education served as an indication for intellectual disability. Item 4 assesses the availability of a social support network the person could rely on when problems arise. Items 5 to 8 and 11 to 13 include cognitively challenging tasks, including arithmetic, writing and reading, and these are usually challenging for people with intellectual disability; performance on these tasks correlates with IQ. Items 9, 10 and 14 address language comprehension and behaviour (i.e., reading newspapers or magazines, comprehension of a Dutch saying, and telling time), which correlate with $I Q$ as well.

A reliability analysis of the 14 items of the SCIL showed a Cronbach's alpha $\alpha=$ .84 (Kaal et al., 2013). In the present sample ( $N=177)$, Cronbach's alpha of the 14 SCIL-items was $\alpha=.64$. After two weeks, 28 people of the original Kaal et al. (2013) sample were retested resulting in a high test-retest reliability, $r=.92, p=.000$. Kaal and colleagues (2013) tested the validity of the SCIL with a Receiver Operating Characteristic (ROC) analysis used to determine an optimal cut-off score based on the Area Under the Curve (AUC; Streiner \& Cairney, 2007). It was found that a cut-off score of 19 indicated an AUC value of .93, which means that there is a chance of $93 \%$ that a random individual with intellectual disability (i.e., an 10 score lower than 85) will score lower than an individual without intellectual disability (Kaal et al., 2013). The corresponding sensitivity was .82 , and the specificity was .89 , which indicates that the SCIL correctly identified $82 \%$ of people suffering from intellectual disability, whereas the screener mistakenly identified about $11 \%$ of people without intellectual disability as suffering from intellectual disability (Kaal et al., 2013). 


\section{Wechsler Adult Intelligence Scale, 3rd edition, Dutch Version (WAIS-III-NL)}

As previously mentioned, suspects with intellectual disabilities may face serious problems during police interrogations with understanding legal rights and questions, making rational decisions, and overseeing implications of their answers (Gudjonsson \& Joyce, 2011; Young et al., 2013). Because these problems concern to cognitive abilities, we decided to use an $1 \mathrm{Q}$ test, and did not perform further assessments of the conceptual, social, and practical aspects, which is required to determine intellectual disabilities according to the DSM-5 (American Psychological Association, 2013).

A WAIS-III-NL SF was used to estimate general intellectual ability. Velthorst et al. (2013) constructed this SF, which consists of four subtests of the WAIS-III-NL (Wechsler, 1997; Dutch version: Uterwijk, 2000), namely: Information (Verbal Comprehension), Block design (Perceptual Organization), Arithmetic (Working Memory), and Symbol Substitution (Processing Speed). The participants of the original validation study were 75 patients diagnosed with schizophrenia, 73 of their non-schizophrenia siblings, and 84 unrelated and healthy controls (Velthorst et al., 2013). The correlation coefficient between the WAIS-III-NL (Uterwijk, 2000) and the WAIS-III-NL SF (Velthorst et al., 2013) was $r=.95$, and the four subtests showed adequate predictive accuracy and differentiated well between patients, relatives and healthy controls. In sum, the WAISIII-NL SF is a valid alternative to estimate general intellectual ability (Velthorst et al., 2013).

\section{Data analysis}

First, a Principal Component Analysis (PCA) was performed with orthogonal rotation (Varimax with Kaiser normalization; Kaiser, 1974) to gain more insight into the factor structure of the SCIL. Second, IQ scores were calculated based on the WAIS-III-NL SF. Third, the predictive validity of the SCIL was examined using ROC analysis, which provides an AUC value and an optimal cut-off score. The dichotomous outcome criterion used in the ROC analysis was $I Q<85$ vs. $I Q \geq 85$, as estimated by the WAIS-IIINL SF. Fourth, the correlations between the $14 \mathrm{SCIL}$ items and IQ scores were calculated using Pearson's $r$. Statistical analyses were performed with IBM SPSS Statistics v24. 


\section{Results}

First, a principal component analysis (PCA) was conducted on the $14 \mathrm{SCIL}$ items. In order to verify the sample adequacy for a PCA, the Kaiser-Meyer-Olkin (KMO) measure was inspected. All items met the minimum criterion of $K M O>.50$ (Stevens, 2009), the average $K M O$ was .70, and all individual items showed $K M O>.64$. The correlation coefficients between the 14 items were significantly different from zero and were sufficiently large for a PCA, Bartlett's test of sphericity was $\chi^{2}(91)=283.11(p=.000)$. Slightly ambiguous scree plots as shown in Figure 3.1 provided inflexions that would justify retaining two or four components. Because the original SCIL consisted of four a priori factors (Factor 1 'Education'; Factor 2 'Social Contacts'; Factor 3 'Arithmetic, Reading and Writing Abilities'; Factor 4 'Language Comprehension and Behaviour'; Kaal et al., 2013), we decided to retain four components. The four components showed eigenvalues over Kaiser's criterion of 1 and explained $47.7 \%$ of the variance. The factor loadings after rotation are shown in Table 3.1, which indicated that the original four factors were not clearly replicated in both samples.

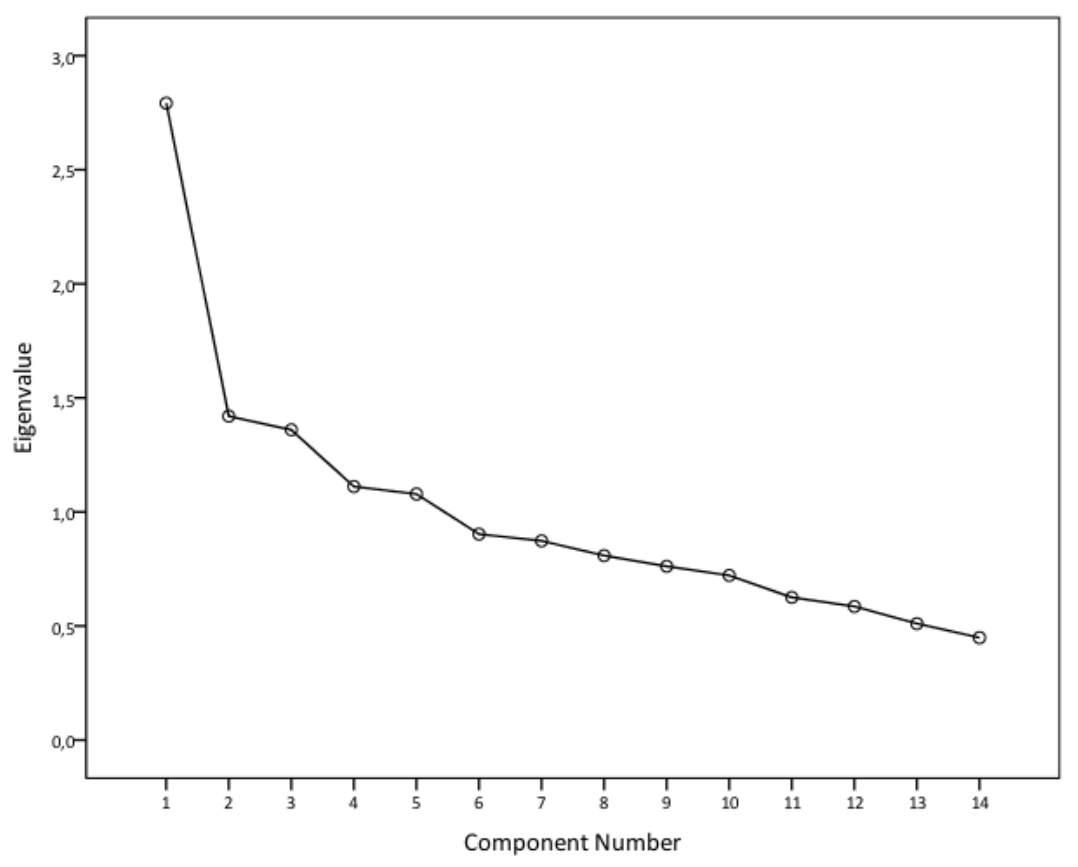

Figure 3.1. Scree plot of the principal component analysis on the 14 items of the SCIL. 
Third, IQ scores were calculated based on the WAIS-III-NL SF (Velthorst et al., 2013). IQ scores ranged from 49 to $112, M=75.2, S D=11.3, M d n=75.00$. Table 3.2 provides an overview of $\mathrm{IQ}$ categories based on the classification by Resing and Blok (2002), a classification commonly used by health professionals in the Netherlands and within Dutch public social services. Results showed that, of our sample, $28.7 \%$ had an 10 below 70, 39.3\% had an 10 between $70-79,21.9 \%$ had an 10 between 80 - 89, and only $10.1 \%$ had an IQ above 90 . In addition, 55.6\% (99 participants) had a borderline IQ (IO between 70 - 84).

Table 3.1. Principal Component Analysis (rotated component matrix) on the 14 items of the SCIL $(N=177)$.

\begin{tabular}{ccccc}
\hline \multicolumn{5}{c}{ Component } \\
\hline Item & 1 & 2 & 3 & 4 \\
\hline 1 & & .72 & & \\
2 & & .49 & & \\
3 & & .65 & & \\
10 & & .53 & & \\
6 & .38 & & & \\
7 & .42 & & & \\
8 & .59 & & & \\
12 & .72 & & & \\
13 & .68 & & .51 & \\
5 & & & .75 & \\
11 & & & & \\
14 & & & & \\
4 & & & & \\
9 & & & & \\
\hline
\end{tabular}

Note. Rotation method is Varimax with Kaiser normalization.

Component 1: Eigenvalue 2.79 (\% of variance $=19.94), \alpha=.55$.

Component 2: Eigenvalue $1.42(\%$ of variance $=10.14), \alpha=.51$.

Component 3: Eigenvalue $1.36(\%$ of variance $=9.71), \alpha=.47$.

Component 4: Eigenvalue $1.11(\%$ of variance $=7.94), \alpha=.14$. 
Table 3.2. Numbers and percentages of Resing \& Blok IQ categories (2002), based on the WAIS-III-NL SF $(N=178)$.

\begin{tabular}{lccc}
\hline IQ category (IO scale values) & $n$ & Percentage & $\begin{array}{c}\text { Cumulative } \\
\text { percentage }\end{array}$ \\
\hline 1. Mild mental retardation ( $\leq 69)$ & 51 & 28.7 & 28.7 \\
2. Well below average (70-79) & 70 & 39.3 & 68.0 \\
3. Below average (80-89) & 39 & 21.9 & 89.9 \\
4. Average (90-109) & 16 & 9.0 & 98.9 \\
5. Above average $(\geq 110)$ & 2 & 1.1 & 100.0 \\
\hline
\end{tabular}

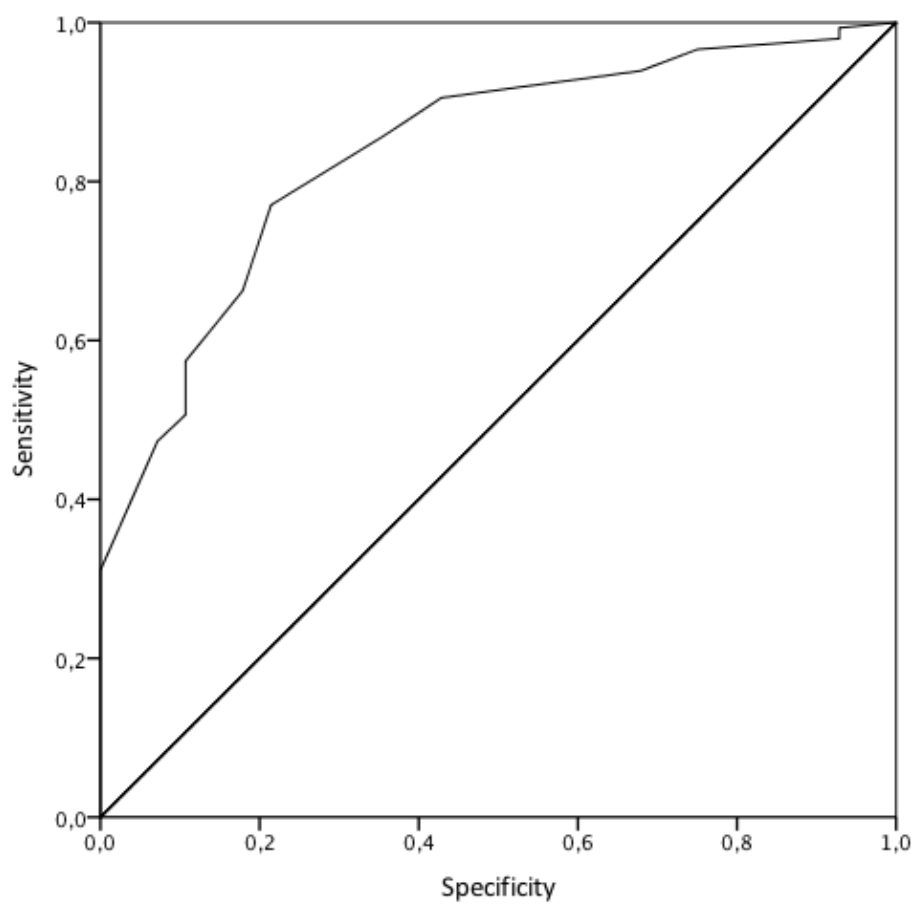

Figure 3.2. Receiver operating characteristic analysis of the SCIL based on the on the WAIS-III-NL SF (cut-off score IQ < 85). 
Fourth, ROC analyses were performed to examine the predictive validity of the SCIL for detecting intellectual disability $(I Q<85)$, which resulted in an AUC value of .78 $(S D=.04, p=.000)$. Results of the ROC analysis are shown in Figure 3.2 and Table 3.3. Furthermore, the SCIL screened 89 (50.0\%) participants as suffering from mild intellectual disability (IO < 85; Kaal et al., 2013), while the four subtests of the WAIS classified 150 (84.3\%) participants as having an IQ below 85 .

Table 3.3. Sensitivity and specificity for different SCIL cut-off scores with a cut-off IQ score of $85(N=177)$.

\begin{tabular}{|c|c|c|}
\hline Cut-off point & Sensitivity & Specificity \\
\hline 3.0 & .00 & 1.00 \\
\hline 5.5 & .00 & .99 \\
\hline 7.5 & .02 & .99 \\
\hline 8.5 & .04 & .99 \\
\hline 9.5 & .06 & .99 \\
\hline 10.5 & .10 & .98 \\
\hline 11.5 & .18 & .97 \\
\hline 12.5 & .20 & .95 \\
\hline 13.5 & .26 & .94 \\
\hline 14.5 & .38 & .90 \\
\hline 15.5 & .54 & .85 \\
\hline 16.5 & .68 & .80 \\
\hline 17.5 & .72 & .71 \\
\hline 18.5 & .76 & .68 \\
\hline 19.5 & .80 & .61 \\
\hline 20.5 & .86 & .52 \\
\hline 21.5 & .88 & .39 \\
\hline 22.5 & .92 & .28 \\
\hline 23.5 & .98 & .23 \\
\hline 24.5 & 1.00 & .14 \\
\hline 25.5 & 1.00 & .09 \\
\hline 26.5 & 1.00 & .04 \\
\hline 27.5 & 1.00 & .02 \\
\hline 29.0 & 1.00 & .00 \\
\hline
\end{tabular}




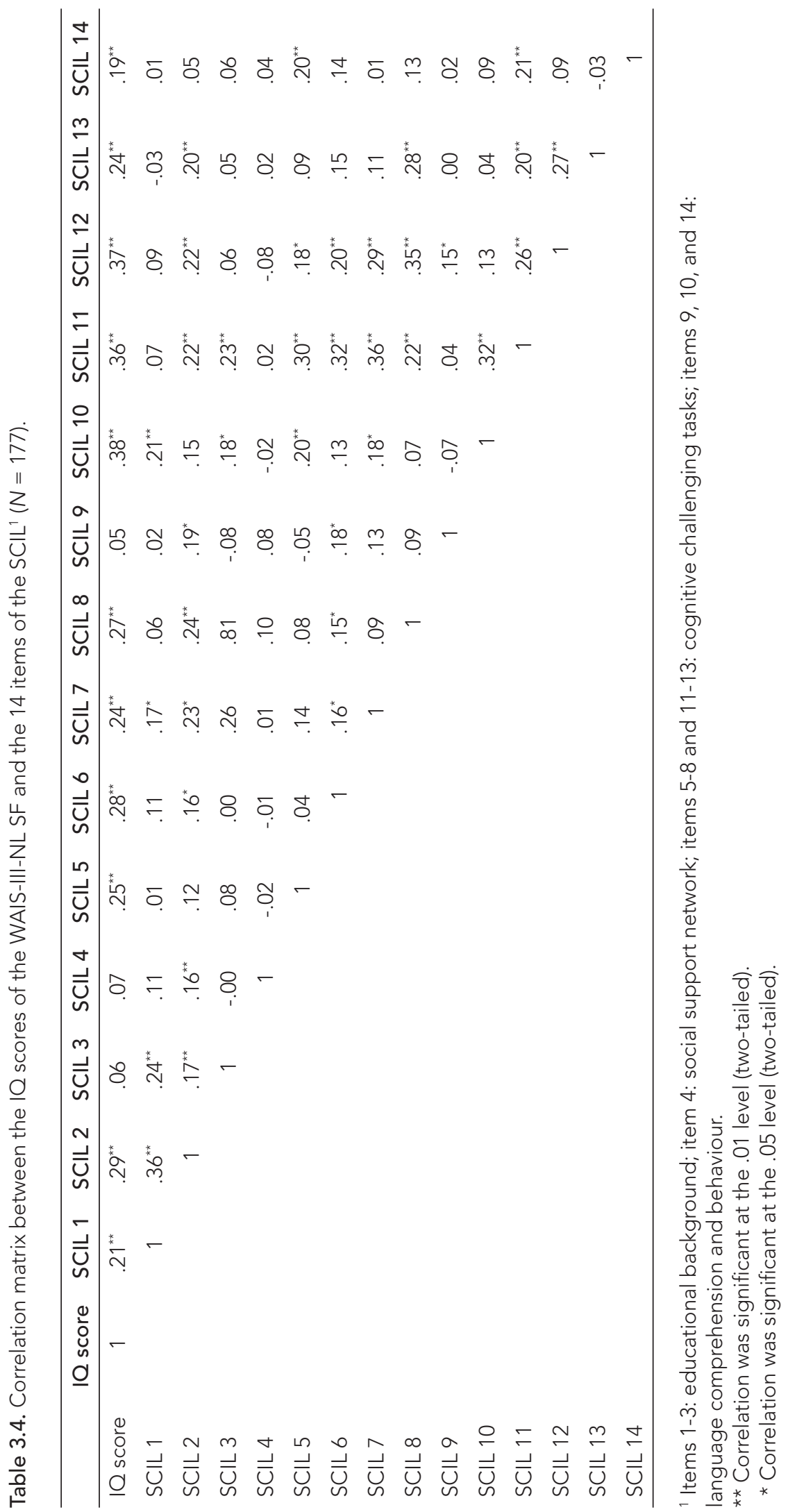


Results showed that the correlation between the SCIL total score and $1 \mathrm{Q}$ scores based on the WAIS-III-NL SF was moderate, $r=.56, p=.000$. Correlations between IQ scores and the $14 \mathrm{SCIL}$ items are presented in Table 3.4. SCIL items 3, 4, and 9 (i.e., contact with social services, social safety net, and reading newspapers and magazines) did not correlate significantly with $1 \mathrm{Q}$, however, items on educational background (items 1 and 2), comprehension of a Dutch saying (item 10), and the more cognitively challenging items (items 5 - 8 and 11 - 14) did correlate significantly with $I Q$ (r's between .19 and .38).

Finally, IQ scores obtained in our sample were compared to IQ scores obtained in previous studies on suspects in police custody and detainees in regular prisons (see Table 3.5). Because previous studies used different IQ-measures and score cut-offs, Table 3.5 shows various categories $(<70,70-79$, and $70-84)$ and the different test instruments for comparative purposes. 
Table 3.5. IQ-scores of suspects in police custody and in prison from previous studies compared to the present study.

\begin{tabular}{|c|c|c|c|c|}
\hline Study & $\begin{array}{l}\text { Country; setting; } \\
\text { participants }\end{array}$ & Instrument & $1 \mathrm{Q}$ & Percentage \\
\hline \multirow[t]{3}{*}{ Present study } & $\begin{array}{l}\text { Netherlands; police } \\
\text { custody; } N=178\end{array}$ & WAIS-III-NL SF & $<70$ & 28.7 \\
\hline & & & 70-79 & 39.3 \\
\hline & & & $70-84$ & 55.6 \\
\hline \multirow[t]{2}{*}{$\begin{array}{l}\text { Gudjonsson et } \\
\text { al. (1993) }\end{array}$} & $\begin{array}{l}\text { England; police custody; } \\
N=156\end{array}$ & WAIS-R² & $<70$ & 8.6 \\
\hline & & & $70-79$ & 42.0 \\
\hline \multirow[t]{2}{*}{$\begin{array}{l}\text { Hayes et al. } \\
(2007)\end{array}$} & $\begin{array}{l}\text { England; prison; } \\
N=140\end{array}$ & WAIS-III-UK ${ }^{3}$ & $<70$ & 7.1 \\
\hline & & & $70-79$ & 23.6 \\
\hline $\begin{array}{l}\text { Murphy et al. } \\
\text { (2017) }\end{array}$ & $\begin{array}{l}\text { England; prison; } \\
N=2,429\end{array}$ & $\mathrm{LDSQ}^{4}$ & $<70$ & 7.0 \\
\hline \multirow[t]{2}{*}{$\begin{array}{l}\text { Parton et al. } \\
(2004)\end{array}$} & $\begin{array}{l}\text { Australia; prison; } \\
N=74\end{array}$ & WASI $^{5}$ & $55-69$ & 9.5 \\
\hline & & & $70-79$ & 23.0 \\
\hline \multirow[t]{2}{*}{$\begin{array}{l}\text { Søndenaa et al. } \\
\text { (2008) }\end{array}$} & $\begin{array}{l}\text { Norway; prison; } \\
N=143\end{array}$ & WASI ${ }^{5}, \mathrm{HASI}^{6}$ & $<70$ & 10.8 \\
\hline & & & $70-84$ & 20.1 \\
\hline $\begin{array}{l}\text { Young et al. } \\
\text { (2013) }\end{array}$ & $\begin{array}{l}\text { England; police custody; } \\
N=195\end{array}$ & $\mathrm{LDSQ}^{4}$ & $<70$ & 6.7 \\
\hline
\end{tabular}

${ }^{1}$ Velthorst et al., 2013; ${ }^{2}$ Wechsler, 1981; ${ }^{3}$ Wechsler, 1999b; ${ }^{4}$ McKenzie et al., 2012; ${ }^{5}$ Wechsler, 1999a; ${ }^{6}$ Hayes, 2000. 


\section{Discussion}

Early identification of intellectual disabilities in police suspects is essential in view of an effective and efficient investigation process (Gudjonsson \& Joyce, 2011; Herrington \& Roberts, 2012; Sheyett et al., 2009). Up until now, not much is known about the prevalence of intellectual disabilities in police suspects in the Netherlands (Kaal, 2014). The main goal of this study was to explore the predictive validity of the recently developed Screener for Intelligence and Learning Disability (SCIL) in suspects in police custody, and the second goal was to examine the prevalence of intellectual disability in this sample.

Our first hypothesis was that the SCIL is an adequate instrument to detect intellectual disability in police suspects. The results of our study showed that factor loadings of the 14 items did not correspond very well with the a priori factors proposed in the original study (Kaal et al., 2013). An exploratory factor analysis such as PCA requires at least five cases per item (i.e., 14 * $5=70$ ) and preferably more (O'Rourke \& Hatcher, 2013). Thus, our sample of 178 cases was adequate in this respect. However, the distribution of 10 in our sample was quite skewed, which may have affected PCA findings. Future studies need to examine the SCIL's factor structure in different samples with more normal and/ or heterogeneous distributions.

Second, we explored the prevalence of intellectual disability among police suspects. Our second hypothesis was that this prevalence would be similar to that found in the study of Gudjonsson et al. (1993) among police suspects. In their study, $42.0 \%$ of police suspects had an 10 score between 70 and 79 , and $8.6 \%$ of police suspects had an 10 score below 70 . We found that $39.3 \%$ of Dutch police suspects had an IQ between 70 and 79, which seems to be in line with the study of Gudjonsson et al. (1993). However, we found that $28.7 \%$ had an 10 below 70 , which is a much higher percentage than previous studies in police suspects, who found that $8.6 \%$ (Gudjonsson et al., 1993) and $6.7 \%$ (Young et al., 2013), respectively, had an 10 below 70. Previous studies performed in adjucated prisoners in the United Kingdom found that $16.4 \%$ had an 10 between 70 and 79 (Hayes et al., 2007) and that about 7\% had an 10 below 70 (Hayes et al., 2007; Murphy, Gardner, \& Freeman, 2017). Furthermore, $83.4 \%$ of our sample had an IQ below 85 . Thus, intellectual disabilities appeared to be more prevalent in our police suspects compared with previous studies on intellectual disabilities in police suspects and detainees in regular prisons.

The prevalence of borderline $\mathrm{IQ}$ among suspects - detained in police custody as well as in regular prisons - seems to be substantial (Jones, 2007), and the prevalence of borderline $\mathrm{IQ}$ among suspects in police custody compared with prison detainees 
appears to be even higher. This could perhaps be explained by the circumstances in which the IO assessments took place. Possibly, the distress caused by the recent arrest and the circumstances in police detention (Baksheev, Thomas, \& Ogloff, 2012 Herrington \& Roberts, 2012) resulted in increased anxiety, lack of concentration, and fatigue. Police detention is characterised by uncertainties about the police investigation, smaller, noisier and less comfortable cells, limited contact with relatives, friends and other inmates, and lack of daily activities, in comparison with regular prison regimes (Blaauw, Kerkhof, \& Vermunt, 1998). Another possible explanation to account for differences in observed prevalence rates of intellectual disability in detainees is that different definitions of intellectual disability have been used, as well as different diagnostic criteria, and a variety of assessment tools (see Table 3.5). In fact, research studies found that studies on the prevalence of intellectual disabilities in individuals held in the criminal justice system showed a large range of estimates, from $2 \%$ to $40 \%$ (Jones, 2007), mostly between $20 \%$ and $30 \%$ (Talbot, 2007).

Fourth, the predictive validity of the SCIL was examined. We found a significant but moderate correlation $(r=.56)$ between SCIL and IQ scores based on the short WAIS, and lower sensitivity (.72) and specificity (.71) in comparison with the original validation study (i.e., sensitivity $=.82$, specificity $=.89$; Kaal et al., 2013). This moderate correlation is expected because the SCIL used a broader intelligence construct than the WAIS-III-NL SF, which is entirely focused on cognitive intelligence. In addition, the AUC value for $10<85$ obtained in the present study was .78, whereas the AUC value in the original study by Kaal et al. (2013) was .93. It remains an empirical question whether the practical and social aspects of intellectual disability, as measured with the SCIL, are cause for vulnerability within a police interrogation setting. Future research needs to examine which aspects of the current DSM-5 definition of intellectual disability (American Psychiatric Association, 2013) predict problems during actual interrogations, such as source monitoring errors and errors in judgement.

\section{Limitations}

This study has a number of limitations. First, the sample size was relatively small, therefore our results should be interpreted with some caution. Second, we used a WAIS-III-NL SF to assess cognitive functioning in police suspects because we believed that the cognitive domain of intellectual disability, in comparison with the practical and social domains, is the most relevant to the interrogation situation. Although Velthorst et al. (2013) showed that their SF provides a reliable and valid estimation of the full-scale IQ score, ideally, we would have tested all domains and used a full WAIS. However, this was not possible given time constraints in police detention. Third, the assessments 
were conducted in police detention centres, which could have had negative effects on participants' performance levels. On the other hand, the assessments took place in a real-world police detention environment, supporting the ecological validity of our findings.

\section{Conclusion}

The detection of suspects with intellectual disability is the professional responsibility of Dutch police officers according to a policy guideline (Aanwijzing auditief en audiovisueel registreren van verhoren van aangevers, getuigen en verdachten, 2014), yet previous international research has shown that police officers lack the required knowledge and experience to adequately identify these suspects (Gudjonsson, 2003; Parton et al., 2004). We found that the screening instrument SCIL did not detect a significant proportion (about 34\%) of police suspects who were found to suffer from mild intellectual disabilities ( $\mathrm{IQ}$ below 85) according to an $\mathrm{IQ}$ measure. We also found a somewhat different factor structure for the SCIL in our sample compared with the originally hypothesised factor structure of Kaal et al. (2013). The social and practical items of the SCIL could mask actual lower IQ scores when assessing police suspects by means of the SCIL. Future studies in different forensic (e.g., police suspects, prisoners) and non-forensic samples must test whether the SCIL is a useful screener for police suspects who may need further assessment of their intellectual abilities (Hayes, 2002; Kaal et al., 2013). As mentioned above, the possible relevance of social and practical disabilities for police interrogations needs to be further investigated.

To conclude, a large percentage of this study's sample of police suspects suffered from intellectual disabilities (Gudjonsson et al., 1993; Hayes et al., 2007; Murphy et al., 2017; Parton et al., 2004; Søndenaa et al., 2008; Young et al., 2013). Pending future research on the prevalence of intellectual disabilities in Dutch police suspects and on the impact of both cognitive and practical aspects of intellectual disabilities on functioning within the interrogation room, we hope our study contributes to raising awareness among police interrogators that it is quite likely they will run into suspects with intellectual disabilities on a regular basis, and that they need to take special precautions when interrogating them (Gudjonsson \& Joyce, 2011; Herrington \& Roberts, 2012; Scheyett et al., 2009). 
3 
I warned the team supervisor that he was a vulnerable suspect because I suspected he was suffering from psychoses. But both the team supervisor and the public prosecutor literally said

that they wanted pressure on the suspect during interrogation. Later, it turned out that, according to the psychiatric report of the Dutch Institute of Forensic Psychiatry and Psychology, I had been right. But apologies: no way! Sometimes people just don't listen to me.

Police psychologist employed by the Dutch National Police

(2015) 


\section{Chapter Four}

\section{The interrogation of police suspects in the Netherlands}

Current practices

This chapter is a translated and modified version of the published paper: Geijsen, K. \& De Ruiter, C. (2017). Het Nederlandse politieverhoor van verdachten anno 2017. Strafblad, 79(2), 157-162. 


\section{Introduction}

Interrogating suspects is core business of the police and has gained more interest from researchers during the past years (Häkkänen, Ask, Kebbell, Alison, \& Granhag, 2009). Research in the United Kingdom has shown that inappropriate interrogation techniques, such as confronting suspects with false evidence, minimization and maximization techniques, appealing to suspects' conscience and other tricks to deceive suspects, can make both guilty and innocent suspects confess (Gudjonsson, 2003, 2010; Kassin, 2017). However, until today it has remained relatively unknown how appropriate Dutch police interrogations are executed. The few researchers granted access to police interrogation rooms reported that Dutch police officers do not always use appropriate interrogation methods (Duker \& Stevens, 2009; Stevens \& Verhoeven, 2011; Verhoeven \& Duinhof, 2017). Therefore, it is time to review current Dutch interrogation methods. For this purpose, empirical research on police interrogation practices in the United Kingdom and the Netherlands will be compared.

\section{Police interrogation in the United Kingdom: Investigative interviewing}

The United Kingdom has a long tradition of scientific research on police interviews of victims, witnesses, and suspects. The main reason for this is that in 1984 the Police and Criminal Evidence (PACE) Act was introduced. The PACE Act was a major innovation after it was found out that the British police had used coercive interrogation practices on IRA suspects. The purpose of the PACE Act was to formulate ethical and transparent guidelines for police interrogations (Shepherd \& Griffiths, 2013). In addition, the police had to record all interrogations, and these recordings were made accessible for scientific research. Subsequent research showed that police interrogators often used an accusatory interrogation style and that their main aim in the interrogation was to obtain a confession (Baldwin, 1993). In several cases, it was proven that suspects falsely confessed due to inappropriate interrogation methods (Griffiths \& Milne, 2005; Gudjonsson, 1994). In-depth research showed that during interrogation, police officers first confronted suspects with the available evidence, subsequently asked suspects for a reaction on the accusation, and next tried to convince suspects to provide a confession (Soukara, Bull, Vrij, Turner, \& Cherryman, 2009).

In 1992, a new interrogation framework, the so-called PEACE framework, was introduced in the UK. The term 'police interrogation' was replaced by 'investigative interviewing', to emphasize the importance of interviewing suspects without biases. The main goal of a police interview is to find the facts of a case and not necessarily to 
obtain a confession. The new interviewing framework was based on scientific research on good communication skills, the functioning of human memory, and conversation management techniques (Clarke, Milne, \& Bull, 2011).

The PEACE framework comprises five stages: Planning and preparation, Engage and explain, Account, clarification and challenge, Closure, and Evaluation. The PEACE framework is based on three principles: (1) a neutral, unbiased interviewing style; (2) transparency about the goal of the interview, and (3) free recall. Suspects are given the opportunity to provide a statement and the interviewers pose questions about this statement in a neutral manner (Shepherd \& Griffiths, 2013). At the time the PEACE framework was implemented, the registered intermediate was also introduced to assist vulnerable suspects during interviews. A registered intermediate is expected to engage in the interview in an active manner, thereby protecting a fair interview and contributing to adequate communication between the police interviewers and the suspect (Medford, Gudjonsson, \& Pearse, 2003).

About ten years later, a new educational model was introduced to train police officers in investigative interviewing. This model, based on scientific research and tailored to the severity of offences, consists of five tiers. At tier one, junior police officers are taught the basics of investigative interviewing. Tier two is a two-weeks interview training for senior police officers who are involved in more complex police investigations. Tier three is a specialized six-weeks course about interviewing vulnerable suspects and children. Tiers four and five are courses for supervisors and police management who provide interview guidance to police staff (Griffiths \& Milne, 2005). During the past years, the interview training programme has been refined and is now called the Professionalising Investigation Programme (College of Policing, 2017), which consists of four tiers. Tiers one to three involve training in basic interviewing techniques and supervision, and tier four is designed for strategic supervision during interviews in more complex police investigations (McGrory \& Treacy, 2012). Research into investigative interviewing practice showed that police interviews are better prepared, structured, and contain more transparent interviewing techniques (Clarke, Milne, \& Bull, 2011), which results in more cooperative suspects and more extensive accounts (Bull \& Soukara, 2010). Nowadays, Investigative interviewing has been introduced in several police forces around the world, for example, in Australia, Canada, New-Zealand, and Norway (Walsh \& Bull, 2015). 


\section{Police interrogation in the Netherlands: The General Interrogation Strategy}

Dutch police officers commonly use the General Interrogation Strategy (GIS; in Dutch: Standaard Verhoorstrategie, SVS) to interrogate suspects. The GIS is described in the Interrogation Manual (Van Amelsvoort, Rispens, \& Grolman, 2015), which is used by the Police Academy of the Netherlands to train police officers in interrogation techniques. The GIS divides an interrogation into three parts, which are: a first contact part, a second 'person-oriented' part, and a third 'case-oriented' part. During the first contact part, the interrogator explains suspects' legal rights, the role of the lawyer (if the lawyer is present during interrogation), and the interrogation procedure. Next, during the person-oriented part, the interrogator informs about personal circumstances of the suspect, such as education, occupation, family, and financial circumstances. During the substantive, case-oriented part, the suspect is interrogated with the GIS. The GIS is based on building up 'internal pressure', minimizing reluctance to provide an account, ruling out alternative explanations, and challenging the suspect's account (Hoekendijk \& Van Beek, 2015). Although the GIS is believed to possess scientific components, to date the GIS has not been scientifically tested on its reliability and validity (Nierop, 2005; Stevens \& Verhoeven, 2011).

Two major theoretical shortcomings of the GIS are discussed next. First, the GIS may lead to guilty and confirmation biases in police officers. The GIS is based on minimizing resistance of the suspect about telling 'the truth' (Van Amelsvoort et al., 2015, p. 445), and building up confrontations with evidence in frequency, severity, and pace (Van Amelsvoort et al., 2015, p. 446), whereby tactical clues are being encircled (which means verifying or falsifying suspects' explanations for tactical or technical evidence), and suspects are rewarded when telling 'the truth' (Van Amelsvoort et al., 2015, p. 445). The problem is that the Interrogation Manual does not explain what exactly is meant by the term 'the truth'. Probably, the authors mean that the statement of the suspect must concur with the technical evidence. This implies that the utility of the GIS depends on the evidence available at the time of the interrogation (Kortlever, 2011). This obviously enhances the likelihood of confirmation bias and guilty bias (Hill, Memon, \& McGeorge, 2008; Leo \& Drizin, 2010). Police officers will likely assume that the suspect is guilty and will probably seek evidence that confirms the guilt of a suspect and ignore evidence to the contrary (Gudjonsson, 2003; Leo \& Drizin, 2010), especially in cases with little technical evidence (Häkkänen et al., 2009; Vrij, 2010). In addition, previous research has shown that police interrogators who presume a suspect is guilty will use a more accusatory interrogation style and more pressure and will try to obtain a confession of the suspect (Hill et al., 2008; Stevens \& Verhoeven, 2010). Moreover, 
the Interrogation Manual mentions that if the suspect adjusts his or her statement in line with 'the truth', the interrogators have to reward the suspect (Van Amelsvoort et al., 2015, p. 455). This implies that, contrary to what is claimed in the Manual, the GIS is not solely an information gathering interrogation method in regard to several accusatory components (Duker \& Stevens, 2009; Geijsen \& De Ruiter, 2017; Kortlever, 2011; Nierop, 2005).

Second, a major principle of the GIS is the build-up of pressure during the interrogation, which is problematic. The Interrogation Manual mentions that the GIS may only be used when a suspect is 'normally sensitive to pressure' (Van Amelsvoort et al., 2015, p. 455), but what this entails is not explained in the manual. Recently, Hoekendijk and Van Beek (2015) described two types of interrogative pressure: external and internal pressure. External pressure is believed to be pressure put on suspects by threatening them, making promises, maximization or minimization techniques, or longlasting interrogations. According to the Interrogation Manual, this type of pressure is not to be used during interrogations (Van Amelsvoort et al., 2015). Internal pressure is pressure experienced by suspects due to confrontations with evidence, and this kind of pressure is believed to make suspects confess in line with 'the truth' (Hoekendijk \& Van Beek, 2015). However, the exact difference between these two types of pressure remains unclear. The truth of the matter is that both types of pressure will lead to heightened stress levels in suspects, which is unnecessary because suspects already experience a lot of stress when being questioned by the police (Van Koppen, 2009). Furthermore, previous research on Dutch interrogations showed that suspects who refuse to talk are more likely to encounter police officers who use a more intimidating interrogation style (Stevens \& Verhoeven, 2010). This, in fact, may elicit a boomerang effect when suspects feel being treated unfairly or when experience too much pressure, resulting in even greater reluctance to talk with the police (Gudjonsson, 1994).

In sum, the Interrogation Manual warns police officers that 'distress may lead to false confessions' (Van Amelsvoort et al., 2015, p. 372), yet paradoxically it also advises that 'if most tactical clues have been used, it is possible to increase the pressure within the suspect by increasing confrontations, without letting the suspect respond' (Van Amelsvoort et al., 2015, p. 455). Thus, the GIS is not merely an information gathering interrogation method because it contains controversial accusatory components as well - some of which even appear to resemble the controversial Reid interrogation technique (Gudjonsson, 2003). 


\section{Police interrogation in the Netherlands: Scientific research}

Not much is known about what takes place in Dutch police interrogation rooms (Duker \& Stevens, 2009; Kortlever, 2011). A study by Stevens and Verhoeven (2011) showed mixed results. They observed 168 police interrogations of murder and manslaughter suspects. On the one hand, police officers used appropriate interrogation methods, such as encircling tactical clues (45-52\%) and building trust (71\%). On the other hand, police officers used inappropriate interrogation methods as well, for example, referring to hypothetical scenarios (23\%), acting out impatience, frustration or anger (28.6\%), asking suggestive questions (44.0\%), and addressing feelings of guilt and conscience (49.4\%). Moreover, the most important interrogation method of the GIS, namely confronting the suspect with evidence, was used only in half (52\%) of the 168 interrogations (Stevens \& Verhoeven, 2011).

Recently, Siemerink and Van der Laan (2016) interviewed Dutch police officers, a public prosecutor, a judge, and an investigative judge (rechter-commissaris) ( $N=16)$. The interviewees revealed that most police interrogations are based on gut feelings rather than on proper preparation. In addition, most police interrogators are not selected on the basis of how skilled or trained they are but merely selected based on availability. Furthermore, their research showed that police interrogators believe that interrogation training does not have any association with the quality of police interrogators, that interrogators lack knowledge about the police investigation, and that older police officers are used to a different style of interrogating than younger police officers (Siemerink et al. 2016).

Odinot, Boon and Wolters (2015) showed that police officers lack knowledge about how human memory works, and about the factors that influence the reliability of statements. They asked 191 police interrogators 18 questions about episodic memory and about factors that might influence the reliability of witness' statements. About two-thirds of the police interrogators answered incorrectly to questions about, for example, if a witness under the influence of alcohol can provide a reliable statement, if traumatic memories can be recovered after a few years, and whether asking leading questions to child witnesses result in false memories. The researchers concluded that there was no relationship between police officers' level of knowledge about human memory and their interrogation training level (Odinot et al., 2015).

More recently, Geijsen, Vanbelle, Kop and De Ruiter (2017) analysed transcripts from Dutch interrogations of 36 police suspects. For this purpose, they used the Griffiths Questions Map (GQM), which can be used to analyse the quality of police interrogations. The GQM labels the questions asked during an interrogation as either appropriate questions (i.e., open, probing, and appropriate closed questions) or as 
inappropriate questions (i.e., inappropriate closed questions, leading questions, multiple questions, opinion statement, and forced choice). No less than $86 \%$ of the interrogations were labelled as inappropriate interrogations, because of the use of inappropriate questions and the lack of a logical structure of open, probing, and appropriate closed questions. Results showed that only five (about 14\%) of the 36 interrogations could be labelled as appropriate interrogations (see Chapter Five).

\section{Discussion}

Appropriate police interrogation techniques are essential in order to obtain an accurate and full account from suspects, yet the scarce research on interrogation practices in the Netherlands indicates that Dutch police officers often use inappropriate interrogation techniques. This does not come as a complete surprise, in view of the GIS principles and the instructions on how to perform a police interrogation described in the Interrogation Manual. The GIS may lead to guilty bias and confirmation bias in police officers and the basic principle of building pressure during interrogations leads to stress in suspects. This is unnecessary and undesirable, because it may increase the chance of obtaining an unreliable account or even a false confession (Gudjonsson, 2010; Kassin, 2017). In the past, several scientists have questioned the appropriateness of the GIS (e.g., Boon et al., 2016; Duker \& Stevens, 2009; Israëls \& Horselenberg, 2010; Kortlever, 2011; Nierop, 2005; Odinot et al., 2015; Siemering \& van der Laan, 2016; Verhoeven \& Stevens; Stevens \& Verhoeven, 2010, 2011; Verhoeven \& Duinhof, 2017; Van Koppen, 1998, 2009; Vrij, 1998, 2010), yet to date no empirical research has examined the potentially adverse effects of the GIS, and teachers at the Dutch Police Academy continue to use the Interrogation Manual to train police officers in interrogation techniques.

In addition, during the past years case law has shown that the current Dutch legislation might not be sufficient to protect suspects from inappropriate interrogation techniques (Duker \& Stevens, 2009). Although Article 6 of the Convention for the Protection of Human Rights and Fundamental Freedoms (Council of Europe, 1950) prescribes that suspects have the right to a fair trial without prejudice, and Article 29 of the Dutch Code of Criminal Procedure (2018) prescribes that statements must be given freely and that interrogators are not allowed to put unlawful physical or psychological pressure on suspects, in actual Dutch legal cases only one example of unlawful pressure can be found. In 1997, the High Court of the Netherlands ruled that the so- 
called Zaanse interrogation method was not allowed. In this method, suspects relived the crime as a result of coercive interrogation methods and being shown pictures of the crime scene and family members of the victim. ${ }^{4}$ More recent legal cases showed, however, that judges allowed police officers to interrogate (silent) suspects frequently and incisively to enhance pressure ${ }^{5}$ to slam their fists on the table and to interrogate using a raised voice, ${ }^{6}$ to exaggerate available evidence, ${ }^{7}$ and to make inferences about what fellow suspects have already stated ${ }^{8}$ (Blom, 2011). In sum, although research has shown that these techniques may lead to unreliable statements, and the Manual rejects these techniques because they are considered to constitute unlawful external pressure, Dutch Courts do not deem these interrogation techniques inadmissible.

\section{Conclusion}

Appropriate interrogation methods are necessary to obtain accurate and reliable accounts from suspects. However, research has shown that Dutch interrogation practices often include inappropriate techniques, which is not a surprise in view of the basic principles of the GIS and the instructions provided in the Manual. The GIS may contribute to guilty bias and confirmation bias in police officers, and the basic principle of building pressure leads to increased stress in suspects. In the past, scholars have expressed concerns about these risks of the GIS (e.g., Boon et al., 2016; Duker \& Stevens, 2009; Van Koppen, 2009; Kortlever, 2011; Nierop, 2005), however, until now without tangible results. Teachers at the Police Academy of the Netherlands continue to use the Interrogation Manual to instruct police officers in interrogation methods. Furthermore, legal safeguards for the use of inappropriate interrogation methods appear to be failing (Blom, 2011; Duker \& Stevens, 2009).

\footnotetext{
${ }^{4}$ Dutch High Court, 13 May, 1997, ECLI:NL:HR:1997:ZD0705, NJ 1998, 152 m.nt. Schalken.

${ }^{5}$ e.g., Court of Appeal Arnhem, 12 December, 2000, ECLI:NL:GHARN:2000:AA8995, LJN AA8995; Court Dordrecht, 20 September, 2003, ECLI:NL:RBHAA:2007:BB7483, LJN BB7483; Court Amsterdam, 17 March, 2005, ECLI:NL:RBAMS:2005:AT0873, LJN AT0873; Court Groningen, 10 April, 2008, ECLI:NL:RBGRO:2008:BC9249, LJN BC9249.

${ }^{6}$ Court of Appeal 's-Hertogenbosch, 8 October, 2012, ECLI:NL:GHSHE:2012:BX9413, LJN BX9413.

${ }^{7}$ Court of Appeal 's-Hertogenbosch, 29 November, 2006, ECLI:NL:GHSHE:2006:AZ4141, LJN AZ4141.

${ }^{8}$ Court Midden-Nederland, 18 March, 2014, ECLI:NL:RBMNE:2014:1019, 16-703042-13 (P).
} 
It has been demonstrated that investigative interviewing is a reliable and effective way of questioning police suspects (Clarke, Milne, \& Bull, 2011; Shepherd \& Griffiths, 2013). Many police organisations across the globe have adopted investigative interviewing to obtain reliable and full accounts from suspects (Bull \& Soukara, 2010; Hill, Memon, \& McGeorge, 2008). Investigative interviewing could avert guilty bias and confirmation bias among Dutch police officers, and, on top of that, the GIS basic principle of building up pressure would no longer be necessary. We agree with Odinot et al. (2015) there is a need to develop a new scientifically, up-to-date Interview Manual for the Dutch police, in order to close the gap between current police practices and scientific evidence on police interrogation. In addition, we advise the development of this new manual using the investigative interviewing framework. It is not efficient and effective, even potentially dangerous, if police interrogators do not possess the required knowledge and skills to perform police interviews ethically and appropriately, that is, based on scientific evidence, instead of experience and gut feeling (Boon et al., 2016; Duker \& Stevens, 2009; Gudjonsson, 2003; Kassin, 2017; Kortlever, 2011; Odinot et al., 2015; Soukara et al., 2009). 
Lately, I was present during an

interrogation performed by a former

student of mine, who had received

all different kinds of interrogation

training courses. Multiple things went

wrong, he seemed to be forgotten

all training. Unbelievable.

I think many detectives just switch to

old routines that they are accustomed to.

Teacher of the Police Academy of the Netherlands

(2015) 


\section{Chapter Five}

\section{The interrogation of vulnerable suspects in the Netherlands}

\section{An exploratory study}

This chapter is a modified version of the published paper:

Geijsen, K., Vanbelle, S., Kop, N., \& De Ruiter, C. (2018).

The interrogation of vulnerable suspects in the Netherlands:

An exploratory study. Investigative Interviewing: Research and Practice, 9(1), 34-51.

For this study, Andy Griffiths, Ph.D., FCMI, was so kind to assist with analyses preparation with the Griffiths Question Map. 


\section{Introduction}

On July 30, 2004, the Dutch optometrist Isabella Pongs (48) was stabbed to death in her shop. It wasn't until August 2007 that the police arrested two male suspects (20 and 22 years old at time of their arrest), who were interrogated 11 times by the police, and eventually confessed to committing the crime. During trial, the court noted that the suspects' confessions were contradictory on certain points, and they stated they were uncertain about their confessions. Experts testified that the first suspect suffered from intellectual disabilities and schizophrenia, as well as cannabis dependence. The second suspect was diagnosed with intellectual disabilities, a drug dependence, psychosis, and possible autism. In addition, another expert testified that the police investigators had used inappropriate interrogation methods, such as putting too much pressure on the suspects, use of suggestive questions and maximisation techniques, and providing misleading clues and negative feedback. As a consequence, the court ruled that the suspects falsely confessed to the crime due to their mental disorders and the inappropriate interrogation techniques. They were found not guilty (Maastricht Court, 2008).

The Isabella Pongs case first illustrates that certain individuals are psychologically more vulnerable to give a false confession during police interrogations, regardless of guilt or innocence (Gudjonsson, 2010; Herrington \& Roberts, 2012; Kassin, Appelby, \& Torkildson Perillo, 2010a). Gudjonsson (2003) defines psychological vulnerabilities in suspects as: 'psychological characteristics or mental states which render a suspect prone, in certain circumstances, to providing information which is inaccurate, unreliable (or invalid) or misleading' (p. 316). Gudjonsson (2003) contends there are four major categories of psychological vulnerability in police suspects: mental disorders, intellectual disabilities, abnormal mental states, and personality characteristics. Suspects suffering from a mental disorder (such as depression, ADHD, or psychosis) experience troubles with perception, emotion, cognition, self-control and reality monitoring. These suspects often fail to provide a detailed and coherent statement (Gudjonsson, 2003; Kassin et al., 2010b). Suspects with intellectual disabilities may have difficulty understanding their legal rights and the interview questions (Gudjonsson \& Joyce, 2011; Herrington \& Roberts, 2012). In addition, these suspects face problems with memory capacity, and they are more sensitive to suggestion (giving in to leading questions) and prone to confabulation (Gudjonsson, 2003; Gudjonsson \& Joyce, 2011). Suspects with an abnormal mental state do not necessarily suffer from a mental disorder, yet they have problems functioning in a stressful situation, such as a police interrogation, due to extreme distress caused by detention circumstances, alcohol or 
drug abuse, or medical symptoms (e.g., cardiovascular problems, diabetes, epilepsy; Gudjonsson, 2003; Van Oorsouw, Merckelbach, \& Smeets, 2015). Some personality characteristics of suspects, such as suggestibility and compliance, are related to unreliable and inaccurate statements as well (Gudjonsson, 2003; Smeets, Leppink, Jelicic, \& Merckelbach, 2009). Suggestibility implies personal acceptance of questions or information, while compliance implies complying with requests and instructions for some immediate instrumental gain (Gudjonsson, 2003). Both traits are related to social desirability, eagerness to please, and avoidant coping, but the main difference is that suggestibility implies personal acceptance of questions or information (thus, some degree of internalization), while compliance implies complying with requests and instructions of someone else for some immediate instrumental gain (Gudjonsson, 2003). These vulnerabilities are best viewed as risk factors (Gudjonsson, 2010). Psychologically vulnerable suspects are at increased risk of providing untruthful statements and/or false confessions, particularly in conjunction with inappropriate interrogation techniques (Gudjonsson, 2003; Kassin et al., 2010a; Kassin et al., 2010b; Walsh \& Bull, 2012).

The Isabella Pongs case also illustrates that suspects - particularly psychologically vulnerable suspects - must be interrogated appropriately in order to obtain a reliable and accurate statement (Farrugia \& Milne, 2012; Herrington \& Roberts, 2012; Leo \& Davis, 2010; O'Mahony, Milne, \& Grant, 2012). A number of key principles are important during police interrogations, for example, interrogators should be openminded and act fairly (Soukara, Bull, Vrij, Turner, \& Cherryman, 2009), and they should use appropriate questions (Shepherd \& Griffiths, 2013). Appropriate or productive questions are relevant, respectful, sensible, sensitive, short, single, simple and sincere, and stimulate the suspect's thinking and disclosing of thoughts. These questions are open prompts, for example, instructions (tell, describe, explain), or probing questions (what, how). Appropriate questions contribute optimally to obtain an accurate and extensive account, in contrast to inappropriate questions. Inappropriate or counterproductive questions are, for example, leading (suggestive) questions, option posing or forced choice questions, multiple questions, or hypothetical questions (Oxburgh, Myklebust, \& Grant, 2010; Shepherd \& Griffiths, 2013). Especially when interrogating suspects with psychological vulnerabilities, such as a mental disorder or intellectual disabilities, it is important that police officers slow down the pace of the interrogation, try to reduce stress, and avoid inappropriate questions and lengthy interrogations (Herrington \& Roberts, 2012; Leo \& Davis, 2010).

At the time of this study, Dutch police officers are taught to perform interrogations as prescribed in the so-called Interrogation Manual (Handleiding Verhoor; Van 
Amelsvoort, Rispens \& Grolman, 2015), first published in 2005 and used by the Police Academy of the Netherlands to educate police officers up until today. The authors are a police psychologist and two police experts, who wrote the Interrogation Manual based mainly on past experiences of police officers (Nierop, 2005), and a small laboratory experiment, which explored effective interrogation behaviour with the help of four experienced police interrogators and four actors, in order to derive basic interrogation principles (Hoekendijk \& Van Beek, 2015).

The Dutch Interrogation Manual divides a police interrogation into three parts. The first part is called 'first contact', in which the suspect is informed of his/her rights, and the procedure of the interrogation is explained. The second part, termed the 'personoriented interrogation', aims to establish rapport, to collect information about the suspect (e.g., education, family, work, finances), and to explore whether the suspect is willing to provide a statement. The third part, the 'case-oriented interrogation', concerns interrogating the suspect about the alleged crime (Van Amelsvoort et al., 2015). During this third part, Dutch police officers use the General Interrogation Strategy (GIS; Duker \& Stevens, 2009; Hoekendijk \& Van Beek, 2015) as described in the Interrogation Manual (Van Amelsvoort et al., 2015). The GIS basic rules are: (1) minimizing resistance of suspects against telling the truth, (2) encircling tactical clues to avoid evasions, which is done by asking questions about possible alternatives in order to rule them out, (3) building up pressure by confronting the suspect with evidence, and (4) rewarding the suspect if 'he or she adjusts his or her statement in line with the truth' (Van Amelsvoort et al., 2015, p. 445). Obviously, some of these basic rules are accusatory in nature, and some even appear to resemble the highly criticized Reid technique of interrogating police suspects (Duker \& Stevens, 2009; Gudjonsson, 2003). The GIS may be used when three conditions are satisfied: (1) availability of enough tactical and technical clues for making an interrogation plan, (2) the suspect must be 'sensitive to pressure in a normal manner', and (3) the suspect is willing to provide a statement (Van Amelsvoort, 2015, p. 445).

Some of these conditions are problematic. First, the Interrogation Manual does not explain how many tactical and technical clues are necessary in order to use the GIS. A previous version of the Interrogation Manual, called the Suspect Interrogation Manual (Van den Adel, 1997), mentioned a number of five to ten clues, but did not describe the rationale for these numbers (Duker \& Stevens, 2009). Second, the Interrogation Manual does not provide guidelines on how to determine whether a suspect is 'sensitive to pressure in a normal manner', it only mentions that the suspect 'must not give extreme reactions, or no reactions at all, where you would normally expect this' (Van Amelsvoort et al., 2015, p. 445). Yet, studies have demonstrated that pressure during interrogations 
may increase stress levels in suspects, especially in vulnerable suspects, which in turn increases the risk of inaccurate statements, or even false confessions (Gudjonsson, 2010; Herrington \& Roberts, 2012; Kassin et al., 2010b). Still, it is stated in the Interrogation Manual the aim of the GIS is to build up so-called 'internal pressure', which is assumed to be 'the tension aroused in the mind of the suspect by the perceived incriminating power of the pieces of evidence at hand' (Hoekendijk \& Van Beek, 2015, p. 4), and which is believed to be different from external pressure, described as 'everything that might be used to force the suspect to talk or confess' (Hoekendijk \& Van Beek, 2015, p. 4). Nevertheless, 'internal pressure' is a form of pressure which aims to influence a suspect's statements, and it could thus be argued that there is actually little difference between internal and external pressure (Gudjonsson, 2003; Kortlever, 2011; Leo \& Davis, 2010; Verhoeven \& Stevens, 2012). Moreover, the Interrogation Manual mentions that it is allowed for police interrogators 'to incisively interrogate the suspect and thereby use a certain amount of pressure' (Van Amelsvoort et al., 2015, p. 340). According to the GIS, the interrogation ends 'if the suspect's statement is in line with the tactical clues' (Van Amelsvoort et al., 2015, p. 456). This implies not only that police officers will continue to interrogate the suspect in case he or she provides a statement that is not in line with the tactical clues, but it also enhances the risk of confirmation bias and guilty bias in police officers (Duker \& Stevens, 2009; Kortlever, 2011; Leo \& Davis, 2010). To conclude, although the GIS is officially termed an information gathering interrogation method, its aim is to deliberately build up pressure in suspects (Van Amelsvoort et al., 2015, pp. 445-457) reveals an accusatory component (Boon, Odinot, Horselenberg, \& Geijsen, 2016; Duker \& Stevens, 2009; Kortlever, 2011; Stevens \& Verhoeven, 2011; Verhoeven \& Stevens, 2012; Vrij, 2003).

Research on police interrogation in The Netherlands has demonstrated that police officers use inappropriate questions and tactics (e.g., maximisation, minimisation, accusation, or suggesting a particular scenario). Stevens and Verhoeven (2012) analysed 168 Dutch police interrogations of murder and manslaughter suspects and found that police interrogations only partially conformed to the guidelines in the Interrogation Manual. Three interrogation techniques, viewed by the Interrogation Manual as appropriate, were used frequently (i.e., building trust, 71.4\%; encircling tactical and technical clues, $44.6 \%-51.8 \%$ ), yet inappropriate interrogation techniques were used frequently as well (i.e., leading and suggestive questions, $44 \%$; asking about hypothetical scenarios, 22.6\%; pushing to evoke feelings of guilt, $49.4 \%$; expressions of impatience, frustration and anger, 28.6\%; Stevens \& Verhoeven, 2012). Moreover, these authors found that an important interrogation technique of the GIS (e.g., confrontation with evidence) was used in only $51.8 \%$ of the interrogations, and that Dutch police 
officers sometimes even resorted to manipulation and intimidation techniques, especially during the second and third interrogations (i.e., physical intimidation, 4.2\%; minimization techniques, 4.2\%; Stevens \& Verhoeven, 2012). By using inappropriate interrogation techniques, police officers risk to obtain an unreliable statement, or even a false confession, especially from vulnerable suspects (Gudjonsson, 2003; Herrington \& Roberts, 2012; Kassin et al., 2010b).

Since a number of years, the Dutch National Police and the Police Academy are paying attention to the issue of vulnerable suspects. During initial training, police recruits receive information about interrogation techniques in regard to vulnerable suspects. In 2013, a new training program 'Interrogation of Vulnerable Suspects' was launched, which trains police officers to signal vulnerabilities in police suspects and to effectively interrogate these suspects (Nierop \& Van den Eshof, 2014).

Based on the guideline in the Interrogation Manual and previous research, the question arises if vulnerable suspects are appropriately interrogated by Dutch police officers. We hypothesise that, as prescribed by the Interrogation Manual (c.f., Van Amelsvoort et al., 2015, pp. 95-101), Dutch police officers conduct interrogations by mostly using appropriate questions (i.e., open questions), and by avoiding inappropriate questions (e.g., closed questions, multiple questions, forced choice questions). We expect comparable results to the study of Stevens and Verhoeven (2012). In addition, we expect the percentage of appropriate interrogations to be significantly higher for vulnerable suspects, compared to non-vulnerable suspects, as a consequence of increased awareness building on vulnerable suspects within the Dutch police force. To investigate our hypotheses, tests for different psychological vulnerabilities (i.e. intellectual disabilities, mental disorders, and an abnormal mental state; Gudjonsson, 2003), and the Griffiths Question Map (GQM; Shepherd \& Griffiths, 2013) for classifying interview questions, are used in a sample of police suspects detained in Dutch police detention centres.

\section{Method}

\section{Participants}

Subjects ( $N=178$ ) who participated in a study on the prevalence of psychological vulnerabilities among police suspects in the Netherlands (see Chapter One and Two) were asked to participate in the current study. Subjects were at least 18 years of age, not visibly intoxicated by alcohol or drugs, and able to speak the Dutch language. Subjects were psychologically assessed at six police detention centres (Amsterdam, 
Breda, Eindhoven, Heerlen, Maastricht and Tilburg) between June 24, 2014, and May 7,2015 . Thirty-seven subjects gave permission to use their interrogation transcripts, so they were included in the present study. Their age ranged from 18 to $60\left(M_{\text {age }}=\right.$ 31.68; $\left.S D_{\text {age }}=11.37\right)$. Thirty-two male subjects (86.5\%) and five female subjects (13.5\%) participated and all subjects stated they possessed the Dutch nationality. The distribution of subjects across the police detention centres was: Breda, $n=9$ (24.3\%); Eindhoven, $n=15$ (40.5\%); Heerlen, $n=9$ (24.3\%); and Maastricht, $n=13$ (35.1\%).

\section{Procedure}

Assessors approached prospective subjects in their cells and invited them to participate. If a subject agreed, the aim and procedures of the study and the informed consent were explained in a separate room. The subjects were assured that the assessors were bound by confidentiality and that they would be free to stop their participation at any moment without having to provide a reason. Before starting the assessment, all subjects were asked to sign an informed consent, by which they agreed to voluntarily participate in the psychological assessment. In addition, 37 subjects granted access to their interrogation transcripts by signing an additional consent. The psychological assessments were performed by a M.Sc. psychologist (first author) and two Master's students in Forensic Psychology from Maastricht University, carefully instructed and supervised. It was assured that the psychological assessment would not interfere with the police investigation in any possible way. The assessments lasted for about one hour and one hour and a half. Four months after completion of all assessments, the interrogation transcripts of the 37 subjects were collected. All interrogation transcripts were anonymised after the analyses.

This study was approved by the standing Ethical Review Committee Psychology and Neuroscience of Maastricht University (ERCPN number: 03_10_2014), the Office of the Attorney General of the Netherlands, the Chief Constable of the Dutch National Police Force.

\section{Measures}

\section{Malingering}

In order to detect possible malingering of symptoms, a short form (SF) of the Wildman Symptom Checklist (WSC; Wildman \& Wildman, 1999) was included in the assessment battery. Previous research found that out of the original 70 items of the WCS, four items discriminated optimally between respondents who were asked to answer honestly and respondents asked to exaggerate symptoms (Merckelbach, Smeets, \& Jelicic, 2008; Merckelbach, Langeland, De Vries, \& Draijer, 2014). The four items of the WSC SF 
concern non-credible, yet disturbing, cognitive symptoms: 'I have headaches that are so severe my feet hurt', 'The buzzing in my ears keeps switching from the left to the right', 'I notice that the colour of things around me keeps shifting', and 'I find myself frequently blacking out when I sit down.' These items are answered on a 5-point Likert scale $(0=$ not at all to $4=$ extremely). The total score of the WCS SF is the sum of all item scores (range $=0-16$ ), and a score of 4 or higher serves as an indication for malingering (Merkelbach et al., 2014). Cronbach's alpha of the four items in the present study was .75 .

\section{Criteria for identifying vulnerable suspects}

A suspect was classified as a vulnerable suspect when he or she met one or more of the following three criteria, based on the categorisation of vulnerable suspects of Gudjonsson (2003): mental disorder, intellectual disabilities, and/or an abnormal mental state. The fourth category, personal characteristics (suggestibility and compliance), was not included in this study, because there are no cut-off points for the Gudjonsson Suggestibility Scale (GSS; Gudjonsson, 1997) and the Gudjonsson Compliance Scale (GCS; Gudjonsson, 1989), and therefore these scales are not helpful to identify vulnerable suspects in this study.

Mental disorders were screened with the Brief Jail Mental Health Screen (BJMHS; Steadman, Scott, Osher, Agnese, \& Clark Robbins, 2005). The BJMHS is a tool to screen for mental health problems, originally validated against the Structured Clinical Interview for DSM-IV (SCID; First, Spitzer, Gibbon, \& Williams, 2002). In a previous study, the BJMHS correctly classified $73.5 \%$ of male prisoners and $61.6 \%$ of female prisoners on the basis of SCID diagnoses (Steadman et al., 2005). The BJMHS was translated into Dutch by the first and fourth author for the purpose of this study. Examples of BJMHS items are: 'Do you currently believe that someone can control your mind by putting thoughts into your head or taking thoughts out of your head?' (item 1); 'Are you currently taking any medication prescribed for you by a physician for any emotional or mental health problems?' (item 7); and 'Have you ever been in a hospital for emotional or mental health problems?' (item 8). All eight items are scored either 'no' (0 points) or 'yes' (1 point). A score of more than two points on items 1 through 6 and/or 1 point on items 7 and 8 indicate a need for further mental health assessment (Steadman et al., 2005).

Intellectual disabilities were measured with a SF of the WAIS-III-NL (Wechsler, 1997; Dutch version: Uterwijk, 2000): Information (verbal comprehension), Block Design (perceptual organization), Arithmetic (working memory), and Symbol Substitution Coding (processing speed). The validation study of the short form included 75 patients 
with a diagnosis of schizophrenia, 73 of their non-schizophrenia siblings, and 84 unrelated healthy controls (Velthorst et al., 2013). It was found that the four subtests had adequate predictive accuracy and differentiated between patients, relatives and healthy controls. The correlation coefficient between the WAIS-III and the WAIS-III SF was found to be $r=.95$, thus the WAIS-III SF was proven to be a valid alternative to estimate general intellectual ability (Velthorst et al., 2013). In this study, intellectual disabilities were defined by a full-scale IQ score lower than 70 (DSM-IV-TR; American Psychiatric Association, 2000).

First, an abnormal mental state was assessed by means of the Mini Mental State Exam (MMSE; Folstein, Folstein, \& McHugh, 1975). This instrument screens for impaired cognitive functioning. We used the Dutch standardised version of the MMSE (Kok \& Verhey, 2002), with a cut-off score of 25 (a score below 25 indicates an abnormal mental state). Examples of MMSE items are: 'What is the date/day/month/year/season?' and a three-stage instruction: 'Take this piece of paper, fold it in half, and then put it on your lap.'

In addition, an abnormal mental state related to alcohol and/or drug abuse was assessed as well. This was documented based on self-report: subjects were asked about their use of alcohol and/or drugs. If the subject stated that he or she was addicted to alcohol and/or drugs, or admitted that he or she used alcohol and/or drugs on a daily basis, the subject was classified with a substance use disorder.

\section{Interrogations analyses}

In the Netherlands, police interrogations are not recorded as a standard procedure. Audio or video recording of police interrogations is only mandatory in particular cases (according to the judicial guideline 'Aanwijzing auditief en audiovisueel registeren van verhoren van aangevers, getuigen en verdachten', 2012), for example, in cases when the victim is deceased, when the suspect could be sentenced to imprisonment for more than 12 years, or when interrogators are coached by a police psychologist. We chose to include all types of cases (and offences) in our study and analysed the written transcripts of these interrogations. All interrogation transcripts were written in a question-answer format and reflected the first 'case-oriented interrogation' (Van Amelsvoort et al., 2015).

The interrogation transcripts were analysed with the GQM (Shepherd \& Griffiths, 2013). Based on the research literature, the GQM identifies eight types of questions, labelled as either appropriate or inappropriate. Appropriate questions (i.e., openended, probing, and appropriate closed questions) are questions associated with neutral and effective information gathering. An open question is to obtain detailed 
information, a probing question is to get micro-details, and an appropriate closed question is to seek confirmation and/or clarification. In contrast, inappropriate questions (i.e., inappropriate closed, leading, multiple questions opinion statements, and forced choice) produce insufficient and/or unreliable information. Inappropriate closed questions only provide a yes or no answer, leading questions are associated with suggestibility (Gudjonsson, 2003; Oxburgh et al., 2010), multiple questions make it unclear which question is to be answered, and an opinion statement and a forced choice reflect a biased interrogator (Shepherd \& Griffiths, 2013; Walsh \& Bull, 2012). Although the GQM was originally designed for analysis of audio recordings of interrogations for training purposes, we used the GQM because it provides a detailed map with an overview of the type of questions used during an interrogation (Shepherd \& Griffiths, 2013), and because of its proven utility in previous research (Griffiths \& Milne, 2006).

A GQM was constructed for all 37 interrogation transcripts. First, the first author and a Master's student in Forensic Psychology of Maastricht University (who also participated in the data collection) independently scored 16 (43.2\%) interrogation transcripts. Next, the first author scored another 12 (32.3\%) interrogation transcripts, and the Master's student scored the last 9 (24.3\%) interrogation transcripts. The interobserver agreement of the first 16 interrogation transcripts was quantified using Cohen's kappa coefficient, which compares the agreement observed between two observers to the level of agreement expected if the two observers had made the classification randomly. The standard error of the coefficient was adjusted to account for the fact that several questions refer to the same interview (Yang \& Zhou, 2014). The 16 interviews comprised between 8 and 64 questions. According to the GQM, question classification as described above, the quality of the question was further subclassified as appropriate for categories 1, 2 and 3 (coded as 1) and inappropriate for the categories 4 through 8 (coded as 0 ). The two observers agreed on the classification of $403(92.2 \%)$ questions and disagreed on 34 (7.8\%) questions, leading to a Cohen's $\kappa$ $=.88 ; 95 \%$, Confidence Interval $=.82-.94$.

\section{Data analysis}

Data analysis was performed using R v3.3.3. Before analysing the data, the sample ( $N$ = 37) was examined for malingering using the WSC SF. One subject of the sample was suspected of malingering, and the data from this subject were excluded from further analyses (Merckelbach et al., 2014). All analyses described below were thus performed with a sample of $N=36$. 


\section{Results}

First, we examined psychological vulnerabilities in our sample of police suspects $(N=$ 36), based on three of the categories proposed by Gudjonsson (2003): mental disorder, intellectual disabilities, and abnormal mental states. The BJMHS indicated that 20 subjects (55.6\%) scored above the cut-off score. The results of the WAIS-III-NL short form showed that 10 subjects (27.8\%) obtained an IQ score lower than or equal to 70 , which indicated intellectual disabilities. The MMSE indicated that four subjects $(11.1 \%)$ were suffering from impaired cognitive functioning. Based on self-report, 9 subjects (25\%) presented as abusing alcohol and/or drugs. Combining all three categories, 25 subjects (69.4\%) in the sample could be labelled as vulnerable and 11 (30.6\%) as non-vulnerable. Vulnerability scores summarized using means, standard deviations, medians, and ranges on the WAIS-III-NL short form and MMSE are presented in Table 5.1 .

Second, interrogation transcripts ( $N=36)$ were coded by means of Griffiths Question Map and subsequently labelled as either an appropriate or inappropriate interrogation (Shepherd \& Griffiths, 2013). Figures 5.1 and 5.2 present examples of the GQM for two transcripts, classified as an appropriate interrogation (Figure 5.1) and an inappropriate interrogation (Figure 5.2). Only five (about 14\%) of the interrogations met the criteria for an appropriate interrogation, as described by Shepherd and Griffiths (2013). These five interrogations consisted entirely of open, probing, and appropriately closed questions. Consequently, 31 (about 86\%) interrogations did not meet these criteria and were labelled inappropriate interrogations. The inappropriate interrogations contained a minimum of $2.1 \%$ and a maximum of $23.1 \%$ inappropriate questions, all in combination with a lack of a coherent questioning pattern, which requires open questions to introduce a topic, followed by probing questions, and (possibly) ending a topic by an appropriately closed question.

Table 5.1 Mean, median and standard deviation for the WAIS-III-NL and MMSE in the sample $(N=36)$.

\begin{tabular}{lcccc}
\hline & $M$ & $S D$ & $M d n$ & Range \\
\hline WAIS-III-NL & 75.39 & 10.46 & 75.00 & $54-100$ \\
MMSE & 27.25 & 2.37 & 28.00 & $19-30$ \\
\hline
\end{tabular}

Note. WAIS-III-NL: Dutch Short Form of the Wechsler Adult Intelligence Scale $3^{\text {rd }}$ edition (Velthorst et al., 2013). MMSE: Dutch version of the Mini Mental State Exam (Kok \& Verhey, 2002). 


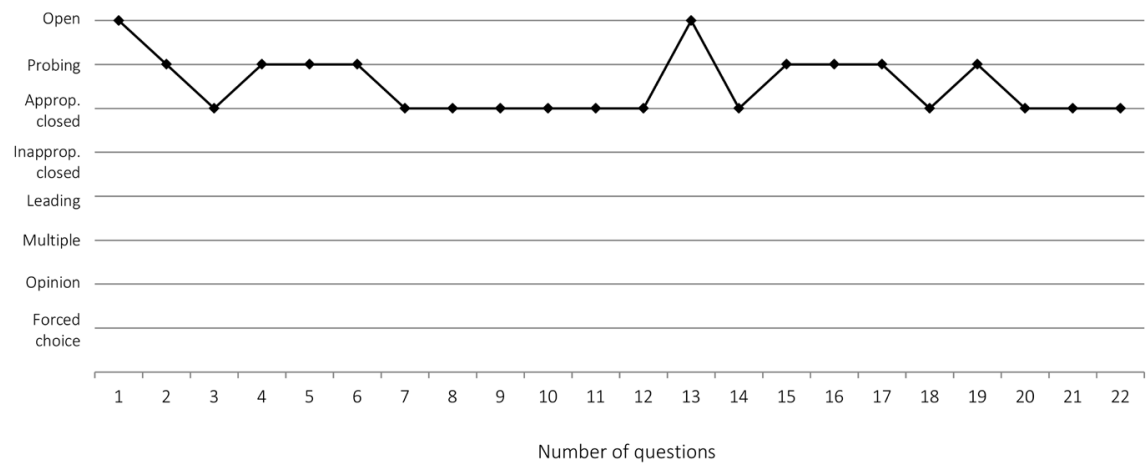

Figure 5.1. Typical representation of an appropriate police interrogation. Appropriate questions are represented at the top three lines (i.e., open, probing, and appropriate closed questions). Inappropriate questions are represented at the bottom five lines (i.e., inappropriate closed questions, leading questions, multiple questions, stating an opinion, and forced choice questions).

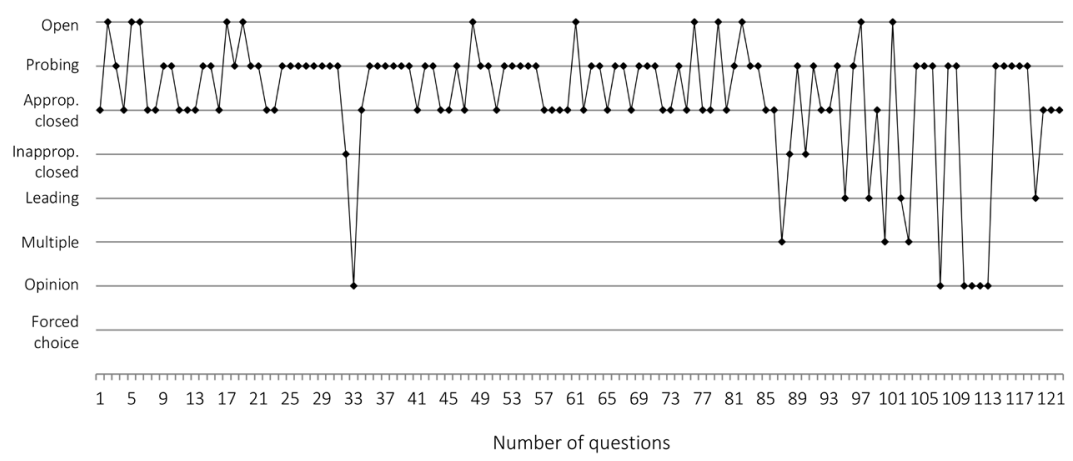

Figure 5.2. Typical representation of an inappropriate police interrogation. Appropriate questions are represented at the top three lines (i.e., open, probing, and appropriate closed questions). Inappropriate questions are represented at the bottom five lines (i.e., inappropriate closed questions, leading questions, multiple questions, stating an opinion, and forced choice questions). 
Table 5.2 shows a cross tabulation of appropriate vs. inappropriate interrogations among vulnerable vs. non-vulnerable suspects. Twenty-one (84.0\%) out of 25 vulnerable suspects were interrogated inappropriately, four vulnerable suspects (16.0\%) were interrogated appropriately. Ten (90.9\%) non-vulnerable suspects were interrogated inappropriately, one non-vulnerable suspect (9.1\%) was interrogated appropriately. No significant difference was found between appropriate and inappropriate interrogations in vulnerable vs. non-vulnerable suspects, $O R=1.90, p=1$.

Table 5.2. Appropriate and inappropriate interrogations in vulnerable and non-vulnerable suspects $(N=36)$.

\begin{tabular}{lcc}
\hline Suspects & \multicolumn{2}{c}{ Interrogations $^{1}$} \\
\cline { 2 - 3 } Non-vulnerable & Appropriate & Inappropriate \\
Vulnerable & $1(9.1 \%)$ & $21(80.9 \%)$ \\
Total & $4(16.0 \%)$ & $31(86.1 \%)$ \\
\hline
\end{tabular}

${ }^{1}$ Appropriate interrogations contained open-ended, probing, and appropriate closed questions. Inappropriate interrogations were performed with the use of inappropriate/ ineffective questions and showed disorganised questioning patterns as well (Shepherd \& Griffiths, 2013). 
There was no difference in the length of interrogations (number of questions) between vulnerable suspects $(M d n=27)$ and non-vulnerable suspects $(M d n=30), p$ $=0.47$. We also examined the association between type of question and the outcome of each screening instrument separately, with the use of a multinomial-poisson model to acknowledge the fact that the length of the interrogation varies between suspects (Lang, 2004). The comparison between vulnerable and non-vulnerable suspects was adjusted for the length of the interrogation. Results in Table 5.3 are presented for an interrogation of 27 questions, which is the median length of the interrogations. ${ }^{?}$

Table 5.3. Percentages of the eight types of questions of the GQM asked during interrogations, for an interrogation of 27 questions in relation to vulnerability, as defined on WAIS-III-NL (IQ $\leq 70$ vs. > 70), BJMHS (further mental health examination needed: yes vs. no), MMSE (impaired cognitive functioning: yes vs. no), and the use of drugs and/or alcohol (yes vs. no).

\begin{tabular}{|c|c|c|c|c|c|c|c|c|c|c|}
\hline & & \multirow[b]{3}{*}{$n$} & \multicolumn{8}{|c|}{ Question types ${ }^{1}$} \\
\hline & & & \multicolumn{3}{|c|}{ Appropriate } & \multicolumn{5}{|c|}{ Inappropriate } \\
\hline & & & 1 & 2 & 3 & 4 & 5 & 6 & 7 & 8 \\
\hline \multirow[t]{2}{*}{ WAIS-III } & $\leq 70$ & 10 & $8.2^{*}$ & $34.8^{*}$ & 42.2 & 2.0 & 5.6 & 6.2 & 1.1 & .0 \\
\hline & $>70$ & 26 & $3.1^{*}$ & $47.7^{\star}$ & 35.9 & 0.8 & 3.0 & 7.8 & 1.8 & .0 \\
\hline \multirow[t]{2}{*}{ BJMHS } & Y & 20 & 4.2 & 44.6 & 37.5 & 1.3 & $4.4^{*}$ & 6.8 & 1.3 & .0 \\
\hline & $\mathrm{N}$ & 16 & 3.2 & 48.1 & 36.0 & 0.4 & $1.4^{*}$ & 8.6 & 2.4 & .0 \\
\hline \multirow[t]{2}{*}{ MMSE } & Y & 4 & $10.1^{*}$ & 43.3 & 40.6 & $0.0^{*}$ & 4.6 & $1.4^{*}$ & $0.0^{*}$ & .0 \\
\hline & $\mathrm{N}$ & 32 & $3.8^{*}$ & 45.6 & 36.7 & $1.0^{*}$ & 3.4 & $7.8^{*}$ & $1.7^{\star}$ & .0 \\
\hline \multirow{2}{*}{$\begin{array}{l}\text { Drugs / } \\
\text { Alcohol }\end{array}$} & Y & 9 & $7.5^{*}$ & 47.3 & 38.0 & 0.5 & 2.3 & $4.4^{*}$ & $0.0^{\star}$ & .0 \\
\hline & $\mathrm{N}$ & 27 & $3.2^{*}$ & 45.2 & 36.6 & 1.1 & 3.7 & $8.3^{*}$ & $1.9^{*}$ & .0 \\
\hline
\end{tabular}

1 (1) open-ended, (2) probing, (3) appropriate closed, (4) inappropriate closed, (5) leading, (6) multiple questions, (7) opinion statements, (8) forced choice.

* Significant difference when $95 \%$ confidence interval for the percentage difference does not contain 0 , based on a multinomial-poisson model.

\footnotetext{
${ }^{9}$ Note: the distribution of the length of the interrogations was skewed to the right, and the number of suspects was moderate $(N=36)$, therefore the median was used instead of the mean.
} 


\section{Discussion}

The aim of this study was to investigate whether police officers in the Netherlands interrogate suspects - vulnerable suspects in particular - appropriately, by the use of appropriate interrogation techniques. We expected that all suspects, but psychologically vulnerable suspects in particular, would be interrogated in an appropriate manner, with open and non-leading questions.

First, in our sample $(N=36)$ about $56 \%$ screened positively for further examination of their mental health, about $28 \%$ suffered from intellectual disabilities (IQ score below 70), $11 \%$ screened positive for an abnormal mental state, and $25 \%$ of the sample stated to be addicted to alcohol and/or drugs and/or to take alcohol or drugs on a daily basis. Only $31 \%$ of our sample could be labelled as non-vulnerable according to our criteria. These findings seem to be in line with previous research. Gudjonsson, Clare, Rutter, and Pearse (1993) reported the prevalence of psychological vulnerabilities in suspects at two police stations in London, United Kingdom. They found that of 173 police suspects, 33\% were intellectually disadvantaged ( $1 \mathrm{C}<75), 20 \%$ experienced high levels of stress and anxiety, and 35\% were in an abnormal mental state because of stress, mental disorder, or drug and/or alcohol abuse (Gudjonsson et al., 1993). A study conducted at Australian police stations ( $N=198)$ showed that about $82 \%$ of male and $94 \%$ of female suspects exhibited high levels of psychological distress (Baksheev, Thomas \& Ogloff, 2012). Another study ( $N=614)$ showed that about onethird of Australian police suspects experienced psychiatric symptoms (Ogloff, Warren, Tye, Blaher, \& Thomas, 2011). Blaauw, Kerkhof, and Vermunt (1998) found high levels of depression (89\%), somatization (74\%) and emotional problems, such as feeling very lonely (70\%), tired (46\%), angry (54\%), and anxious (52\%), among Dutch police suspects. Thus, we can safely conclude that police officers are highly likely to encounter a high percentage of vulnerable suspects during police interrogations.

Second, we hypothesized that police officers would perform interrogations appropriately as prescribed by the Dutch Interrogation Manual (Van Amelsvoort et al., 2015), especially with vulnerable suspects. Our study revealed that about $86 \%$ of all suspects, about $84 \%$ of all vulnerable suspects, and $91 \%$ of all non-vulnerable suspects were interrogated in an inappropriate manner. These inappropriate interrogations showed disorganised questioning patterns and the use of inappropriate questions, which were mainly multiple questions, followed by leading questions, opinion statements and inappropriate closed questions. Importantly, no association was found between the type of suspect (vulnerable vs. non-vulnerable) and the way the interrogation was performed (appropriate vs. inappropriate). 
Exploratory analyses on the use of the different types of questions in relation to psychological vulnerabilities showed a mixed picture of associations. First, leading questions were asked more often during interrogations of suspects who were positively screened for needing further mental health examination, compared to suspects who were not screened positively on this measure. Second, open-ended questions were asked more often, yet probing questions less often, during interrogations of intellectually disabled suspects, compared to suspects without intellectual disabilities. Third, cognitively impaired suspects were less often confronted with inappropriate closed questions, opinion statements, and multiple questions, and more often with open-ended questions, compared to suspects who were not cognitively impaired. In addition, suspects who stated to drink alcohol or use drugs on a daily basis were asked more open questions and experienced fewer opinion statements and multiple questions, compared to suspects who did not drink alcohol or use drugs on a daily basis. However, these differences should be interpreted with some caution because of small sample sizes. Something worth noting is police officers used open-ended questions significantly more often when interrogating vulnerable suspects - at least with suspects who are suffering from intellectual disabilities and abnormal mental states - yet the overall percentage of open questions during all police interrogations was extremely low (about 5\%).

In sum, it can be concluded that police officers often used inappropriate questions during their interrogations and their interrogations were often disorganised, irrespective of the presence of psychological vulnerabilities in suspects. Moreover, if future studies confirm that police officers use more inappropriate questions during interrogations of suspects with putative mental health problems (i.e., those who screened positive on needing further mental health examination), this could mean these suspects are in double jeopardy because their vulnerability increases the risk of inappropriate interrogation. One possibility is that suspects who suffer from mental disorders manifest problems with understanding questions, and with providing a detailed and accurate account of events. This may inadvertently 'tempt' interrogators to use more closed and leading questions in order to seek confirmation from more vulnerable suspects (Herrington \& Roberts, 2012; Hill, Memon, \& McGeorge, 2008; O'Mahony, Milne, \& Grant, 2012). Obviously, this hypothesis needs to be tested by conducting sequential analyses of interrogations in larger samples of vulnerable and non-vulnerable suspects.

Our finding of disorganised questioning patterns and the ample use of inappropriate questions demonstrates that day-to-day police interrogation practice in the Netherlands differs greatly from the guidelines described in the Interrogation 
Manual, which has been reported by other researchers as well. For example, Siemerink and Van der Laan (2016) interviewed 16 police officers, a public prosecutor, and a judge, who were involved in five murder and manslaughter cases with juvenile suspects. They found that older police officers mostly relied on 'old-school' tactics, which were mainly based on gut feelings. Younger police officers were trained in modern interrogation techniques, which led to more proper preparation of interrogations. Duker and Stevens (2009) found that, after graduation from the Police Academy, young police officers' initially trained interrogation techniques were reshaped by older colleagues in the field. Moreover, it was found that in most cases interrogators were selected on the basis of availability and not on the basis of their qualifications. Further, Dutch police officers believe that successful completion of specialised interrogation training has no bearing on the quality of the interrogation (Siemerink \& Van der Laan, 2016). Thus, it is likely that Dutch police officers lack thorough theoretical knowledge of the importance of appropriate interrogation techniques and their effects on suspects (Duker \& Stevens, 2009; Nierop \& Van den Eshof, 2014; Odinot, Boon, \& Wolters, 2015; Siemerink \& Van der Laan, 2016).

It is of eminent importance that police officers undergo extensive training in appropriate interrogation techniques, grounded in empirical research, not only during their initial training, but throughout their career (Clarke, Milne, \& Bull, 2011; Farrugia \& Milne, 2012; Odinot et al., 2015; Soukara et al., 2009). Research has clearly shown that skilled police interrogators ask more open-ended questions (Powell, HughesScholes, Smith, \& Sharman, 2014), and that peer feedback on the interrogators' performance leads to an increase of appropriate questions and enhanced quality of police interrogations (Clarke et al., 2011; Cyr, Dion, McDuff, \& Trotier-Sylvain, 2012; Lamb et al., 2012).

\section{Limitations}

The present study was limited in two respects. First, the sample size was small ( $N=$ 36). Notably, the number of non-vulnerable suspects was small. Second, this study investigated interrogation techniques based on written interrogation transcripts, because audio or video recordings of the interrogations were not available. After we collected the data for this study, Malsch and her colleagues (2015) reported that most written Dutch police transcripts do not fully represent the actual interrogations. They analysed 55 verbatim interrogation transcripts and interviewed 24 experts within the criminal justice system (e.g., police detectives, public prosecutors, judges, and lawyers). According to their results, at most $37 \%$ of all questions asked during interrogations are reproduced in official police transcripts, and circumstances, emotions, pressure, 
confrontations, and remarks of suspects that could exculpate them, are often left out of the transcripts. Dutch police interrogation transcripts are in fact summaries of the interrogation and are not accurate reproductions of reality (Malsch et al., 2015), hence, a replication of our study using audio or video recordings, in order to obtain a more accurate representation of what was actually said in the interrogation room, could provide more accurate data. However, considering that Malsch et al. (2015) found that less appropriate interrogation methods were often left out of the official police transcripts, we hypothesize that the current findings (which used the official transcripts) may actually underestimate the level of inappropriateness of the interrogations.

\section{Conclusion}

Based on our findings, police officers in the Netherlands appear to adhere to inappropriate interrogation methods in a large proportion of interrogations. This is particularly problematic because psychologically vulnerable suspects appear to be at even higher risk to be subjected to inappropriate closed and leading questions compared to non-vulnerable suspects. We would encourage the Dutch National Police to open its interrogation rooms to empirical researchers to further examine to what extent Dutch interrogation methods are appropriate for interrogating suspects - in particular in relation to vulnerable suspects (Duker \& Stevens, 2009; Farrugia \& Milne, 2012; Herrington \& Roberts, 2012; Kassin et al., 2010a; Soukara et al., 2009; Vrij, 2003). Furthermore, the possible increased vulnerability of police interrogators to revert to inappropriate questioning, in response to vulnerable suspects' behaviours during the interrogation, is in need of further investigation. 
5 


\section{I am staying in this cell for two}

days now, and yesterday I suddenly saw bugs crawling on the wall. The green colour of the cell, it drives me crazy.

Male police detainee, 48 years old (2015) 


\title{
Chapter Six
}

\section{Staying overnight in a police cell}

\author{
A study on suspects' psychological \\ wellbeing and sleep problems
}

This chapter is a translated and modified version of the published paper: Geijsen, K., Kop, N., \& De Ruiter, C. (2018). Overnachten in een politiecel: Een onderzoek naar het psychisch welzijn en slaapproblemen van verdachten. Tijdschrift voor Criminologie, 60(3), 312-326. DOI: 10.5553/TvC/0165182X2018060003003. 


\section{Introduction}

In recent years, many studies have addressed the influence of environments on behaviour and psychological wellbeing. Studies have found that if people find their environment stressful, negative performance and negative emotions increase (Bell, Green, Fisher, \& Baum, 2001). This effect has been found in psychiatric wards (Karlin \& Zeiss, 2006), hospitals (Drahota et al., 2012; Dijkstra, Pieterse, \& Pruyn, 2006), and prisons (Hancock \& Jewkes, 2011; Morris \& Worral, 2010). For example, prison design affects prisoners' behaviour and psychological states (Bell, Greene, Fisher, \& Baum, 2000). Prisoners' behaviour is related to various aspects of their environment, such as interiors, architecture, and social factors (Steinke, 1991). Temperature, colours, air quality, and the amount of daylight are also related to problematic behaviour by prisoners (Morris, Carriaga, Diamond, Leeper Piquero, \& Piquero, 2012; Steinke, 1991). Deprivation of mental stimulation due to incarceration may lead to stress, anger, and frustration, and has a negative effect on the relationship with prison staff and prisoners' psychological wellbeing (Nurse, Woodcock, \& Ormsby, 2003; Steinke, 1991).

To date, very little research has addressed the influence of police detention centre environments on suspects' psychological wellbeing and sleep problems. The present study explores this issue.

\section{Environmental psychology}

Environmental psychologists have used different theoretical models to attempt to understand environmental influences on psychological wellbeing and behaviour (Bell et al., 2001; Gifford, Steg, \& Reser, 2011). For instance, stimulation theory asserts that people adapt to their environments to a certain level and that overstimulation or under-stimulation heightens levels of arousal and stress (Gifford et al., 2011; Wohlwill, 1996). Control theory emphasizes the importance of people's ability to control stimuli in their environments (Altman, 1975; Gifford et al., 2011). Integral approaches (e.g., interactionism and organic models) attempt to describe the full yet complex interrelationship between the environment and people (Altman \& Rogoff, 1987; Gifford et al., 2011). Although different models address specific environments, they also overlap (Gifford et al., 2011).

Bell et al. (2001) combined different theoretical models into an eclectic model of theoretical perspectives about how environments affect people's behaviour and emotions. They assumed that people experience the environment in unique ways. If coping is successful, people will eventually adapt to the environment, sometimes leading to higher self-esteem and skill development. If the environment 
is experienced in a negative manner due to under-stimulation (deprivation of stimuli) or overstimulation (too many stimuli), then the ability to adapt to that environment leads to avoidance behaviour, continued arousal and stress, and eventually possible decreased psychological wellbeing, so-called learned helplessness, and/or decreased performance (Bell et al., 2001). Figure 6.1 presents a simplified theoretical model from Bell et al. (2001).

\section{Police detention centres in the Netherlands}

Little research has investigated the influence of police detention centres' environments on the psychological wellbeing of suspects. Every year, about 240,000 people are incarcerated in police detention centres in the Netherlands (Inspectie Veiligheid en Justitie, 2015), mostly because they are suspected of committing a crime. Often police suspects must be detained for some time, ranging from several hours to several days. The period depends on the severity of the crime and the police investigation (e.g. whether witnesses need to be interviewed, other evidence must be investigated, or a suspect must be questioned multiple times).

Blaauw, Vermunt, \& Kerkhof (1997) investigated the quality of Dutch police detention centres and concluded that they differ in interior design, procedures, number of prison staff, and facilities (e.g., availability of a nurse). They also concluded that physical circumstances in police detention centres are worse than in regular prisons (e.g., because of the size and design of cells, the possibility to contact family, friends, and other inmates, daily activities, and levels of crowding and noise). Dutch police
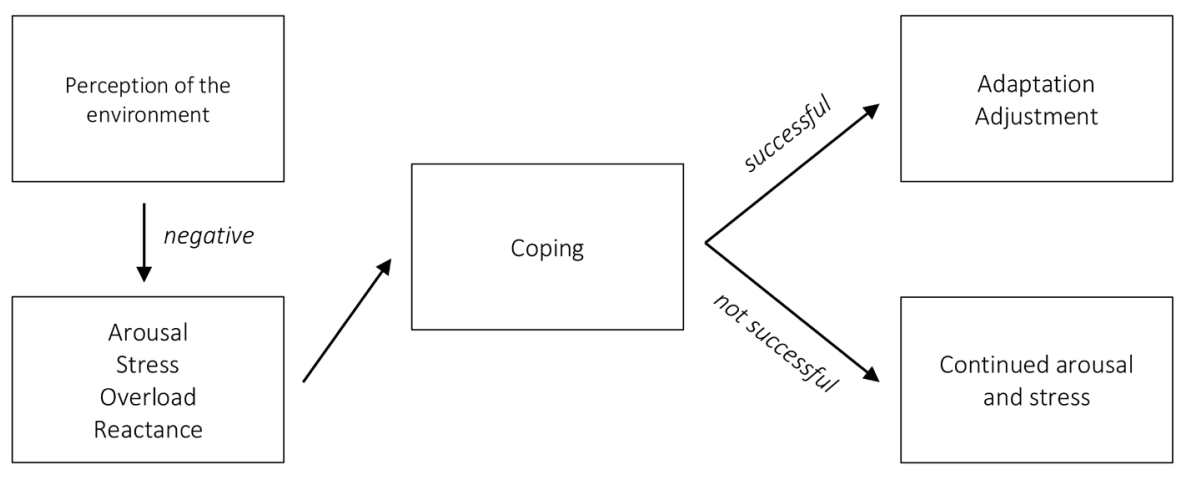

Figure 6.1. Simplified eclectic model of theoretical perspectives on the influence of environments on people's behaviour and emotions (from Bell et al., 2001). 
detention centres are designed with a view toward functionality, security, and safety, not specifically for suspects' comfort (Blaauw et al., 1997).

Some changes have occurred in recent decades. The interiors of police detention centres must meet strict national regulations (Regeling politiecellencomplex, 2017) and international regulations (see Hagens, 2011, for detailed information). For safety and hygiene reasons, cells are furnished with a plastic mattress and pillow, a woollen blanket, and paper sheets. In some of the more recently built centres, suspects can control lighting, heating, and the toilet, and some cells are equipped with TV, radio, and/or a game console. However, the house rules of police detention centres differ, for example in how often and how long suspects are allowed to smoke and stay in the courtyard for fresh air and exercise, and whether an extra meal or blanket is provided on request. To check the wellbeing of suspects during the night, staff may leave a small light on to check suspect's wellbeing through the door hatch on a regular basis, or they even might use flashlights. Most of the time, police detention centres are noisy - during the night as well - because of irritated, aggressive, and/or confused suspects being locked up in cells.

\section{Sleep problems}

If suspects experience sleep problems, they might face problems during police interrogations (Gudjonsson, 2003; Harrison \& Horn, 2000). For example, sleep deprivation has negative effects on cognitive abilities (Ratcliff \& Van Dongen, 2009), such as attention, memory, emotions, and executive functions (Ben Simon, Greene, Fisher, \& Baum, 2017; Deak \& Stickgold, 2010). It can also affect preparedness, reaction time, and decision-making (Killgore, Balkin, \& Wesensten, 2006). Research has also found that sleep deprivation may enhance psychological symptoms (Baksheev, Thomas, \& Ogloff, 2012; Blaauw et al., 1998). For example, Ratcliff and Van Dongen (2009) tested the cognitive abilities of two groups of participants. One group was allowed to sleep, the second group was kept awake for three days. On the third day, the second group gave significantly more random answers on cognitive tests and were less able to effectively retrieve information from stimuli, compared to the first group. Another example is the experiment by Killgore et al. (2006), who tested the effect of sleep deprivation on decision-making in uncertain circumstances. For this purpose, they used the lowa Gambling Task (IGT), a computerized gambling test in which participants take a card from one of four piles. They must choose between an immediate large reward accompanied by a high chance of potential loss during the test, or small, long-term rewards with less risk. Results of the IGT showed that sleep deprivation negatively affects long-term decision-making because sleep-deprived 
participants took a lot of risks and lost a lot of money (Killgore et al., 2006). A third experiment, conducted by Thomas et al. (2010), showed that even one night of sleep deprivation negatively affects attention and high-order cognitive processing, such as planning, organising, and information processing. Furthermore, a fourth experiment, by Frenda et al. (2016), showed that sleep deprivation is related to false confessions. Participants ( $N=88$ ) were involved in a computer test and were told to absolutely not touch the escape button because information would then be lost. The participants were divided into two groups: one group $(n=44)$ was allowed to sleep during the night, while the other group $(n=44)$ was kept awake all night. The next morning, all the participants were questioned and told they had hit the escape button - which had not happened. Subsequently, 30 (68\%) of the sleep-deprived participants falsely confessed, compared to 16 (36\%) of the participants who had slept (Frenda et al., 2016). In sum, suspects who experience sleep problems are less able to make considered decisions (Harrison \& Horne, 2000), and can be influenced more easily (Blagrove, 1986; Frenda et al., 2016; Gudjonsson, 2003).

\section{This study}

Based on the theory and research described above, circumstances in police detention centres raise four research questions. The first research question is what the current situation is with regard to the psychological wellbeing of suspects in Dutch police detention centres. The second question concerns the extent to which police suspects experience sleep problems. The third research question is to what extent sleep problems are related to the psychological wellbeing of suspects. The fourth question is whether there are differences in psychological wellbeing and sleep problems between suspects who sleep at home and suspects who sleep in a police detention centre. Subsequently, five hypotheses were formulated. It was hypothesized that suspects detained in police detention centres experience (1) a lower level of psychological wellbeing and (2) a higher level of sleep problems compared to a sample of the general Dutch population, that (3) sleep problems among police suspects negatively affects their psychological wellbeing, and that suspects who sleep in a police cell experience (4a) a lower level of psychological wellbeing and (4b) a higher level of sleep problems than suspects who sleep at home (Baksheev et al., 2012; Blaauw, Kerkhof, \& Vermunt, 1998; Gudjonsson, 2003; Harrison \& Horne, 2000). 


\section{Method}

\section{Participants}

The sample of police suspects detained in police detention centres in this study is the same sample as described in Chapter Two and Three. The psychological assessments were performed between 24 June 2014 and 7 May 2015. Only suspects who were at least 18 years old, who were able to speak the Dutch language were invited for the psychological assessment. If a suspect had been placed in an observation cell or if there was any prospect of release, that suspect was excluded from this study. A number of psychological assessments had to be terminated for various reasons. These included serious language problems, which made the assessment impracticable ( $n=63$ ), unforeseen developments in the police investigation (e.g., unannounced interrogations, lawyer visits, or immediate release; $n=21$ ), or because after the start of the assessment the participant stated that he or she was suffering from psychoses (e.g., acoustic or visual hallucinations) or severe depressive symptoms $(n=13)$. Eventually, 178 suspects voluntarily participated in this study: 37 in Amsterdam, 35 in Breda, 31 in Eindhoven, 26 in Heerlen, 8 in Tilburg, and 41 in Maastricht. Their age range was 18 to 63 years $\left(M_{\text {age }}=31.7, S D_{\text {age }}=11.2\right)$.

Unfortunately, it was not feasible to keep a record of how many suspects were incarcerated in the police detention centres during the assessment period. This was because many suspects were not placed in continued detention and hence were released within six hours after being incarcerated, because they were detained based on immigration status or unpaid fines, or because they stayed there briefly while awaiting transportation to a pre-trial detention centre.

\section{Procedure}

The psychological assessments were performed by the first author, who at the time of the assessments was a M.Sc. psychologist who had obtained the Basic Qualification for Psychodiagnostics (Basisaantekening Psychodiagnostiek, BAPD) from the Dutch Association of Psychologists (Nederlands Instituut van Psychologen, NIP). During the assessment period, he was a member of the NIP and was not employed by the Dutch police. He was assisted by three second-year students from the Master's programme in Forensic Psychology at Maastricht University. They had completed various courses on psychological diagnostics and were closely supervised during the assessments. The three Master's students underwent an official security screening by the Police Academy and signed a confidentiality agreement. 
Suspects were approached in their cells and asked if they were willing to participate in a psychological assessment. If they agreed, the aim and outline of the assessment were explained in a separate room (an interrogation room or lawyer room). All potential participants were told that they could only participate anonymously, that the results of the assessment were confidential and could not be used in the police investigation, and that the assessor was bound by professional secrecy. Finally, the informed consent form was explained, and participants were told that they could end the assessment at any time.

This study was approved by the standing Ethical Review Committee Psychology and Neuroscience of Maastricht University (ERCPN number: 03_10_2014), the Office of the Attorney General of the Netherlands, and the Chief Constable of the Dutch National Police.

\section{Instruments}

The following instruments were part of a psychological test battery used to assess several psychological vulnerabilities.

To check for malingering (simulation of physical and psychological symptoms), we used a short form (SF) of the Wildman Symptom Checklist (WCS; Wildman \& Wildman, 1999). The WCS SF contains four items about serious but non-credible symptoms that have proven to be a reliable predictor of malingering (Merckelbach, Smeets, \& Jelicic, 2008; Merckelbach, Langeland, De Vries, \& Draijer, 2014). An example of a WSC item is: 'Sometimes I have such a bad headache that my feet hurt'. The items were scored on a five-point Likert scale ( $0=$ not at all to $4=$ extreme). The total score is the sum of the scores, which varies from 0 to 16 , and a score of 4 or higher is an indication of malingering. Previous research found good internal reliability for the four items, namely a Cronbach's alpha from .56 to .73 (Deetman et al., 2011). In our study, the Cronbach's alpha was .73.

Psychological wellbeing was first measured with the total scale for Psychoneuroticism from the Symptom Checklist 90 (SCL-90, Derogatis, 1997; Dutch version: SCL-90-R-NL, Arrindell \& Ettema, 2005). The SCL-90-R-NL is a validated instrument that is used to measure psychological distress. The checklist contains 90 questions, scored on a fivepoint Likert scale ranging from 1 'not at all' to 5 'very much' (Arrindell \& Ettema, 2005).

Additionally, psychological wellbeing was measured by a negative affect (Watson, Clark, \& Carey, 1988), for which the Depression Anxiety and Stress Scale was used (DASS; Lovibond \& Lovibond, 1995; Dutch version: de Beurs, van Dyck, Marquenie, Lange, \& Blonk, 2001). The DASS provides insight into subjectively experienced negative emotions. The Depression scale measures symptoms such as a lack of 
initiative and interest, and pessimism about the future. The Anxiety subscale measures symptoms such as panic, a dry mouth, fear of bad performance, and tremors. The Stress subscale measures symptoms such as tension, being unable to come to rest, irritation, and being hot-tempered (de Beurs et al., 2001). In this study, we used the 21-item DASS, which contains seven items per subscale. Scores ranged from 0 'never' to 3 'most of the time'. The total sum-scores of the subscales were multiplied by two so that scores from the 21-item version could be compared with the original 42 -item version (de Beurs et al., 2001).

Sleep problems were measured using the Sleep Problems subscale of the SCL-90$\mathrm{R}-\mathrm{NL}$, and by asking two specific questions about sleep problems. The Sleep Problems subscale contains three items about problems falling asleep, waking up too early, and experiencing disturbed or restless sleep (Arrindell \& Ettema, 2005). However, this subscale refers to sleep problems 'during the last week including today', so two additional questions were asked: 'How did you sleep last night on a scale from 1 to 10, where 1 is very bad and 10 is very good?' and 'Did you sleep in the police detention centre last night (yes/no)?'

\section{Data analyses}

Scores from the SCL-90-R-NL and the DASS were compared with scores of populations from previous research (i.e., the SCL-90-R-NL manual; Arrindell \& Ettema, 2005) and validation research about the DASS (de Beurs et al., 2001). Differences were analysed with ANOVAs and Tukey post-hoc tests. Differences between sleep deprivation scores found in this research and previous research (SCL-90-R-NL) were analysed with a t-test. Differences between psychological wellbeing and sleep problems were analysed with t-tests and post-hoc with a power analysis. Correlations between sleep problems and psychological wellbeing were calculated with Pearson's correlation coefficient r. All analyses were performed with IBM SPSS v24, except for the power analysis, which was calculated with G*Power (Faul, Erdfelder, Lang, \& Buchner, 2007).

\section{Results}

Before performing the analyses, we screened participants $(N=178)$ for malingering based on the WSC SF. This screening found that 14 participants scored above the threshold score of the WSC SF (and results on the WSC SF were missing for 15 participants). We excluded the results of those 29 participants from further analyses, which left $N=149$. We confirmed that there was a normal distribution of scores on the 
total Psychoneuroticism scale and the Sleep Problems subscale of the SCL-90-R-NL, and the Depression, Anxiety, and Stress subscales of the DASS.

First, the mean score of the total Psychoneuroticism scale of the SCL-90-R-NL was 151.2 (SD = 47.2). Previous research (Arrindell \& Ettema, 2005) in a sample of the general Dutch population ( $N=2394$ ) found a general mean score of $118.3(S D=32.4$ ). In a sample of Dutch prisoners detained in general prisons $(N=257)$, a general mean score of $153.1(S D=52.0)$ was found. These scores differed significantly: $F(2,1432)=$ $114.83, p=.000$. A Tukey post-hoc test found that scores of this study population and the prison sample did not differ, $p>.05$.

Second, scores on the Depression, Anxiety, and Stress subscales of the DASS are presented in Table 6.1, next to scores found in previous research (de Beurs et al., 2001) in a clinical sample (outpatients of a psychiatric hospital; $N=173$ ), and a sample of the general Dutch population (students; $N=289$ ). Significant differences were found between the Depression subscale $(F(2,608)=41.50, p=.000)$, the Anxiety subscale $(F(2,608)=56.27, p=.000)$, and the Stress subscale $(F(2,608)=39.50, p=.000)$. Tukey post-hoc tests showed that scores from the three samples differed significantly (all p's $<$.01) except for the Depression subscale: the score found in this study did not differ significantly from the score found in the clinical population $(p=.21)$.

Table 6.1. Scores (means and standard deviations) of the DASS subscales of suspects in police custody, a clinical population, and a general Dutch population.

\begin{tabular}{|c|c|c|c|}
\hline & $\begin{array}{c}\text { Police suspects }{ }^{1} \\
N=149 \\
M(S D)\end{array}$ & $\begin{array}{c}\text { Clinical } \\
\text { population }^{2} \\
N=173 \\
M(S D)\end{array}$ & $\begin{array}{c}\text { General } \\
\text { population }{ }^{2} \\
N=289 \\
M(S D)\end{array}$ \\
\hline Depression & $11.6(9.4)^{*}$ & $13.4(11.9)$ & $5.7(7.7)^{\star}$ \\
\hline Anxiety & $9.2(7.4)^{*}$ & $11.7(10.1)^{\star}$ & $4.2(5.9)^{\star}$ \\
\hline Stress & $12.3(7.9)^{\star}$ & $15.7(10.2)^{\star}$ & $8.4(8.0)^{\star}$ \\
\hline
\end{tabular}

${ }^{*} p<.05$, tested two-sided.

1 This study.

${ }^{2}$ De Beurs et al., 2001. 
Third, the mean score on the Sleep Problems subscale of the SCL-90-R-NL was $6.6(S D=3.0)$. Previously, in a sample of the general Dutch population $(N=2394)$ a score of 4.5 ( $S D=2.2)$ was found, and in a sample of Dutch male prisoners detained in general prisons a score of $7.1(S D=3.8)$ was found. Scores differed significantly between these three samples $(F(2,2797)=172.65, p=.000)$. A Tukey post-hoc test showed that the score found in this study's sample and the sample of prisoners did not differ significantly $(p=.11)$. Furthermore, suspects rated the quality of sleep during the night prior to the psychological assessment a mean score of $M=4.7(S D=2.18)$ on a 1-10 scale.

In addition, sleep problems measured with the Sleep Problems subscale of the SCL90-R-NL, as well as with the self-report items, correlated negatively with psychological wellbeing (measured with the total Psychoneuroticism scale of the SCL-90-R-NL and the DASS), except for the Stress subscale of the DASS. Correlations are presented in Table 6.2. A Bonferroni-correction was not applied intentionally to avoid Type-Il errors (false-negative), in view of the exploratory character of this study (Field, 2012).

Table 6.2. Correlations between sleep problems: self-report [Self] and the subscale Sleep Problems [SLE] of the SCL-90-R-NL; ${ }^{1}$ and psychological wellbeing: total scale Psychoneuroticism of the SCL-90-R-NL (PSY), ${ }^{1}$ and the subscales of the DASS2: Depression (DEP), Anxiety (ANX), and Stress (STR) ( $N=149)$.

\begin{tabular}{lcccccc}
\hline & Self & SLE & PSY & DEP & ANX & STR \\
\hline Self & 1 & $-.31^{* \star}$ & $-.22^{* *}$ & $-.17^{\star}$ & $-.18^{*}$ & -.06 \\
SLE & & 1 & $.69^{* \star}$ & $.46^{* *}$ & $.40^{* *}$ & $.31^{* \star}$ \\
PSY & & 1 & $.74^{* *}$ & $.64^{* *}$ & $.65^{* *}$ \\
DEP & & & 1 & $.66^{* *}$ & $.70^{* *}$ \\
ANX & & & & 1 & $.61^{* *}$ \\
STR & & & & & & 1 \\
\hline
\end{tabular}

${ }^{*} p<.05$, tested one-sided.

${ }^{* *} p<.01$, tested one-sided.

${ }^{1}$ Arrindell \& Ettema, 2005.

${ }^{2}$ De Beurs et al., 2001. 
Finally, differences between suspects who slept at home the night prior to the psychological assessment $\left(n=15 ; 12\right.$ males, 3 females, $M_{\text {age }}=29.9 ; S D_{\text {age }}=12.4$; $M d n_{\text {age }}=25.0$ ), and suspects who slept in a police detention centre ( $n=134 ; 124$ males, 10 females; $M_{\text {age }}=32.0 ; S D_{\text {age }}=10.8 ; M d n_{\text {age }}=28.5$ ) were explored. T-tests showed that the two groups (slept at home vs. slept in a police detention centre) differed significantly in regard to Psychoneuroticism, Depression, Anxiety, and the selfreported quality of sleep, but not in regard to Sleep Problems and Stress. The mean scores of suspects who slept at home and in a police cell, and the results of the T-tests, are presented in Table 6.3.

Table 6.3. Scores of police suspects who slept at home or slept in a police detention centre prior to the psychological assessment in regard to psychological wellbeing (total score Psychoneuroticism of the SCL-90-R-NL and the subscales Depression, Anxiety, and Stress of the DASS), sleep problems (self-report and the subscale Sleep Problems of the SCL-90-R-NL), and results of the $t$-tests.

\begin{tabular}{ccc}
\hline $\begin{array}{c}\text { Sleeping } \\
\text { at home }\end{array}$ & $\begin{array}{c}\text { Sleeping in a } \\
\text { police detention } \\
\text { centre }\end{array}$ & T-test \\
$n=15$ & $n=134$ \\
$M(S D)$ & $M(S D)$ & \\
\hline
\end{tabular}

Psychological

wellbeing

$\begin{array}{lrrrr}\text { Psychoneuroticism } & 126.27(32.09)^{\star} & 154.00(47.83)^{\star} & t(22)=-3.00, p=.007^{\star} \\ \text { Depression } & 6.27(5.44)^{\star} & 12.15(9.63)^{\star} & t(25)=-2.32, p=.022^{*} \\ \text { Anxiety } & 3.87(5.57)^{\star} & 9.75(7.43)^{\star} & t(23)=-4.38, p=.000^{*} \\ \text { Stress } & 9.86(4.67) & 12.60(8.12) & t(22)=-1.91, p=.068\end{array}$

Sleep problems

\begin{tabular}{llllll} 
SCL-90-R-NL & 5.60 & $(2.41)$ & 6.76 & $(3.00)$ & $t(147)=-1.45, p=.150$ \\
Self-report & 7.27 & $(2.63)^{*}$ & 4.45 & $(2.63)^{*}$ & $t(147)=3.93, p=.000^{*}$ \\
\hline
\end{tabular}

${ }^{*} p<.05$. 


\section{Discussion}

The first hypothesis was that suspects detained in a police detention centre would experience lower levels of psychological wellbeing. The results confirmed this. Study participants reported higher levels of psychological distress than a normative sample of the general Dutch population and scored comparably to prisoners detained in general prisons. In addition, police suspects reported higher levels of depression, anxiety, and stress. Although a direct comparison with the study of Blaauw et al. in 1998 is not possible (e.g., they used an older version of the Symptoms Checklist), our results indicate that many suspects detained in Dutch police detention centres still experience diminished psychological wellbeing.

The second hypothesis was that suspects detained in police detention centres would experience higher levels of sleep problems, which results confirmed as well. Police suspects in police detention centres slept significantly worse than a normative sample of the general Dutch population. Their scores were similar to those found in a sample of prisoners detained in general prisons (Arrindell \& Ettema, 2005).

The third hypothesis was that sleep problems in police suspects negatively affects their psychological wellbeing, which the results confirmed. Self-report of the experienced quality of sleep during the night prior to the psychological assessment correlated significantly (although low) with psychological wellbeing - again with the exception of stress.

The fourth hypothesis was that suspects who slept in a police cell prior to the psychological assessment would report lower levels of psychological wellbeing and higher levels of sleep problems than suspects who slept at home, which was confirmed by the results. Suspects who slept in a police cell during the night prior to the psychological assessment rated their quality of sleep with a mean number of 4.5, in contrast to suspects who slept at home prior to the psychological assessment, who rated it with a mean number of 7.3. No differences were found between these samples in regard to sleep problems measured with the SCL-90-R-NL. A possible explanation for this is that the self-reported items referred to the quality of sleep during the night prior to the psychological assessment, yet the items of the SCL-90-R-NL referred to the last seven days including the day of the psychological assessment. Furthermore, we found differences between these two groups for depression and anxiety, but not for stress. The reason for this is unknown; future research should address this. Although the sample of suspects who slept at home was relatively small, it could nonetheless be argued that the results support the fourth hypothesis.

Perhaps, in view of the circumstances in police detention centres described in the 
introduction, the results of this study seem to be stating the obvious. However, as mentioned above, poor psychological wellbeing and sleep problems among police suspects may negatively affect police interrogations. Therefore, we recommend that police do their best to prevent sleep problems among suspects detained in police detention centres.

We propose the guidelines of the Dutch Institute for Healthcare Quality (Kwaliteitsinstituut voor de Gezondheidszorg; 2004) may be helpful in this effort. These guidelines emphasize the need to avoid disturbing environmental elements (e.g. noise and lightning) and provide a comfortable bed and bed linen, enough ventilation, and a temperature lower than 24 degrees Celsius (about 75 degrees Fahrenheit).

In addition, police can use simple and cheap measures derived from environmental psychology (e.g., from healing environments). For example, during the construction and renovation of hospitals and psychiatric institutions, designers are now including natural elements (e.g., plants, pictures of nature), paying attention to colours and lightning, and including as much daylight and as many views of the outside world as possible to avoid disturbing biorhythms (Bell et al., 2000; Dalke et al., 2006; Dijkstra et al., 2006; Frumkin, 2001; Karlin \& Zeiss, 2006; Ulrich, 1991, 2000). These measures have proven effective in reducing feelings of stress, anxiety, and depression among patients, which results in better psychological wellbeing, shorter stays in hospital, reduced costs, and less use of sick leave and higher labour satisfaction among staff as well (Morris et al., 2012; Nurse et al., 2003; Steinke, 1991; Ulrich, 2001).

Furthermore, isolation in a separation cell within psychiatric emergency services is nowadays seen as a traumatic experience. In response, many institutions have transformed their separation cells into 'comfort rooms' (Steenbergen \& Pinedo, 2016). A comfort room is a room specially designed for agitated patients and has homey touches, comfortable furniture, music, and soothing colours. Staying in a comfort room helps to decrease negative symptoms (e.g., pain, anxiety, disturbance, hallucinations) and to prevent escalation of violent behaviour (Souverijn, 2009).

\section{Limitations}

A limitation of this study is that our measure of sleep problems was based on the Sleep Problems subscale of the SCL-90-R-NL and on self-report and did not comprise sleep deprivation. However, we were not able to control for the actual hours of sleep, that is, an accurate registration of the level of sleep deprivation among police suspects who participated in this study (e.g. with psycho-physiological measures). Another limitation was that sleep problems could have been caused by circumstances outside the police detention centre, such as personal factors like medicine or alcohol and/or 
drug abuse (or abstinence). We could not control for those factors, mostly because of the lack of information about them. Furthermore, as mentioned above, items on the SCL-90-R-NL and the DASS refer to the last seven days, including the day of the psychological assessment. Future research should therefore include instruments that measure psychological wellbeing at the moment of the psychological assessment. Unfortunately, it was not possible to extend the test battery of this study with these instruments because of the test duration. Finally, the sample size of suspects who slept at home prior to the psychological assessment was small $(n=15)$, which implies that the results must be interpreted with some caution and cannot easily be generalized.

\section{Conclusion}

Suspects incarcerated in police detention centres reported lower levels of psychological wellbeing and higher levels of sleep problems than the general population, and they slept more poorly in police cells than at home. Future research on the interiors and circumstances in police detention centres, with the aim of enhancing psychological wellbeing and preventing sleep problems in police suspects, is recommended - not only from a humane perspective but also in view of police investigations and interrogations. If 'comfort police cells' could positively contribute to police interrogations, then the effectiveness and efficiency of police investigations will be served. 
6 
I hope, for most, the police will learn something about it. Because that would make it all

a little bit less meaningless.

\author{
Ina Post
}

EenVandaag, 6 October 2010 
Chapter Seven

\section{General discussion}

Summary 


\section{General discussion}

The quotes on the chapters' covers are drawn from a log, which I kept during the data collection and writing phases of my dissertation project. Remarkable 'off-therecord' statements were noted down without further inquiry. At the time these quotes were written down, the findings of the research were unknown, but in hindsight, they provide another window into Dutch police interrogation practice and police suspects' experiences.

In this final chapter, first, a brief summary of the findings reported in Chapter Two through Chapter Six is provided. Next, the findings in relation to the CIPH framework (Gudjonsson, 2003; Gudjonsson \& MacKeith, 1988, 1997), ${ }^{10}$ implications for police practice, and directions for future research will be discussed.

\section{Summary}

This dissertation concerned persons at risk during interrogations in police custody. The research questions were how often police officers engage vulnerable suspects, if they are able to make an adequate estimation of the prevalence of vulnerable suspects, how they interrogate vulnerable suspects in theory and in practice, and how police detention environments affect police suspects' psychological wellbeing and sleep problems. During a one-year period, 178 suspects detained in six police detention centres across the Netherlands (i.e., Amsterdam, Breda, Eindhoven, Heerlen, Tilburg, and Maastricht) were assessed with a set of psychological instruments for mental disorders, intellectual disability, an abnormal mental state (e.g., due to high levels of stress, alcohol or drug abuse), and certain personality characteristics (i.e., interrogative suggestibility and compliance).

\footnotetext{
${ }^{10} \mathrm{CIPH}$ is an abbreviation for Circumstances, Interaction, Personality, and Health. Gudjonsson and MacKeith (1997) introduced this framework as a standard to assess defendants in order to assist psychiatrists and psychologists in evaluations and writing court reports (for more details, see: General introduction).
} 


\section{Personality and health}

\section{Psychological vulnerabilities}

Chapter Two explored the prevalence of psychological vulnerabilities in police suspects. The research questions were in which percentage of cases a number of specific psychological vulnerabilities occur in police suspects, and if police officers are able to make an accurate estimation of the prevalence of psychological vulnerabilities in police suspects.

In the first part of Chapter Two, it was found that $60 \%$ of police suspects scored positive on a mental health screening instrument that indicated a need for further examination of their mental health. About $38 \%$ needed further examination specifically about possible Attention Deficit Hyperactivity Disorder (ADHD), 21\% reported daily use of drugs (e.g., cannabis, cocaine, GHB), and $4 \%$ drank alcohol on a daily basis and more than 15 glasses of alcohol per week. In addition, levels of general psychological distress, depression, anxiety and stress, and interrogative suggestibility, were significantly higher compared to general Dutch population samples.

In the second part of Chapter Two, findings derived from a questionnaire completed by 103 Dutch police detectives were presented. These detectives had worked on average 21 years in the police force, and 11 years as a police detective. About 77\% had received one or more advanced criminal investigation training courses, however, $22 \%$ had not participated in any training on criminal investigation. In addition, $76 \%$ had not received any advanced interrogation training. Police detectives stated they had seen about five vulnerable suspects on average during the past 12 months, ranging between 0 and 90 . Some police detectives knew they were interrogating a vulnerable suspect because of known mental health problems, or they noted that suspects were exhibiting strange behaviour or were not responding adequately to questions. About $55 \%$ of police detectives stated they did not take any precautions when interrogating vulnerable suspects. Finally, no associations were found between the number of advanced criminal investigation training courses or interrogation training courses taken and the estimated number of vulnerable suspects. The combined findings of the two studies reveal that police officers seriously underestimate the likelihood they will meet a vulnerable suspect in their interrogation rooms.

Chapter Three described a study on a specific psychological vulnerability: intellectual disability. The research questions concerned whether the Screener for Intelligence and Learning Disability (SCIL; Kaal, Nijman, \& Moonen, 2013) is a useful screening instrument for the police to detect intellectual disability in police suspects, and what the prevalence of intellectual disabilities in police suspects is. The SCIL contains 14 
items, which refer to educational background, a social support network, cognitive abilities, language comprehension and behaviour. The SCIL screens for an IQ below 85.

Results showed that the average 10 score in our sample of police suspects was 75 , with a range from 49 to 110 . About $84 \%$ showed an 10 below 85 , and $29 \%$ showed an IQ below 70. The SCIL detected $50 \%$ of the suspects as having an 10 below 85 . The factor structure of the SCIL found in the present study diverged from the structure described in the SCIL Manual, possibly because of a skewed distribution of IO scores in our sample. The correlation between the $\mathrm{IQ}$ score and the SCIL score was only moderate $(r=.56)$. A possible explanation for the difference between IQ scores and SCIL results was that social and practical SCIL items (e.g., having a social safety net, contact with social services, reading a newspaper) could have masked actual lower IO scores, which should be a subject for future research to examine if the different aspects of intellectual disability predict problems during police interrogations.

\section{Interaction}

\section{Interrogation}

Chapter Four provides a conceptual analysis of current police interrogation practices in the Netherlands in light of cognitive psychological research on police interviewing practices. The central research question was whether current Dutch police interrogation practices meet modern, evidence-based investigative interviewing standards.

A closer look at UK interrogation practice and policy revealed that, around 25 years ago, multiple miscarriages of justice in which false confessions had played a pivotal role led to the Police and Criminal Evidence Act (PACE; 1984), and to new guidelines for police interviewing and investigative interview training. The term interrogation was abandoned and replaced by the term investigative interviewing, reflecting a new framework for the police interview, grounded in cognitive psychological theory on information processing and memory. Fact-finding instead of obtaining a confession became paramount in police interviews.

At the time of the study presented in Chapter Four, Dutch police officers were trained in the General Interrogation Strategy (GIS) described in the Interrogation Manual (Van Amelsvoort, Rispens, \& Grolman, 2015, $6^{\text {th }}$ edition). To date, the GIS has never been subjected to an empirical test. Several aspects of the GIS are problematic. First, the GIS may foster guilty and confirmation biases in police officers. Second, deliberately building up pressure in suspects is unwanted and unnecessary. Third, it appears from Dutch case law that there are no safeguards to protect suspects from the use of inappropriate interrogation methods. 
Chapter Five investigated 36 transcripts of police interrogations, in an attempt to answer the research question if vulnerable suspects are interrogated appropriately. Appropriateness of the interrogations was examined by means of Griffiths Question Map (Shepherd \& Griffiths, 2013). Interrogations were labelled either as appropriate (containing open-ended, probing, and appropriate closed questions) or inappropriate (e.g., containing inappropriately closed, leading, or multiple questions, and/or lacking a logically organised questioning pattern). Results showed that $86 \%$ (31) of the 36 interrogations were conducted inappropriately, and that $84 \%$ (21) of the interrogations of vulnerable suspects were performed inappropriately. The percentage of open questions used during all interrogations was only $5 \%$. In sum, Dutch police officers use inappropriate interrogation tactics in a large proportion of interrogations, regardless of the psychological vulnerability of the suspect. More research on the use of the GIS in actual police interrogations in larger samples is needed.

\section{Circumstances}

\section{Police detention centre environments}

Chapter Six examined suspects' stay in a police detention centre in relation to their psychological wellbeing and sleep problems. The research questions were whether police suspects experience poorer psychological wellbeing and more sleep problems when detained in a police cell, and to what extent sleep problems affect suspects' mental health.

Findings confirmed that police suspects experienced decreased levels of psychological wellbeing and increased levels of sleep problems while being in police detention. Suspects who slept at home prior to the psychological assessment rated their quality of sleep as satisfactory (7.3), while suspects who had slept in a police cell prior to the assessment judged their quality of sleep as unsatisfactory (4.5). In addition, suspects who had spent the night in a police cell prior to the assessment experienced significantly lower levels of psychological wellbeing and higher levels of sleep problems compared to suspects who had slept at home the night prior to the assessment. Promoting psychological wellbeing and preventing sleep problems in police suspects could probably serve to enhance the effectiveness of police interrogations. Principles of environmental psychology could provide relevant guidance for this. 


\section{Discussion}

\section{Personality and health}

\section{Psychological vulnerabilities}

The findings of Chapter Two and Three showed that most police officers likely engage vulnerable suspects on a daily basis, and much more frequently than their own estimates. The term base rate neglect (a form of selective attention to pertinent information whereby base-rate information is ignored) is used to denote this problem (Case, Fantino, \& Goodie, 1999). In addition, many police officers stated they do not take any precautions when interrogating vulnerable suspects. In the next section, we will discuss Dutch and European law, to examine whether police provide proper legal safeguards for vulnerable suspects during interrogations in police custody, in view of possible recommendations for adjustments to police interrogations.

First, the Dutch judicial guideline about audio and video recordings of interrogations of victims, witnesses, and suspects (Aanwijzing audiovisueel registreren van verhoren van aangevers, getuigen en verdachten, 2013; hereafter: Aanwijzing) prescribes mandatory audio or video recording when the police interrogates a vulnerable suspect (a) who is suspected of a crime for which he/she could be sentenced to imprisonment for 12 years or more, (b) in cases victims suffered from a severe physical injury, (c) in specific sexual offences, or (d) in any other case in view of the suspect (e.g., mental disorder), the nature of the case (e.g., severe injuries, impact on society), and/or interrogation proceedings (e.g., unforeseen incidents). The Aanwijzing defines vulnerable suspects as suspects with an age below 16 , with mild intellectual disability, or with impaired cognitive functioning (e.g., Parkinson's disease, stroke, or other serious neurological problems). The Aanwijzing also mentions that individual police officers have to decide whether a suspect suffers from intellectual disability. The latter is problematic, because intellectual disabilities are hard to detect on the basis of mere observation during communication, because many intellectually disabled people are apt at masking and cloaking their disability (Kaal, Overvest, \& Boertjes, 2017; Young, Goodwin, Sedgwick, \& Gudjonsson, 2013), as discussed in more detail in Chapter Three. Additionally, audio or video recording of interrogations with persons with mental disorders is not mandatory, but only by discretion of the public prosecutor, or by decision of a detective unit's staff member, in cases when 'the course of the interrogation urges to record the rest of the interrogation' (Aanwijzing, 2013). 
Second, the European Commission provided a recommendation on procedural safeguards for vulnerable persons suspected or accused in criminal proceedings (European Commission, 2013; hereafter: Recommendation). The Recommendation describes vulnerable suspects as suspects 'who are not able to understand and to effectively participate in criminal proceedings, due to age, their mental of physical condition, or disabilities', and 'persons with serious psychological, intellectual, physical or sensory impairments, or mental illness or cognitive disorders' (for an in-depth discussion, see: Van der Aa, 2016). In view of the findings reported in this dissertation, it can be argued that a majority of police suspects fit this definition. The Recommendation prescribes that a lawyer and/or an registered intermediate must be present during interrogations of vulnerable suspects (Article 10), that these suspects have the right to regular and systematic access to health care services (Article 12), that the right to consult a lawyer cannot be waived (Article 12), that audio recording of all pre-trial interrogations is mandatory (Article 13), that detaining these suspects must be seen as a last resort and that it must take place under conditions suited to their needs (Article 14), and that police officers should receive specific training on psychological vulnerabilities in police suspects (Article 17). Although the Recommendation is nonbinding with regard to Dutch national legislation, the proposed measures formulated in the Recommendation will likely contribute to more appropriate and ethical police interrogations with vulnerable suspects, as discussed next.

Firstly, suspects may benefit from the presence of a lawyer during interrogations. Verhoeven and Stevens (2012) found that when a lawyer was present, Dutch police detectives used intimidation tactics (i.e., evoking emotional reactions and misleading suspects) less frequently, and the authors argued that 'the presence of a lawyer might prevent the use of the kind of coercion that might lead to false confessions' (p. 87). In addition, Verhoeven and Duinhof (2017) concluded that the presence of a lawyer during interrogations does not make suspects tell less about the case. Furthermore, if lawyers are allowed to actively participate in police interrogations, they could ask suspects questions that could disculpate them (Duker \& Stevens, 2009). At present, however, suspects probably do not benefit optimally of the assistance of a lawyer. Lawyers have a passive role during Dutch police interrogations. They are, for example, not allowed to interfere with the interrogation, but only allowed to communicate with the police officers and the suspect at the beginning and the end of an interrogation. Further, if police officers believe the lawyer is 'disturbing the order of the interrogation', he or she can be expelled from the interrogation room (Besluit inrichting en orde politieverhoor, 2017; Blom, 2011). Additionally, to date, lawyers who are assigned to provide legal aid for police detention centre work receive 85 Euros per consultation, 
probably making it economically unviable to do more than the standard 30 minutes of consultation (Hodgson, 2015). In sum, the question is whether Dutch lawyers are able and allowed to provide appropriate legal assistance to vulnerable suspects, which should be a subject for further research.

Secondly, recording all interrogations, as suggested by Kassin (2017), has several advantages. First, it prevents police officers from using inappropriate interrogation methods (Kassin, Kukucka, Lawson, \& DeCarlo, 2014). A second advantage is that it provides an exact registration of what happened in the interrogation room (Kassin, 2017) - which is the aim of the previously mentioned Aanwijzing after all. A third advantage is that police officers no longer have to type during interrogations and will be able to completely focus on the conversation (Kassin, 2017). In addition, recordings can be used for educational and coaching purposes, and for scientific research as well. Furthermore, in the past, several evaluation reports on the police investigation process in the Netherlands have recommended recording all police interrogations (Openbaar Ministerie, Politie, \& NFI, 2005; Posthumus, 2005).

Third, the Recommendation describes that police officers are educated in how to deal with vulnerable suspects. However, as discussed before, it is rather difficult to detect psychological vulnerabilities in suspects on the basis of observations during interaction (Gudjonsson, 2010; Kaal et al., 2017; Kassin, 2012). In the past, the Police Academy of the Netherlands initiated the development of an experimental questionnaire to screen for psychological vulnerabilities in police suspects (Politieacademie, 2014). Such a screener was recently recommended from a legal perspective as well, in order to ensure that vulnerable suspects are provided with proper legal procedural safeguards, for example, being able to consult a lawyer (Gremmen, 2018). However, during the course of the psychological assessments of the present dissertation project, several suspects stated they were only participating because the assessment was anonymous and the assessors were bound by professional confidentiality. Suspects also stated they would not participate in a psychological assessment performed by police officers, because they were afraid of being sentenced to a forensic psychiatric hospital on the basis of their test results. Further, as previously mentioned, even trained psychologists and psychiatrists need considerable time to assess mental deficits in people. Therefore, a screener for psychological vulnerabilities in police suspects administered by police officers will most likely not be very helpful.

In conclusion, based on this dissertation's findings regarding (a) the prevalence of psychological vulnerabilities in police suspects, $(b)$ the base rate neglect among police 
officers, (c) Dutch and European law and regulations, and (d) the utility of a screener for psychological vulnerabilities, my first advice would be that police officers need to consider every suspect as a potentially vulnerable suspect. My second advice is that all police interrogations need to be recorded.

\section{Interaction}

\section{Interrogation}

The findings of Chapter Four and Five concern Dutch interrogation in theory and practice. Below, the recently revised Dutch Interrogation Manual (Van Amelsvoort \& Rispens, 2017), research on interrogations performed by Dutch police officers in practice, and Dutch and European case law, is discussed in light of the investigative interviewing framework.

First, there is an important difference between traditional police interrogations and modern police interviews. An interrogation is 'a heuristic approach, including coercive and/or manipulative techniques, designed to obtain a confession', while interviewing is 'an evidence-based approach designed to gather and test accurate and reliable information ... balancing the need for accurate information from suspects with respect for individual human rights and the rule of law' (Griffiths \& Rachlew, 2018, p. 155). Up until now, Dutch interrogation practices, as described in the Seventh Manual, are not substantiated by empirical evidence. Dutch interrogation practices are mostly based upon experience and gut feelings of police officers, which was already reflected in the first Suspect Interrogation Manual (Van den Adel, 1997) and is still echoed in the Seventh Manual, 20 years later (Van Amelsvoort \& Rispens, 2017). However, it could be argued that the Seventh Manual is an improvement compared to the previous sixth edition that was discussed in Chapter Four (Van Amelsvoort, Rispens, \& Grolman, 2015) because more attention has been paid to recent scientific research, for example, on memory processes and the reliability of statements of suspects. Nevertheless, it could also still be argued that the Seventh Manual is not an appropriate manual for police officers, for different reasons.

The Seventh Manual describes four different interrogation methods, and different versions of these methods, to question police suspects (Van Amelsvoort \& Rispens, 2017). The first interrogation method is termed the Free Statement Method (Vrije Verklaringsmethode), in which the suspect is given the opportunity to freely give a statement. This method is recommended with cooperative suspects, when there are reasons not to present evidence to the suspect, or when there is not enough time to prepare and perform the interrogation. The second method is the Direct Pile Up 
Method (Directe Stapelmethode), in which the suspect is presented with all available technical and tactical clues at once, and is not given the opportunity to react, yet only after completing the pile up. This method is recommended in cases when less time for questioning is available, or when there is overwhelming, solid evidence, and the interrogation is only a formality. The third method is the Scenarios Investigating Method (Scenario's Onderzoekende Methode, SOM) - formerly known as the General Interrogation Strategy, and discussed in more detail in Chapter Four. The fourth method is the Evidence-Question Method (Bewijs-Vraagmethode), to be used when suspects choose to remain silent. It means that the suspect is confronted with the (in the view of police officers) most valuable evidence and is given the opportunity to provide a statement about it. Furthermore, the Seventh Manual describes different versions of these interrogation methods, such as changing the order of confrontations, or clustering confrontations (Van Amelsvoort \& Rispens, 2017).

The problem is that the Seventh Manual does not provide a clear guideline on when to choose a specific interrogation method, or when the use of a combination of different methods (and variations thereof) is indicated. It only states that 'if the suspects' statement is in line with the available evidence', police officers should use the Free Statement Method (Van Amelsvoort \& Rispens, 2017, p. 456), and if the suspect's statement is not in line with the available evidence, police officers are allowed to use a combination of the four interrogation methods, 'in order to find the truth' (Van Amelsvoort \& Rispens, 2017, p. 455). ${ }^{11}$

This implies that police officers must possess profound knowledge and skills to be able to appropriately execute every interrogation method (and variations thereof), to adequately choose an appropriate interrogation method, and to combine different methods and versions. In general, this will most likely not be a realistic assumption, as Chapter Two and other research indicate (e.g., Odinot, Boon, \& Wolters, 2015). Additionally, the Direct Pile Up Method may not be that effective, while gradual disclosure of evidence has been shown to provide more comprehensive accounts (Walsh \& Bull, 2015). Aside from this, as discussed in more detail in Chapter Four, the SOM is merely old wine in new bottles, because the basic principles of the SOM are the same as the basic principles of the GIS, ${ }^{12}$ including several unwanted aspects, such as building up pressure, and rewarding suspects when they adjust their statement in line with the available tactical clues.

\footnotetext{
${ }^{11}$ Note: the Seventh Manual does not explain in more detail what is meant by 'the truth'.

${ }^{12}$ Van Amelsvoort \& Rispens, 2017, p. 466, vs. Van Amelsvoort, Rispens, \& Grolman, 2015, p. 445.
} 
The scarce scientific research on Dutch interrogation practices indicates that police officers use inappropriate interrogation methods quite frequently. This is reported in Chapter Five, as well as in previous research. Verhoeven and Stevens (2012) found in their study on Dutch police interrogations $(N=168)$ in manslaughter and murder cases that in many interrogations risky interrogation techniques were used (i.e., leading questions in $44.0 \%$, showing impatience, frustrations and anger in $28.6 \%$, and presenting hypothetical scenarios in $22.6 \%$ of the interrogations). Furthermore, Verhoeven and Duinhof (2017) recently found that different Dutch interrogation tactics (e.g., evoking emotions, confronting with evidence) contributed little to the willingness of suspects to provide statements. It could be argued that police officers' gut feelings and experience with police interrogations do not naturally lead to the appropriate interrogation methods and to useful statements by the suspects.

In sum, the Seventh Manual does not meet science-based investigative interviewing principles (Clark, Milne, \& Bull, 2011; Farrugia \& Milne, 2011; Griffiths \& Milne, 2018; Shepherd \& Griffiths, 2013), yet the Police Academy of the Netherlands still persists in teaching police officers non-evidence-based - and in some aspects potentially risky - interrogation methods, while at the same time several independent studies have questioned the appropriateness of Dutch interrogation practices, and demonstrated the inability of Dutch police officers to execute interrogations appropriately as well (e.g., Boon et al., 2016; Duker \& Stevens, 2009; Israëls \& Horselenberg, 2010; Kortlever, 2011; Nierop, 2005; Odinot et al., 2015; Siemering \& van der Laan, 2016; Stevens \& Verhoeven, 2010, 2011; Van Koppen, 1998, 2009; Verhoeven \& Duinhof, 2017; Verhoeven \& Stevens, 2012; Vrij, 1998, 2010).

Second, Dutch Courts do not seem to reject inappropriate and undesirable interrogation methods, ${ }^{13}$ as discussed in more detail in Chapter Four. This is worrisome, since on 26 October, 2010, the Amsterdam Court of Appeal ruled in a homicide case that a frequent and accusatory style of interrogation, and the use of extreme interrogative pressure, were not inadmissible, and the suspects' statements were allowed as evidence (De Ruiter, 2015)..$^{14}$ De facto this means that if police detectives use inappropriate and

\footnotetext{
${ }^{13}$ e.g., Court of Appeal Arnhem, 12 December, 2000, ECLI:NL:GHARN:2000:AA8995, LJN AA8995; Court Dordrecht, 20 September, 2003, ECLI:NL:RBHAA:2007:BB7483, LJN BB7483; Court Amsterdam, 17 March, 2005, ECLI:NL:RBAMS:2005:AT0873, LJN AT0873; Court Groningen, 10 April, 2008, ECLI:NL:RBGRO:2008:BC9249, LJN BC9249.

14 e.g., Court of Appeal Amsterdam, 26 October, 2010, ECLI:NL:GHAMS:2010:BL5731, LJN BL5731.
} 
coercive interrogation methods, it is sufficient for the Dutch Courts to take note that these interrogation methods were used, and it will not lead to consequences in terms of inadmissibility of evidence (Blom, 2011). In other words, apparently, there are no legal restrictions for the Dutch police in using inappropriate interrogation tactics.

European case law does not provide more protection of vulnerable suspects' rights during the police investigation process (Mergaerts, Van Daele, \& Vervaeke, 2017). In rulings in 2000 and 2008, the European Court of Human Rights (ECtHR) acknowledged that every suspect involved in a police investigation is in a particularly vulnerable position. ${ }^{15}$ In other rulings, the ECtHR considered that in some circumstances suspects might be vulnerable in regard to, for example, age and maturity, ${ }_{1}^{16}$ physical disabilities, ${ }^{17}$ mental disabilities, ${ }^{18}$ and alcohol addiction. ${ }^{19}$ However, the ECtHR has only described certain individual characteristics and circumstances that place suspects in a vulnerable position but has not provided a clear definition of vulnerable suspects as of yet (Mergaerts et al., 2017). Mergaerts et al. (2017) argued that a vulnerable suspect 'is not able to exercise his or her procedural rights in a conscious, deliberate, and actual manner (...) which hampers effective participation in the investigation procedure, or even makes that impossible' (p. 525). In these authors' view, suspects are only able to participate in the investigation process if three conditions are satisfied: (1) they must have been informed about the accusation and their legal rights, (2) they must understand the accusation and their rights, and (3) they must be able to make reasoned decisions about exercising their rights. Suspects' characteristics (as mentioned above in ECtHR case law) and circumstances (e.g., pressure during interrogation, inappropriate questioning techniques) influence the ability to participate adequately in the investigation process and make suspects vulnerable to provide an unreliable statement or a false confession (Mergaerts et al., 2017).

\footnotetext{
${ }^{15}$ e.g., ECtHR Grand Chamber, 27 June, 2000, No. 21986/93 (Salman vs. Turkey); ECtHR, 13 July, 2006, No. 26853/04 (Popov vs. Russia); ECtHR Grand Chamber, 28 October, 2008, No. 36391/02 (Salduz vs. Turkey).

${ }^{16}$ e.g., ECtHR 16 December, 1999, No. 24724/94 (T. vs. United Kingdom); ECtHR, 17 October, 2006, No. 52067/99 (Okkali v. Turkey).

${ }^{17}$ e.g., ECtHR 5 February, 2013, No. 76317/11 (Bubnov vs. Russia).

${ }^{18}$ e.g., ECtHR 24 November, 2009, No. 23968/05 (Halilovic vs. Bosnia Herzegovina); ECtHR, 20 May, 2010, No. 38832/06 (Alajos Kiss v. Hungary); ECtHR, 11 October, 2011, No. 30951/10 (Gorobet vs. Moldova).

${ }^{19}$ e.g., ECtHR 31 March, 2009, No. 20310/02 (Plonka vs. Poland).
} 
Obviously, current Dutch police interrogation practices are in need of reform. In the past years, police forces in many jurisdictions, for example, the United Kingdom, Australia, New Zealand and Norway, have adopted investigative interviewing, ${ }^{20}$ which is based upon empirical research on good communication skills, conversation management, and human memory (Clarke, Milne, \& Bull, 2011). Investigative interviewing should to be considered as a total concept (not merely as an interviewing technique), which comprises training, supervision, and a solid foundation in legislation about, for example, education, presence of a lawyer during interrogation, and recording all interrogations (Clarke et al., 2011; Farrugia \& Milne, 2012; Griffiths \& Milne, 2018; Shepherd \& Griffiths, 2013). It does not include any coercive or manipulative techniques, contributes to avoiding the negative effects of guilty and confirmation biases, groupthinking, primacy effect and heuristics, and reduces the 'boomerang effect' (i.e., the tendency of suspects who are about to confess, deciding not to confess, because they feel the interview is inappropriate) as well (Griffiths \& Rachlew, 2018; Gudjonsson, 2003). Additionally, it enhances public confidence in criminal investigative procedures (Griffiths \& Milne, 2018).

Farrugia and Milne (2012) reflected on the major shift from interrogation to investigative interviewing in England and Wales in the 1980s as follows: 'Before such a paradigm change, police interviewing focused purely on interrogation techniques (and the subsequent confession), and this ethos was bolstered by influential training guides which promoted such inappropriate practice' (p. 24).

Asbjørn Rachlew - a Norwegian police superintendent, researcher, and university lecturer, involved in modernising police interviews in Norway - recently stated: 'It will not be sufficient only to incorporate certain aspects of investigative interviewing into existing interrogation methods. Ultimately, this will not change the mind-set of police officers, they will just use other, more subtle and manipulative, ways of seeking confirmation' (Mykhailov, 2018).

\footnotetext{
${ }^{20}$ For more detailed information about investigative interviewing, see for example:

- College of Police for England and Wales: https://www.app.college.police.uk/app-content/ investigations/investigative-interviewing/

- Schollum, M. (2005). Investigative Interviewing: The literature. Wellington: Office of the Commissioner of Police. http://citeseerx.ist.psu.edu/viewdoc/download?doi=10.1.1.117.228\& rep=rep $1 \&$ type $=$ pdf
} 
To address the elephant in the room, my third advice is to radically say goodbye to current Dutch interrogation practices. Following several enlightened police forces across the world, the concept of investigative interviewing should be introduced in the Netherlands, including a complete reform of police interviewing techniques (according to the PEACE model, see Chapter Four), interview training (according to the PIP model, see Chapter Four), and Dutch legislation (Clarke et al., 2011; Farrugia \& Milne, 2012; Griffiths \& Milne, 2005, 2018; Griffiths \& Rachlew, 2018; O’Mahony, Milne, \& Grant, 2012; Shepherd \& Griffiths, 2013).

Recently, Griffiths and Milne (2018) introduced the Framework for Investigative Transformation (FIT), based on a growing body of research on investigative interviewing and evidence-based policing. FIT can help police organisations to create a correct environment for professional criminal investigations, executed by professional and open-minded investigators who seek justice for victims and avoid errors which may lead to miscarriages (Griffiths \& Milne, 2018). In short, FIT consists of eight factors: (1) leadership, to foster a learning culture, giving proper workplace support, and providing opportunities to apply new skills; (2) appropriate legislative framework, because it is unrealistic that police officers will adopt moral standards that are not reflected in the law; (3) investigative mind-set or cognitive style (e.g., exploration of alternative hypotheses, open-mindedness), adopted by every police officer; (4) profound investigators' knowledge base, based on temporary theory and research literature; (5) optimal training and knowledge regime; (6) the establishment of meaningful quality assurance mechanisms (e.g., support, supervision, evaluation); (7) appropriate skills/ ability of the investigators, because not every police officer is a skilled interviewer; and (8) technology, for example audio and video recording (Griffiths \& Milne, 2018).

\section{Circumstances}

Police detention centre environments

Chapter Six discussed findings on police detention circumstances on police suspects. During the past years, new police detention centres have been built in the Netherlands. These centres pay more attention to comfort, for example, by applying rubber in doorframes and electronic locks instead of iron latches so doors shut silently, by installing toilets that can be flushed with a button inside the cell instead of by remote control, and by more exposure to daylight. This positive change has been acknowledged by an independent commission that monitors circumstances in police detention centres, who stated that the overall quality and services of Dutch police detention centres meet national and international requirements (Inspectie Veiligheid 
en Justitie, 2015). Nonetheless, the research findings presented in Chapter Six showed that suspects still experience poorer psychological wellbeing and that they sleep poorly when detained in a police detention centre, and that the experience of sleep problems is associated with diminished psychological wellbeing. This is reason for concern, because decreased psychological wellbeing will affect the ability of suspects, and vulnerable suspects in particular, to cope with the demands of police interrogations.

In the $19^{\text {th }}$ century, large and impressive prisons were built, and the interior was designed to intimidate inmates (Hancock \& Jewkes, 2011). Although modern age prisons tend to blend more with other buildings in the environment, people still think that suspects in prisons should be punished. They often do not make a clear distinction between regular prisons and police detention centres, yet obviously, suspects in police detention are not sentenced prisoners but still awaiting trial.

Currently, interiors of many psychiatric emergency wards are being modernised in line with a growing body of international research on interior design which reduces patients' distress and agitation, and enhances psychological wellbeing (Björkdahl, Perseius, Samuelsson, \& Hedlund Lindberg, 2016; Novak, Scanlan, McCaul, MacDonald, \& Clarke, 2012; Wiglesworth \& Farnworth, 2016). A modern psychiatric emergency separation room does not resemble a police cell at all. The former separation chamber is now termed a comfort room or sensory room, designed to create feelings of comfort and safety (Baillon, Van Diepen, \& Prettyman, 2002). The rationale behind this new interior design concept is that it inhibits negative effects of prolonged absence of appropriate stimulation, which can lead to mental health problems (Baillon et al., 2002). It follows the principles of the healing environment as discussed in Chapter Six. A comfort room can be a spacious room, with a white or pastel coloured ceiling and walls, colours that can be adjusted by the patient, as well as adjustable sounds (e.g., sounds of birds) and odours. Doors are made of wood instead of steel, and there is a touchscreen to watch television or to play a computer game (Baillon et al., 2002; Van Steenbergen \& Pinedo, 2016).

My final suggestion is that the Dutch police could draw inspiration from environmental psychology, for example, from recent interior design developments in hospitals and psychiatric wards, to redesign police cells into comfort cells, in order to enhance mental health and prevent sleep problems among suspects (Bell et al., 2001; Björkdahl et al., 2016; Novak et al., 2012; Ulrich, 1991; Wiglesworth \& Farnworth, 2016). This ultimately might promote efficiency and effectivity of police interviews through enhancement of suspects' psychological wellbeing. 


\section{Strengths and limitations}

An important strength of this dissertation is that a number of psychological vulnerabilities were assessed: mental disorders, intellectual disability, an abnormal mental state (including drug and alcohol abuse, and sleep problems), and personality characteristics. Another strength is that the CIPH framework (Gudjonsson, 2003; Gudjonsson \& MacKeith, 1988, 1997) was used to explore these psychological vulnerabilities, as well as external factors that are hypothesized to increase psychological vulnerability in suspects. A third strength is that the research was performed in the field, and therefore, the ecological validity can be considered high. This makes this dissertation relevant for police practices, policy, and educational programs.

However, a number of limitations of this research must be addressed as well. First, it was not possible to control the circumstances in which the assessments took place, because the rooms in the police detention centres slightly differed in terms of the presence of a window, daylight, and colour. Second, the psychological assessment battery used for this study contained several abbreviated versions of psychological tests and a number of screeners, instead of full versions, obviously for reasons of time constraints in the police detention setting. This might have impacted the results. Third, Study Two included only 103 police detectives, and due to the reorganisation of the national police at the time, the recruitment procedure of detectives could not be controlled. The sample might thus not be representative of the current Dutch police detective population. Fourth, only 36 interrogation transcripts could be analysed for the study reported in Chapter Five, and these were not verbatim transcripts. Future studies need to use verbatim transcripts of recordings of police interrogations. Lastly, the study reported in Chapter Six included a small sample of suspects who had slept at home $(n=15)$ compared to a much larger sample of suspects who had slept in a police detention centre $(n=134)$ prior to the psychological assessment. Therefore, more research on the impact of police detention centre environments on suspects is needed. This research could include a larger sample of suspects detained in relatively old as well as in recently built police detention centres, perhaps with the use of EEG monitoring to study actual levels of sleep deprivation in police suspects.

\section{Final remarks}

This dissertation comprised research on persons at risk during interrogations in police custody. Although the focus was on the current situation in the Netherlands, results and recommendations might inspire other countries in the world to review policies and practices on police interviewing. Foremost, I hope my dissertation will lead to more research on the topics discussed here and to policy changes in the Dutch police force 
and the Police Academy of the Netherlands - not only to ensure a fair investigative procedure for vulnerable suspects, but to enhance the quality of police interviews as well. 
I use interrogation tactics

to manipulate suspects.

Ultimately, the interrogation is

about obtaining a confession.

Police interrogator specialist Conference 'Knowledge for the police of tomorrow', The Hague, 5 April 2018 


\section{Samenvatting}

Summary (in Dutch) 


\section{Introductie}

Niemand gelooft dat een verdachte iets zal bekennen wat hij of zij niet heeft gedaan. Toch zijn er genoeg voorbeelden van rechtszaken waarbij later is gebleken dat een psychologisch kwetsbare verdachte een valse bekentenis heeft afgelegd, zoals bijvoorbeeld in de zaak Ina Post en de Schiedammer Parkmoord.

Er kunnen drie verschillende vormen van valse bekentenissen worden onderscheiden. Ten eerste een vrijwillige valse bekentenis, bijvoorbeeld uit sensatiezucht of om een medeverdachte te beschermen. Ten tweede om gunsten te verkrijgen, zoals een einde aan het verhoor te maken. Ten derde omdat de verdachte ten onrechte is gaan denken schuldig te zijn, door manipulatieve verhoortechnieken en confabulatie.

Kort gezegd ontstaan valse bekentenissen door een combinatie van tunnelvisie bij politieagenten (als gevolg van een guilty bias en confirmation bias), het gebruik van onjuiste verhoormethoden en omdat bepaalde verdachten psychologisch kwetsbaarder zijn voor het afleggen van een valse bekentenis.

Psychologisch kwetsbare verdachten zijn verdachten met een psychische stoornis, een lichtverstandelijke beperking, een abnormale mentale toestand (als gevolg van bijvoorbeeld een hoge mate van stress, een alcohol- of drugsverslaving, of slaapproblemen) en/of bepaalde persoonlijkheidskenmerken, zoals suggestibiliteit (interrogative suggestibility) en toegeeflijkheid (compliance). Als psychologisch kwetsbare verdachten niet door politieagenten worden herkend en niet op de juiste wijze worden verhoord, dan kan dat leiden tot verregaande consequenties voor deze verdachten, tot een ineffectief en inefficiënt opsporingsproces, en uiteindelijk tot minder vertrouwen in politie en justitie.

Tot dusver is in Nederland nog niet veel bekend over kwetsbare verdachten die voor verhoor in een politiecellencomplex verblijven; deze dissertatie beschrijft een exploratief onderzoek daarnaar. De onderzoeksvragen zijn: wat is de prevalentie van kwetsbare verdachten in Nederland en zijn politieagenten in staat de prevalentie van kwetsbare verdachten juist in te schatten? Zijn Nederlandse verhoormethoden geschikt om verdachten te verhoren? Hoe worden verdachten (kwetsbare verdachten in het bijzonder) in de praktijk verhoord? En, tot slot, hoe ervaren verdachten hun psychisch welzijn en slaapproblemen als zij in een politiecellencomplex verblijven?

Het onderzoek volgt het CIPH-onderzoeksmodel van Gudjonsson en MacKeith $(1988,1997)$. CIPH is een acroniem voor omstandigheden (Circumstances), interactie 
(Interaction), persoonlijkheidskenmerken (Personality) en gezondheid (Health). Het model werd ontwikkeld als handvat voor psychiaters en psychologen voor psychologische onderzoeken en onderzoeksrapporten - het Nederlandse equivalent zou wellicht kunnen zijn een 'rapportage Pro Justitia', een psychologisch rapport van het Nederlands Instituut voor Forensische Psychiatrie en Psychologie (NIFP) over een verdachte, in opdracht van de Officier van Justitie en/of de Rechter-Commissaris.

Gedurende een jaar werden 178 verdachten die in zes verschillende cellencomplexen verbleven (Amsterdam, Breda, Eindhoven, Heerlen, Tilburg en Maastricht) psychologisch onderzocht met behulp van een testbatterij. Deze testbatterij bestond uit verschillende instrumenten om psychische stoornissen, een lichtverstandelijke beperking, een abnormale mentale toestand (bijvoorbeeld door een hoge mate van stress, alcohol- of drugsverslaving, of slaapproblemen) en bepaalde persoonlijkheidskenmerken (suggestibiliteit en toegeeflijkheid) te onderzoeken.

Hoofdstuk Twee is een replicatie van eerder onderzoek naar kwetsbare verdachten die bij de politie verbleven in het Verenigd Koninkrijk (Gudjonsson, Clare, Rutter en Pearse, 1993) - aangepast naar deze tijd. In dit deelonderzoek werd de prevalentie van verschillende psychologische kwetsbaarheden bij Nederlandse verdachten onderzocht en is gekeken of politieagenten in staat zijn deze prevalentie in te schatten.

In Hoofdstuk Drie wordt een specifieke kwetsbaarheid bij verdachten nader onderzocht, namelijk een lichtverstandelijke beperking. De vragen zijn of de Screener voor Intelligentie en Lichtverstandelijke Beperking (SCIL; Kaal, Nijman, \& Moonen, 2013) een geschikt instrument is voor de politie om verdachten te screenen en daarnaast wat de prevalentie van een lichtverstandelijke beperking bij verdachten is.

Hoofdstuk Vier bespreekt de bruikbaarheid van de Standaard Verhoorstrategie (SVS), een methode die vaak door politieagenten wordt gebruikt en is beschreven in de zesde editie van de Handleiding Verhoor (Van Amelsvoort, Rispens, \& Grolman, 2015). Het probleem is namelijk dat de SVS nog nooit empirisch is onderzocht op effectiviteit. De vraag is hoe de SVS zich verhoudt tot het wetenschappelijk bewezen effectieve verhoorconcept investigative interviewing, met name met betrekking tot kwetsbare verdachten.

Hoofdstuk Vijf onderzoekt Nederlandse verhoormethoden in de praktijk. Tot op heden is namelijk niet duidelijk wat zich precies in de verhoorkamers van de politie afspeelt. De vraag is of kwetsbare verdachten op een adequate manier worden verhoord.

In Hoofdstuk Zes wordt het verblijf in een politiecellencomplex onderzocht. Alle Nederlandse politiecellencomplexen verschillen qua inrichting, procedures en aantal 
arrestantenverzorgers. Bovendien worden politiecellencomplexen niet ontworpen met het oog op een comfortabel verblijf, maar vooral om veiligheid en efficiency te garanderen. De vraag is in welke mate overnachten in een politiecellencomplex het psychisch welzijn en slaapproblemen van verdachten beïnvloedt.

\section{Verschillende perspectieven op kwetsbare verdachten}

\section{Persoonlijkheidskenmerken en gezondheid.}

In Hoofdstuk Twee werd de identificatie van psychologische kwetsbaarheden besproken.

Allereerst werd in navolging van het onderzoek van Gudjonsson et al. (1993) de prevalentie van verschillende psychologische kwetsbaarheden bij verdachten in een politiecellencomplex onderzocht $(N=149)$. De resultaten lieten zien dat $60 \%$ van de verdachten werd gescreend voor nader onderzoek naar hun psychische gezondheid, $38 \%$ werd gescreend voor nader onderzoek naar Attention Deficit Hyperactivity Disorder (ADHD), 21\% gebruikte dagelijks drugs (soft-/harddrugs) en 4\% gebruikte dagelijks alcohol (in combinatie met minimaal 15 alcoholische consumpties per week). Daarnaast waren scores van psychopathologie, depressie, angst, stress en suggestibiliteit (interrogative suggestibility) hoger in vergelijking tot scores van de algemene Nederlandse populatie.

Het tweede gedeelte van Hoofdstuk Twee beschrijft de resultaten van een vragenlijst ingevuld door 103 Nederlandse rechercheurs, waarmee werd onderzocht in welke mate rechercheurs in staat zijn een inschatting te maken van de prevalentie van kwetsbare verdachten. De deelnemende rechercheurs werkten gemiddeld 21 jaar bij de politie en daarvan gemiddeld 11 jaar als rechercheur. Ongeveer 77\% volgde één of meerdere gevorderde recherchecursus(sen), terwijl $22 \%$ geen enkele recherchecursus had gevolgd. Bovendien had $76 \%$ geen enkele speciale/gevorderde verhoorcursus gevolgd. De rechercheurs zeiden in de afgelopen twaalf maanden gemiddeld vijf kwetsbare verdachten te hebben geïdentificeerd, variërend van 0 tot 90 kwetsbare verdachten, en 55\% van de rechercheurs zeiden geen enkele kwetsbare verdachte te hebben verhoord in de afgelopen 12 maanden. Ook meldde 55\% van de rechercheurs geen maatregelen te nemen als ze een kwetsbare verdachte verhoren, en antwoordden $42 \%$ van de rechercheurs wel maatregelen te nemen als zij een kwetsbare verdachten verhoren, zoals het raadplegen van een recherchepsycholoog, teamchef, gespecialiseerde collega of een officier van justitie. 
Hoofdstuk Drie beschrijft een onderzoek naar een specifieke psychologische kwetsbaarheid bij verdachten, namelijk een licht verstandelijke beperking (LVB) - in Nederland een IQ (intelligentie quotiënt) lager dan 85. De vraag was wat de prevalentie van een LVB onder verdachten in politiecellencomplexen was, en of de SCIL een bruikbare screener voor de politie is om een LVB bij verdachten te herkennen. De SCIL bestaat uit 14 items over gevolgd onderwijs, het bestaan van een sociaal vangnet, cognitieve capaciteiten, taalbegrip en gedrag, en screent voor een IQ lager dan 85. Het IQ werd gemeten met een verkorte versie van de Wechsler Adult Intelligence Scale en met de SCIL.

Het gemiddelde IQ van verdachten was 75 , variërend van 49 tot 110 . Ongeveer $85 \%$ had een IQ lager dan 85 en $29 \%$ lager dan 70 . De SCIL screende $50 \%$ van de verdachten voor een 10 lager dan 85. In deze studie werd een andere factorstructuur van de SCIL gevonden in vergelijking met de handleiding van de SCIL, waarschijnlijk vanwege de scheve verdeling van IQ-scores. De correlatie tussen IQ-scores en de scores van de SCIL was matig $(r=.56)$, mogelijk omdat de sociale items van de SCIL (items over onder andere een sociaal vangnet, contact met hulpverlening en het lezen van een krant) lagere IQ-scores maskeren, hetgeen nader onderzoek behoeft.

\section{Interactie}

In Hoofdstuk Vier is de stand van zaken met betrekking tot het Nederlandse verdachtenverhoor besproken. Daarbij was de vraag of Nederlandse verhoorpraktijken zich kunnen meten met recent empirisch onderzoek naar het politieverhoor. Een duik in de geschiedenis leert dat in Engeland ongeveer 25 jaar geleden verschillende gerechtelijke dwalingen hebben geleid tot afschaffing van het politieverhoor en tot de introductie van nieuwe wetten en richtlijnen met betrekking tot een transparant politie-interview en vernieuwde interview trainingen voor de politie (het investigative interviewing concept). Onderzoek naar het politie-interview hebben laten zien dat - over het algemeen - de interviews meer gestructureerd en effectiever verlopen in vergelijking tot oude verhoormethoden.

Ten tijde van het onderzoek zoals beschreven in Hoofdstuk Vier gebruikten Nederlandse politieagenten over het algemeen de Standaard Verhoorstrategie (SVS; Van Amelsvoort, Rispens \& Grolman, 2015, zesde editie). Twee problematische aspecten van de SVS werden besproken. Ten eerste leidt de SVS tot tunnelvisie (confirmation bias en guilty bias). Ten tweede wordt de SVS een informatie-vergarende verhoormethode te zijn, maar bevat het ook beschuldigende aspecten. Tot op heden is nog niet veel bekend over wat er precies in Nederlandse verhoorkamers gebeurt en is de SVS nog nooit wetenschappelijk getoetst op validiteit en betrouwbaarheid. 
Bovendien laat het weinige onderzoek naar de SVS zien dat politieagenten soms inadequate verhoortechnieken gebruiken - nota bene, gelet op jurisprudentie, akkoord bevonden door rechters.

Hoofdstuk Vijf beschrijft een onderzoek naar 36 verdachtenverhoren, met als doel te onderzoeken of kwetsbare verdachten adequaat worden verhoord. Allereerst werden de verdachten op basis van het psychologisch testonderzoek geclassificeerd als kwetsbaar of niet-kwetsbaar. Daarna werden de verhoren geanalyseerd aan de hand van de Griffith Question Map (GQM) en geclassificeerd als een adequaat verhoor (op basis van: open vragen, doorvragen en gepaste gesloten vragen) of als een inadequaat verhoor (op basis van, bijvoorbeeld, ongepast gesloten, sturende of suggestieve vragen, meerdere vragen tegelijk stellen en een scenario opwerpen). Ongeveer 69\% (25) van de 36 verdachten werd geclassificeerd als kwetsbare verdachten, ongeveer $86 \%$ (31) van de 36 verhoren waren inadequaat uitgevoerd en $84 \%$ (21) verhoren van kwetsbare verdachten waren inadequaat uitgevoerd. Meer onderzoek is nodig naar Nederlandse verhoorstrategieën.

\section{Omstandigheden}

In Hoofdstuk Zes was de invloed van de omgeving van een politiecellencomplex op het psychologisch welzijn en slaapproblemen van verdachten onderwerp van onderzoek. Alle politiecellencomplexen in Nederland verschillen namelijk van, onder andere, grootte, kleur, verlichting, aantal arrestantenverzorgers per arrestanten, voorzieningen en drukte. De vraag was of een overnachting in een politiecel leidt tot een verminderd psychologisch welzijn en meer slaapproblemen, en of slaapproblemen van invloed zijn op het psychisch welzijn van verdachten.

Resultaten wezen uit dat verdachten in een politiecel inderdaad een verminderd psychologisch welzijn ervaren en slechter slapen. Verdachten die voorafgaand aan het testonderzoek thuis hadden geslapen gaven een gemiddeld cijfer van 7,3 voor de kwaliteit van slaap in de afgelopen nacht, terwijl verdachten die in een politiecel hadden geslapen daarvoor een gemiddeld cijfer van 4,5 gaven. Verdachten die voorafgaand aan het psychologisch assessment in een politiecellencomplex hadden geslapen rapporteerden een lager psychisch welzijn en meer slaapproblemen ten opzichte van verdachten die voorafgaand aan het assessment thuis hadden geslapen. De politie zou er mogelijk goed aan doen psychisch welzijn van verdachten te bevorderen en slaapproblemen bij hen zoveel mogelijk te voorkomen, om zo bij te dragen aan een adequaat verdachtenverhoor. 


\section{Discussie}

\section{Persoonlijkheid en gezondheid}

Hoofdstuk Twee en Drie hebben aangetoond dat politieagenten waarschijnlijk dagelijks te maken hebben met kwetsbare verdachten, maar dat kwetsbare verdachten niet altijd door hen worden herkend; het base rate neglect bij politieagenten blijkt hoog te zijn. ${ }^{21}$

Allereerst schrijft de Aanwijzing audiovisueel registreren van verhoren van aangevers, getuigen en verdachten (2013) voor dat het verhoor van kwetsbare verdachten (verdachten jonger dan 16, met een LVB of met een verminderd cognitief vermogen) verplicht moet worden vastgelegd middels een audio- of video-opname. De aanwijzing bepaalt ook dat politieagenten zelf mogen beslissen wanneer een verdachte kwetsbaar is.

Verder bestaat een aanbeveling van de Europese Commissie waarin is gesteld dat kwetsbare verdachten moeten worden verhoord in aanwezigheid van een raadsman (en dat van dit recht geen afstand kan worden gedaan), dat audio-opname van alle verhoren verplicht is en dat politieagenten getraind moeten worden.

Verdachten - in het bijzonder kwetsbare verdachten - zouden voordeel kunnen hebben als deze wetten zouden worden toegepast. Eerder onderzoek heeft namelijk uitgewezen dat politieagenten minder intimiderende verhoortechnieken gebruiken als een raadsman aanwezig is tijdens het verhoor. Bovendien kunnen audio- of videoopnames leiden tot minder gebruik van inadequate verhoortechnieken, kan het later worden teruggeluisterd/-gekeken om na te gaan wat er precies is gezegd en gebeurd, kunnen politieagenten zich focussen op het verhoor in plaats van ondertussen het proces-verbaal te moeten typen, en kunnen opnames voor wetenschappelijk onderzoek worden gebruikt. Een kanttekening bij het trainen van politieagenten in het herkennen van kwetsbare verdachten is, dat psychiaters en psychologen in de regel meerdere onderzoeken en gesprekken nodig hebben om tot een oordeel of diagnose te kunnen komen. Daarbij verklaarden veel verdachten tijdens dit onderzoek dat zij alleen meededen vanwege hun anonimiteit en de geheimhoudingsplicht van de assessoren. Zij zeiden nooit mee te zullen doen aan een psychologische test afgenomen door de politie, vanwege de kans dat resultaten in een strafzaak gebruikt zouden kunnen worden en de angst voor een eventuele Terbeschikkingstelling (TBS).

\footnotetext{
${ }^{21}$ Base rate neglect: bij het schatten van een kans wordt basis-informatie over de omvang van een populatie genegeerd en laat degene zich leiden door enkele opvallende vertegenwoordigers van die populatie.
} 
Daarom is het gebruik van een screener voor kwetsbare verdachten door de politie onrealistisch.

Mijn eerste advies is, gelet op (a) de prevalentie van psychologische kwetsbaarheden bij verdachten, (b) het base rate neglect bij politieagenten, (c) Nederlandse en Europese regelgeving en (d) de (on)bruikbaarheid van een screener, dat politieagenten iedere verdachte zouden moeten benaderen als een potentieel kwetsbare verdachte.

Mijn tweede advies is dat alle verhoren van verdachten zouden moeten worden opgenomen (audio/visueel).

\section{Interactie}

In de zomer van 2017 is de zevende druk van de Handleiding Verhoor uitgekomen (Van Amelsvoort \& Rispens, 2017). Hoewel ten opzichte van de zesde druk bepaalde aspecten van de Handleiding zijn verbeterd, is de nieuw geïntroduceerde Scenario Onderzoekende Methode (SOM) oude wijn in nieuwe zakken, want in feite is een nieuw etiket op de Standaard Verhoorstrategie (SVS) geplakt. De keuze tussen verschillende verhoortechnieken en het gebruik ervan wordt niet in de Handleiding Verhoor uitgelegd en is nodeloos ingewikkeld. Het is de vraag of politieagenten voldoende competent zijn om adequaat te kunnen kiezen tussen de verhoormethoden en deze te kunnen toepassen - waarschijnlijk niet, zoals uit onderzoek is gebleken. Bovendien kleven enkele ongewenste en potentieel gevaarlijke aspecten aan de Nederlandse manier van verhoren, zoals het opbouwen van druk en tunnelvisie.

Daarbij komt dat de Handleiding Verhoor twintig jaar geleden is ontstaan op basis van ervaring en onderbuikgevoel. Tot op heden zijn Nederlandse verhoormethoden niet empirisch onderzocht, echter, verschillende onderzoekers hebben in het verleden gewezen op negatieve aspecten van Nederlandse verhoormethoden en het onvermogen van Nederlandse politieagenten om het verhoor op een adequate manier uit te voeren.

Uit jurisprudentie blijkt dat Nederlandse rechters inadequate verhoormethoden niet afkeuren. Kortom, voor de politie zijn er dus geen restricties om inadequate verhoormethoden te gebruiken. Ook jurisprudentie van het Europese Hof voor de Rechten van de Mens (EHRM) heeft tot op heden geen duidelijke definitie van een kwetsbare verdachte opgeleverd.

Mijn derde advies is dat de Nederlandse politie, in navolging van onder andere de politie in het Verenigd Koninkrijk, Australië, Nieuw-Zeeland en Noorwegen, moet overgaan op het concept van investigative interviewing. Dit behelst het gebruik van 
een evidence-based, effectieve en ethische interview methode, in combinatie met borging van opleiding in de organisatie en regelgeving. Pleisters plakken op bestaande verhoormethoden heeft geen zin, er moet radicaal afscheid worden genomen van huidige verhoormethoden, vooral om de mind-set van politieagenten te veranderen.

\section{Omstandigheden}

De omstandigheden in Nederlandse politiecellencomplexen kunnen zeker niet worden gekwalificeerd als slecht. Desalniettemin heeft dit onderzoek aangetoond dat verdachten in politiecellencomplexen een verminderd psychisch welzijn en meer slaapproblemen ervaren. Naar voorbeeld van basisprincipes uit de omgevingspsychologie en zogenaamde healing environments in zorginstellingen is meer onderzoek nodig om omstandigheden in politiecellencomplexen te verbeteren. Zoals isolatiecellen bij psychiatrische inrichtingen tegenwoordig worden omgebouwd tot 'comfort rooms' om het gevoel van comfort en veiligheid te vergroten, is mijn laatste advies dat de politie haar politiecellen zou moeten ombouwen tot 'comfort cellen', naar principes uit de omgevingspsychologie. Dit zou kunnen bijdragen aan een verbeterd psychisch welzijn en minder slaapproblemen bij verdachten, en daardoor uiteindelijk aan een effectiever verdachtenverhoor.

\section{Sterke punten en beperkingen}

Een sterk punt van dit onderzoek is dat meerdere psychologische kwetsbaarheden zijn onderzocht, namelijk psychische stoornissen, een lichtverstandelijke beperking, een abnormale mentale toestand en enkele persoonlijkheidskenmerken. Een ander sterk punt is dat gebruik is gemaakt van het CIPH onderzoeksmodel om deze psychologische kwetsbaarheden te onderzoeken in de context van externe factoren die deze kwetsbaarheden beïnvloeden. Een derde sterk punt is dat het onderzoek is uitgevoerd in de praktijk, waardoor de ecologische validiteit hoog is. Daarmee kan dit onderzoek bijdragen aan de politiepraktijk, beleid en onderwijs.

Een beperking in Hoofdstuk Twee is dat slechts 103 rechercheurs de vragenlijst hebben ingevuld en daardoor mogelijk niet representatief zijn voor het totale aantal rechercheurs werkzaam bij de politie. Een tweede beperking is dat de psychologische testbatterij verschillende verkorte versies van oorspronkelijke vragenlijst bevatte, vanwege de omvang en een tijdslimiet. De resultaten kunnen hierdoor beïnvloed zijn. Een derde beperking is dat in Hoofdstuk Vijf slechts 36 verhoren konden worden geanalyseerd aan de hand van het proces-verbaal van verhoor. In toekomstig onderzoek is het aan te bevelen om verbatim verslagen te gebruiken. Een vierde beperking is dat slechts 15 verdachten thuis hadden geslapen voorafgaand aan het psychologisch 
assessment in vergelijking met 134 verdachten die in een politiecellencomplex hadden geslapen. Meer onderzoek naar de invloed van de omgeving van een politiecellencomplex op verdachten is noodzakelijk.

\section{Tot slot}

Dit proefschrift beschrijft een exploratief en toegepast onderzoek naar kwetsbare verdachten die voor verhoor bij de politie verblijven - als zodanig het eerste onderzoek in Nederland. Hoewel de Nederlandse situatie is verkend zouden uitkomsten en aanbevelingen naar andere landen in de wereld kunnen worden vertaald. Hopelijk stellen politieorganisaties en politieacademies zich open voor wijzingen in beleid en praktijk met betrekking tot de besproken onderwerpen, met als uiteindelijk doel de effectiviteit van het politie-interview verder te verbeteren. 
I am left in this cell the whole day, without any sheets,

only with a plastic mattress and

a cushion. They said they had no time to let me smoke but I just saw them all watching television.

Female police detainee, 40-years old 


\section{Valorisation}

Addendum 
The most important implications for police interviewing practices and suggestions for future research are already discussed in the General discussion in Chapter Seven. Therefore, in this Valorisation addendum I will focus on how research in the field of environmental psychology may be used to redesign and improve police detention centre environments.

In 2015, I asked Kate Pietrowska, who was then a Master's student Interior Design at the University of Applied Sciences and Arts (HKU) in Utrecht, the Netherlands, to redesign a police detention centre into 'the police detention centre of the future'. ${ }^{22}$ The object of the redesign was the police detention centre Mijkenbroek, Breda, the Netherlands, built in the 90's of the past century. The following is part of her Master's thesis, called 'Humanisation of Cell Complexes: Creating Balance between Equality and Hierarchy' (Pietrowska, 2015).

Before the start of the design, I helped Kate to formulate four areas of research, which she later subsequently translated into four spatial arrangements: safety for both suspects and staff, order to ensure optimal police work, trust between suspects and police staff, and authority in order to ensure respect and modesty. As she recognized, there is a paradox in designing a humane, comfortable, and respectful space on the one hand, and to maintain a certain level of hierarchy and authority on the other hand (Pietrowska, 2015). Still, the aim was to design a police detention centre where the environment contributes to reduced stress levels in police suspects, and where police staff can carry out their tasks optimally as well.

The design was based on literature review, and a pilot study (i.e., interviews, observations, and surveys). The Theory of Supportive Design (Ulrich, 1991) argues that supportive spaces may reduce stress levels in humans and is nowadays commonly used as the basis for designing health care facilities (as discussed in more detail in Chapter Six). In addition, empirical research showed that when people lose their sense of control, their stress levels increase (Ulrich, 1991). Thus, police cells must provide some privacy and comfort, access to information, and control over lighting and temperature, in order to increase the sense of control of detainees.

\footnotetext{
${ }^{22}$ Kate Piotrowska earned her Master's degree in Interior Design at the University of Applied Sciences and Arts (HKU) in Utrecht, the Netherlands, in 2015. Her thesis can be viewed on her website: www.katepiotrowska.com.
} 


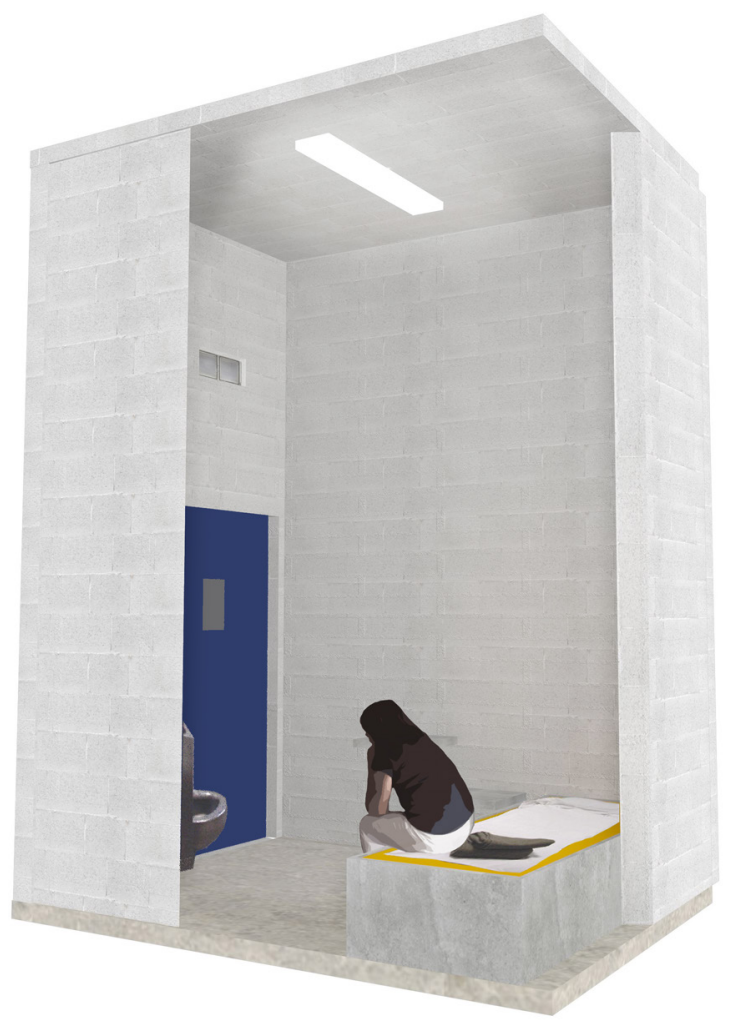

Figure 1. Graphical representation of police cells in the Mijkenbroek police detention centre, Breda, the Netherlands, in 2015. (c) Kate Piotrowska 2015

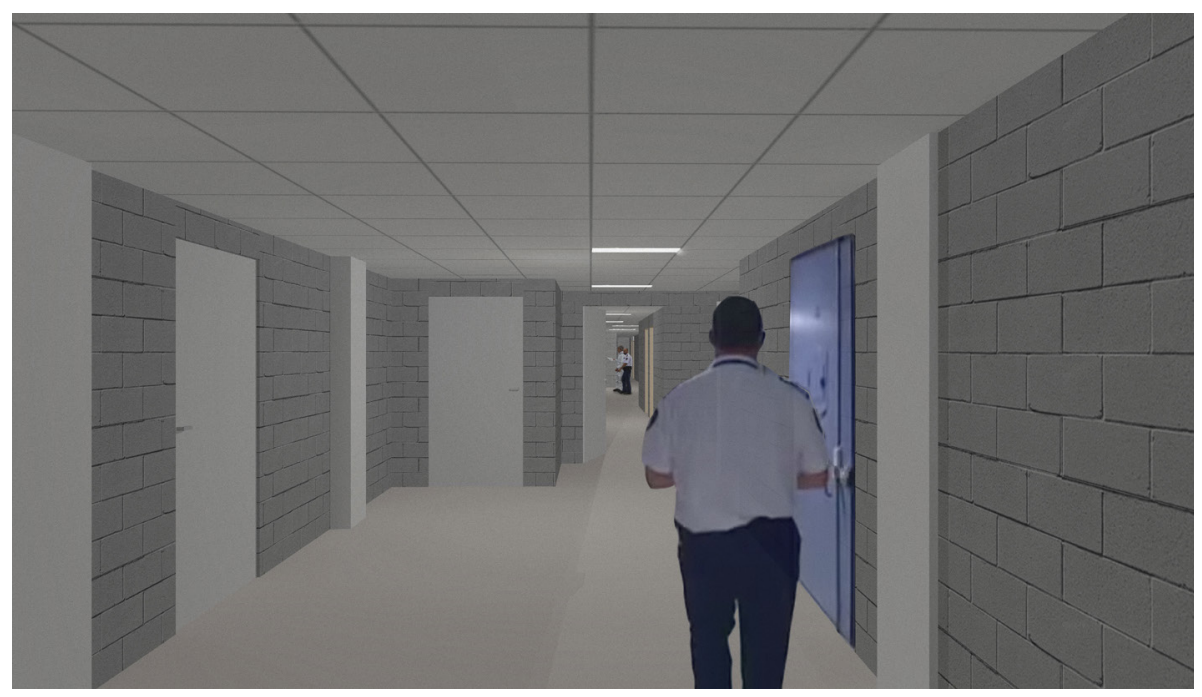

Figure 2. Graphical representation of the interior of the Mijkenbroek police detention centre, Breda, the Netherlands, in 2015. (C) Kate Piotrowska 2015 
Firstly, the redesign comprised more daylight in police cells, for example by placing windows in ceilings. Secondly, a patio with a tree was placed in the central part of the complex, as a reference point, and to provide view to the tree and sky. Thirdly, all dead ends of corridors were removed, for example by creating semi-open walls at the end of hallways to reduce feelings of isolation. Spatial interventions, such as glazed corridor doors, smooth links between inside and outside, and different floor patterns, must make transitions smoother and thereby create a suggestion of more perceived personal control over spaces.

The redesigned cells were painted in white epoxy paint, and cells' furniture were made of soft, sponge-like materials to literally soften the look and feel of it. Warm colours were used in spaces were suspects do not have direct contact with police staff, and wood was used because of its stress-reducing and noise-absorbing properties. All cells were equipped with control panels to control lighting, temperature, toilet, TV, radio, and ventilation. Attention was paid to ceiling height by reducing the ceiling height from 4.3 meters to 3 meters, and daylight by inserting larger windows.

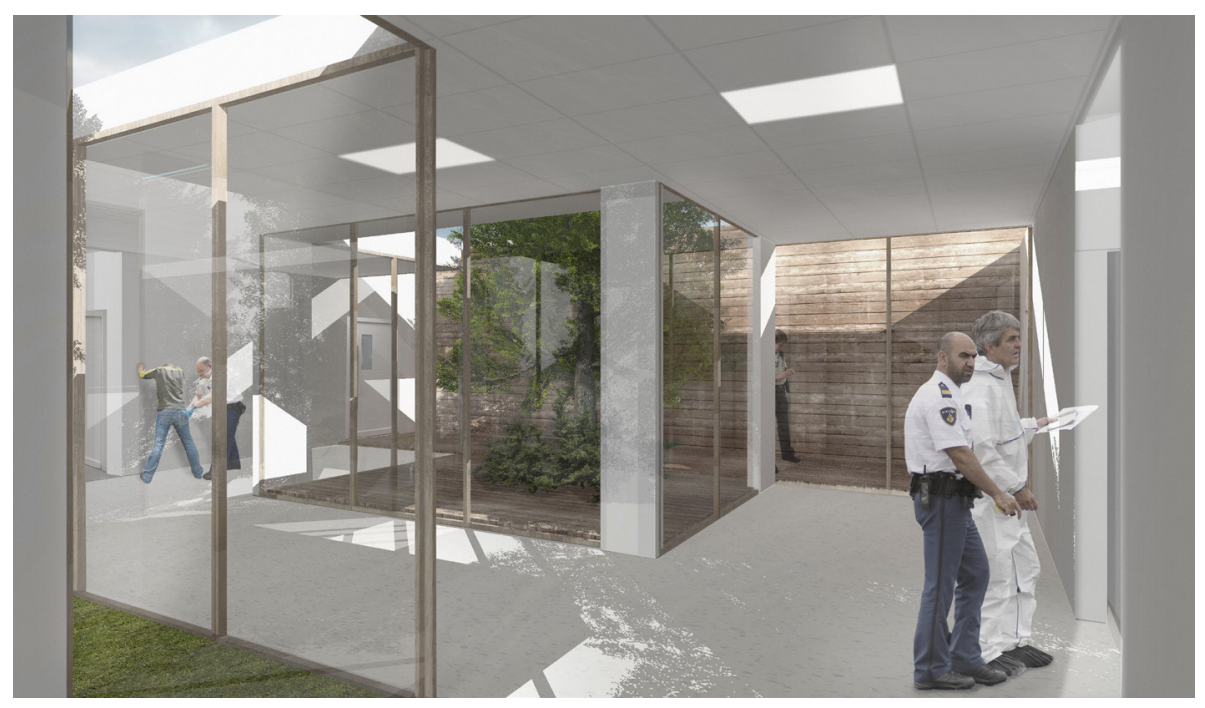

Figure 3. Graphical representation of the future Mijkenbroek police detention centre, Breda, the Netherlands. A patio with a tree, and more daylight.

(C) Kate Piotrowska 2015 
The police staff control room was raised by two steps to suggest hierarchy, and the front was built in a slight angle to suggest a certain distance. Thereby it showed authority and power, without the intention to evoke feelings of stress.

This collaborative project with Kate Pietrowska shows future police detention centres, where the environment contributes to reducing suspects' feelings of stress, anxiety and sleep problems, and to increase work satisfaction in police staff as well. Ultimately, this design may contribute to a more effective police interrogations and police investigation processes.

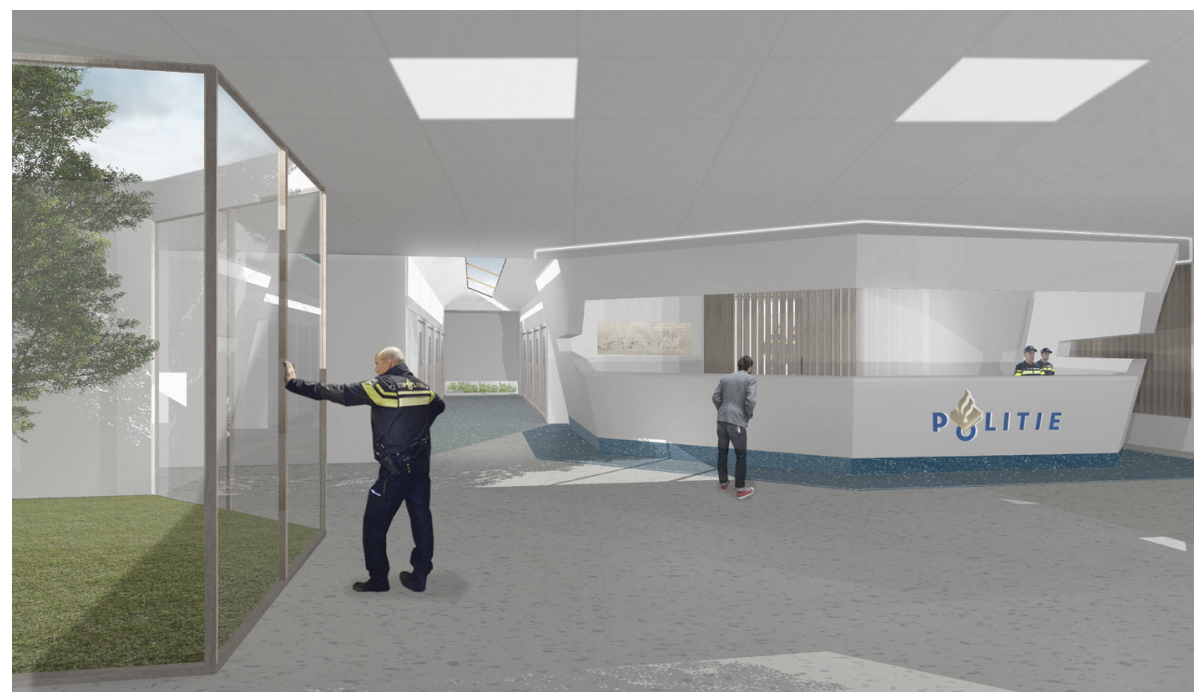

Figure 4. Graphical representation of the future Mijkenbroek police detention centre, Breda, the Netherlands. On the left: the patio with a tree, on the right: the police control room. (C) Kate Piotrowska 2015 
It is a custom in our team that cake is served when a confession has been obtained.

Police detective, Brabant, the Netherlands (2015) 


\section{References}


Aanwijzing auditief en audiovisueel registreren van verhoren van aangevers, getuigen en verdachten (2014). Staatscourant, 2012, 26900. Retrieved from:

http://wetten.overheid.nl/BWBR0032552/Bijlage3/geldigheidsdatum_22-10-2015.

Altman, I. (1975). The environment and social behavior: Privacy, personal space, territoriality, and crowding. Monterey: Brooks/Cole.

Altman, I. \& Rogoff, B. (1987). World views in psychology and environmental psychology: Trait, interactional, organismic and transactional perspectives. In I. Altman \& D. Stokols (Eds.), Handbook of environmental psychology (pp. 245-281). New York: Wiley.

American Psychiatric Association (2000). Diagnostic and Statistical Manual of Mental Disorders (4 ${ }^{\text {th }}$ edition, Text Revision). Washington: Author.

American Psychiatric Association (2013). Diagnostic and Statistical Manual of Mental Disorders (5th edition). Washington: Author.

Angermeyer, M. C., \& Dietrich, S. (2006). Public beliefs about and attitudes towards people with mental illness: A review of population studies. Acta Psychiatrica Scandinavica, 113(3), 163-179.

Arnhem Court (2011). ECLI:NL:RBARN:2011:BR4163. Retrieved from: http://deeplink.rechtspraak.nl/uitspraak?id=ECLI:NL:RBARN:2011:BR4163

Appleby, S. C., Hasel, L. E., \& Kassin, S. M. (2013). Police-induced confessions: An empirical analysis of their content and impact. Psychology, Crime \& Law, 19(2), 111 128.

Arrindell, W. A., \& Ettema, J. H. M. (2005). Symptom Checklist SCL-90: Handleiding bij een multidimensionale psychopathologie-indicator. Amsterdam: Pearson.

Baksheev, G. N., Thomas, S. D. M., \& Ogloff, J. R. P. (2012). Psychopathology in police custody: The role of importation, deprivation and interaction models. International Journal of Forensic Mental Health, 11(1), 24-32.

Baldwin, J. (1993). Police interview techniques: Establishing truth or proof. The British Journal of Criminology, 33(3), 325-352.

Baillon, S., Van Diepen, E., \& Prettyman, R. (2002). Multi-sensory therapy in psychiatric care. Advances in Psychiatric Treatment, 8(6), 444-452.

Bedau, H. A., \& Radelet, M. L. (1987). Miscarriage of justice in potentially capital cases. Stanford Law Review, 40(1), 21-179.

Bell, P. A., Greene, Th. C., Fisher, J. D., \& Baum, A. (2001). Environmental Psychology (5 $5^{\text {th }}$ edition). New York: Taylor \& Francis Group.

Besluit inrichting en orde politieverhoor (2017). Staatsblad 29. Retrieved from: https://zoek.officielebekendmakingen.nl/stb-2017-29.html 
Björkdahl, A., Perseius, K. I., Samuelsson, M., \& Hedlund Lindberg, M. (2016). Sensory rooms in psychiatric inpatient care: Staff experiences. International Journal of Mental Health Nursing, 25(5), 472-479.

Blaauw, J. A. (2001). De Puttense moordzaak: Reconstructie van een dubieus moordonderzoek. Baarn: De Fontijn.

Blaauw, J. A., Vermunt, R., \& Kerkhof, A. (1997). Detention circumstances in police stations: Towards setting the standards. Policing and Society, 7(1), 45-69.

Blaauw, J. A., Kerkhof, A., \& Vermunt, R. (1998). Psychopathology in police custody. International Journal of Law and Psychiatry, 21(1), 73-87.

Blagrove, M. (1996). Effects of length of sleep deprivation on interrogative suggestibility. Journal of Experimental Psychology: Applied, 2(1), 48-59.

Blagrove, M., \& Akehurst, L. (2000). Effects of sleep loss on confidence-accuracy relationships for reasoning and eyewitness memory. Journal of Experimental Psychology: Applied, 6(1), 59-73.

Blom, T. (2011). Vormen verzuimd tijdens het politieverhoor (Oration). Retrieved from: http://www.oratiereeks.nl/upload/pdf/PDF-5336Blom_text_HR.PDF

Boon, R., Odinot, G., Horselenberg, R., \& Geijsen, K. (2016). Van verhoor naar forensisch Interview. Het Tijdschrift voor de politie, 78(4), $20-25$.

Bull, R., \& Soukara, S. (2009). Four studies of what really happens in police interviews. In: D. G. Lassiter \& C. A. Meissner (Eds.), Police interrogations and false confessions: Current research, practice and policy recommendations (pp. 81-95). Washington: American Psychological Association.

Case, D., Fantino, E., \& Goodie, A. (1999). Base-rate training without case cues reduces base-rate neglect. Psychonomic Bulletin \& Review, 6(2), 319-327.

Ceelen, M., Dorn, T., Buster, M., Stirbu, I., Donker, G., \& Das, K. (2012). Health-care issues and health-care use among detainees in police custody. Journal of Forensic and Legal Medicine, 19(6), 324-331.

Clarke, C., Milne, R., \& Bull, R. (2011). Interviewing suspects of crime: The impact of PEACE training, supervision and the presence of a legal advisor. Journal of Investigative Psychology and Offender Profiling, 8(2), 149-162.

Code of Criminal Procedure (Wetboek van Strafvordering; 2018). Retrieved from: http://wetten.overheid.nl/BWBR0001903/2018-01-01

College of Policing (2017). Investigation. Retrieved from: http://www.college.police.uk/What-we-do/Learning/ProfessionalTraining/ Investigation/ Documents/PIP_Policy.pdf

Council of Europe (1950). European Convention on Human Rights. Retrieved from: https://www.echr.coe.int/Documents/Convention_ENG.pdf 
Cyr, M., Dion, J., McDuff, P., \& Trotier-Sylvain, K. (2012). Transfer of skills in the context of non-suggestive investigative interviews: Impact of structured interview protocol and feedback. Applied Cognitive Psychology, 26(4), 516-524.

Dalke, H., Little, J., Niemann, E., Camgoz, N., Steadman, G., Hill, S., \& Stott, L. (2006). Colour and lighting in hospital design. Optics \& Laser Technology, 38(4), 343-365.

Davis, D., \& Leo, R. A. (2012). Interrogation-related regulatory decline: ego depletion, failures of self-regulation, and the decision to confess. Psychology, Public Policy, and Law, 18(4), 673-704.

Deak, M. C., \& Stickgold, R. (2010). Sleep and cognition. Wires Cognitive Science, 1(4), 491-500.

De Beurs, E., Dyck, R. van, Marquenie, L. A., Lange, A., \& Blonk, R. W. B. (2001). De DASS: Een vragenlijst voor het meten van depressie, angst en stress. Gedragstherapie, 34(1), 35-53.

De Graaf, R., Ten Have, M., Van Gool, C., \& Van Dorsselaer, S. (2012). Prevalentie van psychische aandoeningen en trends van 1996 tot 2009: Resultaten van NEMESIS-2. Tijdschrift voor Psychiatrie, 54(1), 27-38.

Deetman, W., Draijer, N., Kalbfleisch, P., Merckelbach, H., Monteiro, M., \& De Vries, G. (2011). Seksueel misbruik van minderjarigen in de Rooms-Katholieke kerk. Amsterdam: Balans.

Derogatis L. R. (1977). SCL-90-R, Symptom Checklist 90 - revised: Administration, scoring and procedures manual. Minneapolis: National Computer Systems.

De Ruiter, C. (2015). Filicide or false confession? In C. de Ruiter, \& N. Kaser-Boyd, Forensic psychological assessment in practise: Case studies (pp. 112-135). New York: Routledge.

De Ruiter, C., Peters, M., \& Smeets, T. (2010). Psychisch kwetsbare verdachten tijdens het politieverhoor: Nut en noodzaak van forensisch psychologische expertise. GZPsychologie, 2(2), 18-23.

Dijkstra, K., Pieterse, M., \& Pruyn, A. (2006). Physical environmental stimuli that turn healthcare facilities into healing environments through psychologically mediated effects: systematic review. Journal of Advanced Nursing, 56(2), 166-181.

Dijkstra, K., Pieterse, M. E., \& Pruyn, A. Th. H. (2008). Individual differences in reactions towards color in healthcare environments: The role of stimulus screening ability. Journal of Environmental Psychology, 28(3), 268-277.

Dorn, T., Ceelen, M., Buster, M., \& Das, K. (2013). Screening for mental illness among persons in Amsterdam police custody. Psychiatric Services, 64(10), 1047-1050. 
Dorn, T., Ceelen, M., Buster, M., Stirbu, I., Donker, G., \& Das, K. (2014). Mental health and health-care use of detainees in police custody. Journal of Forensic and Legal Medicine, 26, 24-28.

Drahota, A., Ward, D., Mackenzie, H., Stores, R., Higgins, B., Gal, D., \& Dean, T.P. (2012). Sensory environment on health-related outcomes of hospital patients (review). The Cochrane Library, 14(3), 1-361. Published online. DOI: 10.1002/14651858.CD005315. pub2.

Duker, M. J. A., \& Stevens, L. (2009). Het politiële verdachtenverhoor: Meer aandacht voor methoden gewenst. In M. J. Borgers, M. J. A. Duker, \& L. Stevens (red.), Politie in beeld (pp. 77-104). Nijmegen: Wolf Legal Publishers.

Een Vandaag (2010). Interview Ina Post. Retrieved from: https://eenvandaag.avrotros.nl/item/interview-ina-post/

Farrugia, L., \& Milne, R. (2012). Suspect interviewing and mental health in the UK: An overview. Investigative Interviewing: Research and Practice, 4(2), 24-32.

Faul, F., Erdfelder, E., Lang, A. G., \& Buchner, A. (2007). G*Power 3: A flexible statistical power analysis program for the social, behavioral, and biomedical sciences. Behavior Research Methods, 39(2), 175-191.

Field, A. (2012). Bonferroni correcting lots of correlations. Retrieved from: https://www.methodspace.com/bonferroni-correcting-lots-of-correlations/

First, M. B., Spitzer, R. L., Gibbon, M., \& Williams, J. B. W. (2002). Structured Clinical Interview for DSM-IV-TR Axis I Disorders, Research Version. New York: New York State Psychiatric Institute.

Folstein, M. F., Folstein, S. E., \& McHugh, P. R. (1975). Mini-mental state: A practical method for grading the cognitive state of patients for the clinician. Journal of Psychiatric Research, 12(3), 189-198.

Frenda, S. J., Berkowitz, S. R., Loftus, E. F., \& Fenn, K. M. (2016). Sleep deprivation and false confessions. Proceedings of the National Academy of Sciences, 113(8), 20472050.

Frumkin, H. (2001). Beyond toxicity: human health and the natural environment. Annual Journal of Preventive Medicine, 20(3), 234-240.

Geijsen, K., \& De Ruiter, C. (2017). Het Nederlandse politieverhoor van verdachten anno 2017. Strafblad, 79(2), 157-162.

Geijsen, K., De Ruiter, C., \& Kop, N. (2018). Identifying psychological vulnerabilities: Studies on police suspects mental health issues and police officers' views. Cogent Psychology, 5(1), 1462133. Published online 19 April 2018. DOI: 10.1080/23311908.2018.1462133. 
Geijsen, K., Kop, N., \& De Ruiter, C. (2018). Screening for intellectual disability in Dutch police suspects. Journal of Investigative Psychology and Offender Profiling. Published online 14 April 2018. DOI: 10.1002/jip.1502.

Geijsen, K., Kop, N., \& De Ruiter, C. (2018). Overnachten in een politiecel: Een onderzoek naar het psychisch welzijn en slaapproblemen van verdachten. Tijdschrift voor Criminologie, 60(3), 312-326. DOI: 10.5553/TvC/0165182X2018060003003.

Geijsen, K., Vanbelle, S., Kop, N., \& De Ruiter, C. (2018). The interrogation of vulnerable suspects in the Netherlands: An exploratory study. Investigative Interviewing: Research and Practice, 9(1), 34-51.

Gifford, R., Steg, L., \& Reser, J. P. (2011). Environmental psychology. In P. R. Martin, F. M. Cheung, M. C. Knowles, M. Kyrios, J. B. Overmier, \& J. M. Prieto, IAAP Handbook of Applied Psychology (pp. 440-470). Chichester: Wiley-Blackwell.

Gosewehr, D., \& Timmerman, H. (2007). Wanneer de waarheid... : Het ware verhaal over Ina Post. Amsterdam: Rozenberg Publishers.

Gremmen, E. M. (2018). De kwetsbare psychisch gestoorde verdachte in het strafproces: Regelgeving, praktijk en Europese standaarden (Doctoral dissertation). Retrieved from: https://www.narcis.nl/publication/RecordID/oai:repub.eur.nl:104821

Griffiths, A., \& Milne, R. (2006). Will it end in tiers? Police interviews with suspects in Britain. In T. Williamson (Ed.), Investigative Interviewing: rights, research, regulation (pp. 167-189). Cullompton: Willan Publishing.

Griffiths, A. \& Milne, R. (2018). The psychology of criminal investigation: From theory to practice. London: Routledge.

Griffiths, A. \& Rachlew, A. (2018). From interrogation to investigative interviewing: The application of psychology. In A. Griffiths \& R. Milne (Eds.), The psychology of criminal investigation: From theory to practice (pp.154-178). London: Routledge.

Gross, S. R., Jacoby, K., Matheson, D. J., \& Montgomery, N. (2005). Exonerations in the United States 1989 through 2003. The Journal of Criminal Law \& Criminology, 95(2), 523-560.

Gudjonsson, G. H. (1984). A new scale of interrogative suggestibility. Personal Individual Differences, 5(3), 303-314.

Gudjonsson, G. H. (1989). Compliance in an interrogative situation: A new scale. Personal and Individual Differences, 10(5), 535-540.

Gudjonsson, G. H. (1997). The Gudjonsson Suggestibility Scales manual. Hove: Psychology Press.

Gudjonsson, G. H. (2003). The psychology of interrogations and confessions: A handbook. Chichester: Wiley. 
Gudjonsson, G. H. (2010). Psychological vulnerabilities during police interviews: Why are they important? Legal and Criminological Psychology, 15(2), 165-171.

Gudjonsson, G. H., Clare, I., Rutter, S., \& Pearse, J. (1993). Persons at risk during interviews in police custody: The identification of vulnerabilities. London: HMSO.

Gudjonsson, G. H., Hannesdottir, K., Petursson, H., \& Bjornsson, G. (2002a). The effects of alcohol withdrawal on mental state, interrogative suggestibility and compliance: An experimental study. The Journal of Forensic Psychiatry, 13(1), 53-67.

Gudjonsson, G. H., \& Joyce, T. (2011). Interviewing adults with intellectual disabilities. Advances in Mental Health and Intellectual Disabilities, 5(2), 16-21.

Gudjonsson, G. H., \& MacKeith, J. (1997). Disputed Confessions and the Criminal Justice System. London: Institute of Psychiatry.

Gudjonsson, G. H., Sigurdsson, J. F., Brynjolfsdottir, B., \& Hreinsdottir, H. (2002b). The relationship of compliance with anxiety, self-esteem, paranoid thinking, and anger. Psychology, Crime \& Law, 8(2), 145-153.

Gudjonsson, G. H., Sigurdsson, J. F., Sigfusdottir, I. D., \& Young, S. (2012). False confessions to police and their relationship with conduct disorder, ADHD, and life adversity. Personality and Individual Differences, 52(6), 696-701.

Hagens, M. (2011). Toezicht op menswaardige behandeling van gedetineerden in Europa: Een onderzoek naar de verhouding tussen het EHRM en het CPT bij de effectuering van het folterverbod. Nijmegen: Wolf Legal Publishers.

Häkkänen, H., Ask, K., Kebbell, M., Alison, L., \& Granhag, P. A. (2009). Police officers' views of effective interview tactics with suspects: The effects of weight of case evidence and discomfort with ambiguity. Applied Cognitive Psychology, 23(4), 468481.

Hancock, Ph., \& Jewkes, Y. (2011). Architectures of incarceration: The spatial pains of imprisonment. Punishment \& Society, 13(5), 611-629.

Hansen, I., Smeets, T., \& Jelicic, M. (2010). Further data on interrogative suggestibility and compliances scores following instructed malingering. Legal and Criminological Psychology, 15(2), 221-228.

Harrison, Y., \& Horne, J. A. (2000). The impact of sleep deprivation on decision making: A review. Journal of Experimental Psychology: Applied, 6(3), 236-249.

Hayes, S. (2000). Hayes Ability Screening Index: Manual. Sidney: University of Sidney. Hayes, S. (2002). Early intervention or early incarceration? Using a screening test for intellectual disability in the criminal justice system. Journal of Applied Research in Intellectual Disability, 15(2), 120-128.

Hayes, S., Shackell, Ph., Mottram, P., \& Lancaster, R. (2007). The prevalence of intellectual disability in a major UK prison. British Journal of Learning Disability, 35(3), 162-167. 
Herrington, V., \& Roberts, K. (2012). Addressing psychological vulnerability in the police suspect interview. Policing: A Journal of Policy and Practice, 6(2), 177-186.

Hill, C., Memon, A., \& McGeorge, P. (2008). The role of confirmation bias in suspect interviews: A systematic evaluation. Legal and Criminological Psychology 13(2), 357 371.

Hodgson, J. (2015). The role of lawyers during police detention and questioning: A comparative study. Contemporary Readings in Law and Social Justice, 7(2), 7-16.

Hoekendijk, J., \& Van Beek, M. (2015). The GIS-model: A Dutch approach to gather information in suspect interviews. Investigative Interviewing: Research and Practice, 7(1), 1-9.

Inspectie Veiligheid en Justitie (2015). Arrestantenzorg Nederland: Landelijke Rapportage. Den Haag: Ministerie van Veiligheid en Justitie.Israëls, H. (2004). De bekentenissen van Ina Post. Alphen a/d Rijn: Kluwer.

Israëls, H. \& Horselenberg, R. (2010). Valse bekentenissen. In P. J. van Koppen, H. Merckelbach, M. Jelicic, \& J. W. de Keijser (Eds.), Reizen met mijn rechter: Psychologie van het recht (pp. 765-784). Deventer: Kluwer.

Jelicic, M. (2017). Verdachten met psychiatrische en neurologische aandoeningen in de verhoorkamer: Wat kan er misgaan? Strafblad, 15(2), 198-203.

Jones, J. (2007). Persons with intellectual disabilities in the criminal justice system. International Journal of Offender Therapy and Comparative Criminology, 51, 723733.

Kaal, H. L. (2014). Licht verstandelijke beperking en crimineel gedrag: Samenhang en prevalentie. In H. Kaal, N. Overvest, \& M. Boertjes, Beperkt in de keten: Mensen met een licht verstandelijke beperking in de strafrechtsketen (pp. 107-127). Den Haag: Boom Lemma.

Kaal, H.L., Overvest, N., \& Boertjes, M. (2017). Beperkt in de keten: Mensen met een licht verstandelijke beperking in de strafrechtsketen. Den Haag: Boom Lemma.

Kaal, H. L., Nijman, H., \& Moonen, X. M. H. (2013). SCIL: Screener voor intelligentie en licht verstandelijke beperking. Amsterdam: Hogrefe.

Kassin, S. M. (2012). Why confessions trump innocence. American Psychologist, 67(6), 431-445.

Kassin, S. M. (2015). The social psychology of false confessions. Social Issues and Policy Review, 9(1), 25-51.

Kassin, S. M. (2017). False confessions. WIRE's Cognitive Science, 1439, 1-11. Published online 9 May 2017. DOI: 10.1002/wcs.1439. 
Kassin, S. M., Appleby, S. C., \& Torkildson Perillo, J. (2010a). Interviewing suspects: Practice, science and future directions. Legal and Criminological Psychology, 15, 39-55.

Kassin, S. M., Drizin, S. A., Grisso, T., Gudjonsson, G. H., Leo, R. A., \& Redlich, A. D. (2010). Police-induced confessions: Risk factors and recommendations. Law and Human Behavior, 34(1), 3-38.

Kassin, S. M. \& Gudjonsson, G.H. (2004). The psychology of confessions: A review of the literature and issues. Psychological Science in the Public Interest, 5(2), 33-67.

Kassin, S. M., Kukucka, J., Lawson, J. Z., \& DeCarlo, J. (2016). Police reports of mock suspect interrogations: A test of accuracy and perception. Law and Human Behavior. Published online 12 December 2016. DOI: 10.1037//hb0000225.

Kassin, S. M., \& Wrightsman, L.S. (1985). Confession evidence. In S. Kassin \& L. Wrightsman (Eds.), The psychology of evidence and trial procedure (pp. 67-94). Beverly Hills: Sage.

Kaiser, H. F. (1974). An index of factorial simplicity. Psychometrika, 39(1), 31-36.

Karlin, B. E. \& Zeiss, R. A. (2006). Environmental and therapeutic issues in psychiatric hospital design: Towards best practices. Psychiatric Services, 57(10), 1376-1378.

Kaufman, A. S., \& Kaufman, N. L. (1993). Manual for the Kaufman Adolescent and Adult Intelligence Test (KAIT). Circle Pines: American Guidance Service.

Kaufman, A. S., \& Kaufman, N. L. (2004). Kaufman Brief Intelligence Test (2 ${ }^{\text {nd }}$ edition). Washington: Pearson.

Kelly, Ch. E., Miller, J. C., Kleinman, S. M., \& Redlich, A. D. (2013). A taxonomy of interrogation methods. Psychology, Public Policy, and Law, 19(2), 165-178.

Killgore. W. D. S., Balkin, Th. J., \& Wesensten, N. J. (2006). Impaired decision making following $49 \mathrm{~h}$ of sleep deprivation. Journal of Sleep Research, 15(1), 7-13.

Kok, R. M., \& Verhey, F. R. J. (2002). Gestandaardiseerde versie van de Mini-Mental State Examination: Een toelichting bij de scoring. Zeist: Altrecht GGZ.

Kooij, J. J. S. (2010). ADHD bij volwassenen: Diagnostiek en behandeling (3rd edition). Amsterdam: Pearson Assessment and Treatment.

Kortlever, C. (2011). Verhoormethoden en hun risico's. Expertise en Recht, 4(1), 3-12.

Kwaliteitsinstituut voor de Gezondheidszorg (2004). Richtlijn: Zorg bij een verstoord slaap-waak ritme. Utrecht: CBO.

Lamb, M. E., Sternberg, K. J., Orbach, Y., Hershkowitz, I., Horowitz, D., \& Esplin, P.W. (2002). The effects of intensive training and ongoing supervision on the quality of investigative interviews with alleged sex abuse victims. Applied Developmental Science, 6(3), 114-125. 
Lamb, H. R., Weinberger, L. E., \& DeCuir, W. J. (2002). The police and mental health. Psychiatric Services, 53(10), 1266-1271.

Lang (2004). Multinomial-Poisson homogeneous models for contingency tables. The Annals of Statistics, 32(1), 340-383.

Lange, A., \& Appelo, M. (2007). De Korte Klachten Lijst, KKL: Handleiding. Houten: Bohn Stafleu van Loghum.

Lange, R. T., Edmed, S. L., Sullivan, K. A., French, L. M., \& Cooper, D.B. (2013). Utility of the mild brain injury atypical symptoms scale to detect symptom exaggeration: An analogue simulation study. Journal of Clinical and Experimental Neuropsychology, 35(2), 192-209.

Lange, R. T., Brickell, T. A., \& French, L. M. (2015). Examination of the Mild Brain Injury Atypical Symptom scale and the Validity-10 Scale to detect symptom exaggeration in US military service members. Journal of Clinical and Experimental Neuropsychology, 37(3), 325-337.

Leo, R. A., \& Davis, D. (2010). From false confession to wrongful conviction: Seven psychological processes. The Journal of Psychiatry \& Law, 38(1), 9-56.

Leo, R. A., \& Drizin, S. A. (2010). The three errors: Pathways to false confession and wrongful conviction. In G. D. Lassiter \& Ch. Meissner (Eds.), Police interrogations and false confessions: Current research and practice, and policy recommendations (pp. 9-30). Washington: American Psychological Association.

Lippa, S. R., Axelrod, B. N., \& Lange, R. T. (2016). The Mild Brain Injury Atypical Symptoms (mBIAS) scale in a mixed clinical sample. Journal of Clinical and Experimental Neuropsychology, 38(7), 721-729.

Lovibond, S. H., \& Lovibond, P. F. (1995b). Manual for the Depression Anxiety Stress Scales. Sydney: The Psychology Foundation of Australia.

Maastricht Court (2008). ECLI:NL:RBMAA:2008:BD0562, retrieved from: http://jure.nl/ECLI:NL:RBMAA:2008:BD0562

Malsch, M., Kranendonk, R., De Keijser, J., Elffers, H., Komter, M., \& De Boer, M. (2014). Kijken, luisteren, lezen: De invloed van beeld, geluid en schrift op het oordeel over verdachtenverhoren. Amsterdam: Reed Business.

Mason, J., \& Murphy, G. (2002). Intellectual disability amongst people on probation: Prevalence and outcome. Journal of Intellectual Disability Research, 46(3), 230-238. McGrory, D., \& Treacy, P. (2012). The Professionalising Investigation Programme. In: M. R. Haberfeld, C. A. Clarke, \& D. L. Sheehan (Eds.), Police Organization and Training: Innovations in research and practice (pp. 113-136). New York: Springer. 
McKenzie, K., Michie, A., Murray, A., \& Hales, C. (2012). Screening for offenders with an intellectual disability: The validity of the Learning Disability Screening Questionnaire. Research in Developmental Disability, 33(3), 791-795.

McKinnon, I., \& Grubin, D. (2010). Health screening in police custody. Journal of Forensic and Legal Medicine, 17(4), 209-212.

Medford, S., Gudjonsson G. H., \& Pearse, J. (2003). The efficacy of the registered intermediate safeguard during police interviewing. Legal and Criminological Psychology, 8(2), 253-266.

Merckelbach, H., Smeets, T., \& Jelicic, M. (2008). Onwaarschijnlijke symptomen simuleren: De Wildman Symptom Checklist. Neuropraxis, 54(2), 53-57.

Merckelbach, H., Langeland, W., De Vries, G., \& Draijer, N. (2014). Symptom overreporting obscures the dose-response relations between trauma severity and symptoms. Psychiatry Research, 217(3), 215-219.

Mergaerts, L., Van Daele, D., \& Vervaeke, G. (2017). De beoordeling van kwetsbaarheid van verdachten in strafprocedures: Op zoek naar een conceptueel model. Strafblad, 15(6), 520-527.

Moonen, X. M. H., Kaal, H. L., \& Nijman, H. (2012). The construction and validation of a screener to assess mild intellectual disability and borderline intelligence. Journal of Intellectual Disability Research, 56(7), 693.

Morris, R. G., \& Worrall, J.L. (2010). Prison architecture and inmate misconduct: A multilevel assessment. Crime \& Delinquency, 60(7), 1-27.

Morris, R.G., Carriaga, M.L., Diamond, B., Leeper Piquero, N., \& Piquero, A.R. (2012). Does prison strain lead to prison misbehavior? An application of general strain theory to inmate misconduct. Journal of Criminal Justice, 40(3), 194-201.

Moston, S., \& Stephenson, G. M. (1993). The changing face of police interrogation. Journal of Community \& Applied Social Psychology, 3(2), 101-115.

Mortimer, A. (1994). Asking the right questions. Policing 10, 111-24.

Murphy, G. H., Gardner, J., \& Freeman, M. J. (2017). Screening prisoners for intellectual disabilities in three English prisons. Journal of Applied Research in Intellectual Disabilities, 30(1), 198-204.

Mykhailov, I. (2018, 20 January). A real alternative to interrogation. LB.ua. Retrieved from: https://en.lb.ua/news/2018/01/20/5372_real_alternative_interrogation.html

Neisser, U., Boodoo, G., Bouchard, Th. J., Boykin, W. A., Brody, N., Ceci, S. J. ... Urbina, S. (1996). Intelligence knowns and unknowns. American Psychologist, 51(2), 77-101.

Nierop, N. M. (2005). Het verdachtenverhoor in Nederland: Wat wordt verhoorders geleerd? NJB, 17, 887-890. 
Nierop, N. M., \& Van den Eshof, P. (2014). Het horen van kwetsbare personen door de politie: Onderzoeksrapport van de werkgroep verhoor kwetsbare personen. Unpublished internal report, National Police of the Netherlands.

Novak, Th., Scanlan, J., McCaul, D., MacDonald, N., \& Clark, T. (2012). Pilot study of a sensory room in an acute inpatient psychiatric unit. Australasian Psychiatry, 20(5), 401-406.

Nurse, J., Woodcock, P., \& Ormsby, J. (2003). Influence of environmental factors on mental health within prisons: Focus group study. British Medical Journal, 327(7413), 480-483.

Odinot, G., Boon, R., \& Wolters, L. (2015). Het episodisch geheugen en getuigenverhoor: Wat weten politieverhoorders hiervan? Tijdschrift voor Criminologie, 57(3), 279-299.

Ofshe, R., \& Leo, R.A. (1997). The social psychology of police interrogation: The theory and classification of true and false confessions. Studies in Law, Politics and Society, 16, 189-251.

Ogloff, J. R. P., Thomas, S. D. M., Luebbers, S., Baksheev, G., Elliot, I., Godfreson, J., ... Moore, E. (2012). Policing services with mentally ill people: Developing greater understanding and best practice. Australian Psychologist, 48(1), 57-68.

O'Mahony, B. M., Milne, R., \& Grant, T. (2012). To challenge, or not to challenge? Best practice when interviewing vulnerable suspects. Policing, 6(3), 301-313.

Openbaar Ministerie, Politie, \& NFI (2005). Versterking opsporing en vervolging: Naar aanleiding van het evaluatierapport van de Schiedammer parkmoord. Retrieved from: https://zoek.officielebekendmakingen.nl/kst-30300-VI-32-b1.pdf

O'Rourke, N., \& Hatcher, L. (2013). A Step-by-Step Approach to Using SAS for Factor Analysis and Structural Equation Modelling (2nd edition). Cary: SAS Institute Inc.

Overeem, S., Hauzer, R., \& Rentmeester, T. R. (2012). Slaapstoornissen. In W. M. A. Verhoeven, J. M. A. Sitsen, \& L. Pepplinkhuizen (Eds.), Het Psychiatrisch Formularium: Een praktische leidraad (7 th edition; pp. 17-32). Amsterdam: Bon Stafleu van Loghum.

Oxburgh, G. E., Mycklebust, T., \& Grant, T. (2010). The question of question types in police interviews: A review of the literature form a psychological and linguistic perspective. Journal of Speech, Language and the Law, 17(1), 45-66.

Parton, F., Day, A., \& White, J. (2004). An empirical study on the relationship between intellectual ability and an understanding of the legal process in male remand prisoners. Psychiatry, Psychology \& Law, 11(1), 96-109.

Payne, J. D., Schacter, D. L., Propper, R. E., Huang, L. W., Wamsley, E. J. ... Stickgold, R. (2009). The role of sleep in false memory formation. Neurobiology of Learning and Memory, 92(3), 327-334. 
Police and Criminal Evidence Act (1984), Chapter 60 (UK). Retrieved from:

https://www.legislation.gov.uk/ukpga/1984/60

Politieacademie (2014). Vragenlijst onderkennen. Unpublished internal document.

Politieacademie (2017). Verhoren van kwetsbare verdachten. Retrieved from:

https://www.politieacademie.nl/onderwijs/onderwijsaanbod/pagesopleiding.aspx?

code $=4300913$ \&interessegebied $=6$ \&thema $=60$

Posthumus, F. (2005). Evaluatieonderzoek in de Schiedammer Parkmoord. Den Haag:

Openbaar Ministerie.

Powel, M. B., Hughes-Scholes, C. H., Smith, R., \& Sharman, S. J. (2014). The relationship between Investigative Interviewing experience and open-ended question usage. Police Practice and Research, 15(4), 293-292.

Ratcliff, R., \& Van Dongen, H.P. (2009). Sleep deprivation affects multiple distinct cognitive processes. Psychological Bulletin Review, 16(4), 742-751.

Rassin, E., \& Israëls, H. (2014). False confessions in the lab: A review. Erasmus Law Review, 7(4), 219-224.

Regeling Politiecellencomplex (2017). Retrieved from: http://wetten.overheid.nl/BWBR0006557/2017-03-18

Resing, W. C. M., \& Blok, J. B. (2002). De classificatie van intelligentiescores: Voorstel voor een eenduidig systeem. De Psycholoog, 37, 244-249.

Roos, J. (2014). Kenmerken en implicaties van een licht verstandelijke beperking. In H. Kaal, N. Overvest, \& M. Boertjes, Beperkt in de keten: Mensen met een licht verstandelijke beperking in de strafrechtsketen (pp. 17-75). Den Haag: Boom Lemma.

Scheyett, A., Vaughn, J., Taylor, M., \& Parish, S. (2009). Are we there yet? Screening processes for intellectual and developmental disability in jail settings. Intellectual and Developmental Disability, 47(1), 13-23.

Schonell, F. J., \& Goodacre, E. J. (1974). The psychology and teaching of reading $\left(5^{\text {th }}\right.$ edition). Harlow: Oliver \& Boyd.

Shepherd, E., \& Griffiths, A. (2013). Investigative Interviewing: The conversation management approach ( $2^{\text {nd }}$ edition). Oxford: Oxford University Press.

Siemering, L., \& Van der Laan, P. H. (2016). Het opsporingsonderzoek in moord- en doodslagzaken met minderjarige verdachten. Het Tijdschrift voor de Politie, 78(4)، 26-31.

Smeets, T. (2008). Gudjonsson Suggestibility Scales en Gudjonsson Compliance Scale. In T. Giesbrecht, C. de Ruiter, \& M. Jelicic (Eds.), Forensisch psychodiagnostisch gereedschap: Malingering, psychopathie en andere persoonlijkheidstrekken (pp. 63-72). Amsterdam: Harcourt. 
Smeets, T., Leppink, J., Jelicic, M., \& Merckelbach, H. (2009). Shortened versions of the Gudjonsson Suggestibility Scale meet the standards. Legal and Criminal Psychology, 14(1), 149-155.

Snook, B., Eastwood, J., Stinson, M., Tedeschini, J., \& House, J. C. (2010). Reforming Investigative Interviewing in Canada. Revue Canadienne de Criminologie et de Justice Pénale, 52(2), 203-218.

Søndenaa, E., Rasmussen, K., Palmstierna, T., \& Nøttestad, J. (2008). The prevalence and nature of intellectual disability in Norwegian prisons. Journal of Intellectual Disability Research, 52(12), 1129-1137.

Soukara, S., Bull, R., Vrij, A., Turner, M., \& Cherryman, J. (2009). What really happens in police interviews of suspects: Tactics and confessions. Psychology, Crime \& Law, 15(6), 493-506.

Souverijn, A. (2009). Een comfortroom voor psychiatrische patiënten. Tijdschrift voor Verpleegkundigen, 11(12), 62-65.

Sparrow, S. S., Balla, D. A., \& Cicchetti, D. V. (1984). Vineland Adaptive Behavior Scales. Circle Pines: American Guidance Service.

Spielberger, C. D., Gorsuch, R., \& Lushene, R. E. (1970). State-Trait Anxiety Inventory Manual. Palo Alto: Consulting Psychology Press.

Steadman, H. J., Clark Robbins, P., Islam, T., \& Osher, F. C. (2007). Revalidating the Brief Jail Mental Health Screen to increase accuracy for women. Psychiatric Services, 58(12), 1598-1601.

Steadman, H. J., Osher, F. C., Robbins, P. C., Case, B., \& Samuels, S. (2009). Prevalence of serious mental illness among jail inmates. Psychiatric Services, 60(6), 761-765.

Steinke, P. (1991). Using situational factors to predict types of prison violence. Journal of Offender Rehabilitation, 17(1), 119-132.

Stevens, J. P. (2009). Applied multivariate statistics for the social sciences. New York: Routledge.

Stevens, L., \& Verhoeven, W. J. (2010). Raadsman bij politieverhoor: Invloed van voorafgaande consultatie en aanwezigheid van raadslieden op de organisatie en wijze van verhoren en de proceshouding van verdachten. Den Haag: Boom Juridische Uitgevers.

Stevens, L., \& Verhoeven, W. J. (2011). Wat is er mis met een 'goed gesprek'? Een exploratief onderzoek naar pressie tijdens politiële verdachtenverhoren en risico's op valse bekentenissen. Delikt en Delinkwent, (41)2, 114-131.

Streiner, D. L., \& Cairney, J. (2007). What's under the ROC? An introduction to receiver operating characteristics curves. The Canadian Journal of Psychiatry, 52(2), 121-128. 
St-Yves, M. (2006). The psychology of rapport: Five basic rules. In T. Williamson (Ed.), Investigative Interviewing: Rights, research, regulation (pp. 87-106). Devon: Willan Publishing.

Talbot, J. (2007). No one knows: Offenders with learning difficulties and learning disabilities. British Journal of Learning Disabilities, 35(3), 154-161.

Tuithof, M., Ten Have, M., Van Dorsselaer. S., \& De Graaf, R. (2014). Prevalentie, persistentie en gevolgen van ADHD in de Nederlandse volwassen bevolking. Tijdschrift voor Psychiatrie, 56(1), 10-19.

Ulrich, R. S. (1991). Effects of interior design on wellness: theory and recent scientific research. Journal of Health Care Interior Design, 3(1), 97-109.

Ulrich, R. S. (2000). Effects of healthcare environmental design on medical outcomes. In Design and Health: Proceedings of the Second International Conference on Health and Design (pp. 49-59). Stockholm: Svensk Byggtjanst.

Uterwijk, J. M. (2000). WAIS-III Nederlandstalige bewerking. Technische handleiding. Lisse: Swets \& Zeitlinger.

Van Amelsvoort, A., Rispens, I., \& Grolman, G. (2015). Handleiding Verhoor (6 $6^{\text {th }}$ edition). Amsterdam: Reed Business.

Van Amelsvoort, A., \& Rispens, I. (2017). Handleiding verhoor (7 $7^{\text {th }}$ edition). Amsterdam: Reed Business.

Van den Adel, H. M. (1997). Handleiding Verdachtenverhoor. Den Haag: Vuga.

Van der Aa, S. (2016). Variable vulnerabilities? Comparing the rights of adult vulnerable suspects and vulnerable victims under EU law. New Journal of European Criminal Law, 7(1), 39-58.

Van Koppen, P. J. (1998). Bekennen als bewijs: Bedenkingen bij het verhoor van de verdachte. In Justitiële verkenningen, 24(4). Den Haag: Wetenschappelijk Onderzoek- en Documentatie Centrum, pp. 61-73.

Van Koppen, P. J. (2003). De Schiedammer parkmoord: Een rechtspsychologische reconstructie. Nijmegen: Ars Aequi.

Van Koppen, P. J. (2009). Waarom ik jou wil laten bekennen: Over valse bekenners en hun ondervragers. Koud Bloed, 1(7), 31-41.

Van Oorsouw, K., Merckelbach, T., \& Smeets, T. (2015). Alcohol intoxication impairs memory and increases suggestibility for a mock crime: A field study. Applied Cognitive Psychology, 29(4), 493-501.

Van Steenbergen, E., \& Pinedo, D. (2016, 3 september). Isoleercel: Van kaal hok tot comfortroom. NRC. https://www.nrc.nl/nieuws/2016/09/03/isoleercel-van-kaal-hoktot-comfortroom-4108097-a1519431 
Velthorst, E., Levine, S. Z., Henquet, C., De Haan, L., Van Os, J., Myin-Germeys, I., \& Reichenberg, A. (2013). To cut a short test even shorter: Reliability and validity of a brief assessment of intellectual ability in schizophrenia - A control-case family study. Cognitive Neuropsychiatry, 18(6), 574-593.

Verhoeven, W. J., \& Duinhof, E. (2017). Effectiviteit van het verdachtenverhoor: Een veldstudie naar de relatie tussen verhoortechnieken, de verklaring van verdachten en de aanwezigheid van de advocaat in zware zaken. Apeldoorn: Politie \& Wetenschap.

Verhoeven, W. J., \& Stevens, L. (2012). The lawyer in the Dutch interrogation room: Influence on police and suspect. Journal of Investigative Psychology and Offender Profiling, 9, 69-92. Published online. DOI: 10.1002/jip.1354.

Vrij, A. (2003). We will protect your wife and child, but only if you confess: Police interrogations in England and The Netherlands. In P. J. van Koppen \& S. D. Penrod (Eds.), Adversarial versus inquisitorial justice: Psychological perspectives on criminal justice systems (pp. 55-79). New York: Springer.

Vrij, A. (2010). Het verhoren van verdachten. In: P. J. van Koppen H. Merckelbach, M. Jelicic, \& J. W. de Keijser (Eds.), Reizen met mijn rechter (pp. 723-764). Deventer: Kluwer.

Walsh, D., \& Bull, R. (2012). Examining rapport in investigative interviews with suspects: Does its building and maintenance work? Journal of Police and Criminal Psychology, 27, 73-84.

Walsh, D., \& Bull, R. (2015). Interviewing suspects. Examining the association between skills, questioning and evidence disclosure, and interview outcomes. Psychology, Crime \& Law, 21(7), 661-680.

Watson, D., Clark, L.A., \& Carey, G. (1988). Positive and negative affectivity and their relation to anxiety and depressive disorders. Journal of Abnormal Psychology, 97(3), 346-353.

Wechsler, D. (1944). The measurement of adult intelligence (3rd edition). Baltimore: Williams \& Wilkins.

Wechsler, D. (1981). Manual for the Wechsler Adult Intelligence Scale - Revised. New York: Psychological Corporation.

Wechsler, D. (1997). Wechsler Adult Intelligence Scale (3 ${ }^{\text {rd }}$ edition). San Antonio: The Psychological Corporation.

Wechsler, D. (1999a). Wechsler Abbreviated Scale of Intelligence. San Antonio: The Psychological Corporation.

Wechsler, D. (1999b). Wechsler Adult Intelligence Scale (3rd UK edition). Oxford: Harcourt Assessment. 
Wiglesworth, S., \& Farnworth, L. (2016). An exploration of the use of a sensory room in a forensic mental health setting: Staff and patient perspectives. Occupational Therapy International, 23(3), 255-264.

Wildman, R. W., \& Wildman, R. W., Jr. (1999). The detection of malingering, Psychological Reports, 84(2), 386-388.

Wohlwill, J. F. (1966). The physical environment: A problem for a psychology of stimulation. Journal of Social Issues, 22(4), 29-38.

Yang, Z., \& Zhou, M. (2014). Kappa statistic for clustered matched pair data. Statistics in Medicine, 33(15), 2612-2633.

Young, S., Goodwin, E. J., Sedgwick, O., \& Gudjonsson, G. H. (2013). The effectiveness of police custody assessments in identifying suspects with intellectual disabilities and attention deficit hyperactivity disorder. BMC Medicine, 11, 248-259. Published online 21 November 2013. DOI: 10.1186/1741-7015-11-248. 
Our supervisor wants us to interrogate people as soon as possible.

He just doesn't want a hassle, so

he assigns any available police detective to interrogate vulnerable people.

Police detective, Amsterdam Police Force (2016) 


\section{Dankwoord}

Acknowledgements

(in Dutch) 
In de afgelopen jaren heb ik zowel met mijn studie als met dit promotieonderzoek geprobeerd om, vanuit mijn 'blauwe hart', een bijdrage te leveren aan verbetering van het politiewerk; het werk waarmee ik op mijn achttiende begon en waarmee ik voor altijd verbonden zal zijn. Graag wil ik een aantal mensen bedanken die mij tijdens mijn promotieonderzoek hebben bijgestaan.

Allereerst mijn promotor, Corine. Het was op een zondag, begin juni 2013, toen ik een artikel over kwetsbare verdachten las, onder andere geschreven door jou. Die avond stuurde ik je een email over een onderwerp voor een mogelijk promotieonderzoek en nog geen half uur later kreeg ik al een reactie van je. Heel veel dank voor je vertrouwen in mij en de kans die je me hebt gegeven om dit onderzoek te doen. Ik heb veel respect voor je visie, bevlogenheid, inspanningen en vooral je persoonlijke betrokkenheid op het gebied van onderwijs en onderzoek binnen het vakgebied forensische psychologie. Dank dat ik af en toe bij je thuis aan de keukentafel met je van gedachten mocht wisselen - inspirerend en leerzaam, net als je befaamde 'rode pen'.

Daarnaast mijn copromotor, Nicolien. We delen betrokkenheid bij en fascinatie voor de politie en wetenschappelijk onderzoek naar het politiewerk. Ik bewonder je voor je gedrevenheid en vasthoudendheid waarmee je jouw kennis en kunde binnen de politie en de politieacademie weet uit te dragen, zoals met onderzoeken, projecten, seminars en bijdragen aan beleid. Daarbij weet je bovendien steeds onderzoekers en promovendi te inspireren en te stimuleren. Fijn dat ik je altijd mocht bellen voor raad en daad, of soms alleen voor een luisterend oor. Heel veel dank voor je vertrouwen, adviezen en ondersteuning.

Van onze gezamenlijke gesprekken in De Bilt en Utrecht kreeg ik iedere keer weer ongelofelijk veel energie en inspiratie, hopelijk blijven er meer volgen in de toekomst. Mijn promotieonderzoek was een intensieve, maar heel bijzondere en leerzame ervaring, dat ik voor geen goud had willen missen. Dank jullie wel!

Uiteraard dank ik de leden van de beoordelingscommissie die tijd en moeite hebben willen nemen om mijn dissertatie te lezen en te beoordelen.

Wetenschappers en politieagenten zijn in Nederland nog geen vanzelfsprekende partners. Bovendien is in de afgelopen jaren binnen de politie de werkdruk steeds hoger geworden en vond mijn onderzoek plaats tijdens een periode van grote 
veranderingen. Daarom waardeer ik het zeer dat de Korpschef en het Openbaar Ministerie toestemming voor mijn onderzoek gaven en ben ik de politie zeer dankbaar dat ze mijn onderzoek hebben gefaciliteerd.

Uiteraard ben ik mijn collega's van de politie die het onderzoek mogelijk hebben gemaakt ook de nodige dank verschuldigd, namelijk de teamleidingen van de zes politiecellencomplexen, de betrokken rechercheafdelingen en alle arrestantenverzorgers van de zes cellencomplexen. Dank voor jullie welwillende medewerking, betrokkenheid, enthousiasme en nieuwsgierigheid.

En verder niet te vergeten:

Juna van der Poort, Ive Reijnders en Vivian Römers.

Ik bewonder jullie inzet, input, professionaliteit en doorzettingsvermogen tijdens het uitvoeren van de psychologische assessments. Het was een unieke en mooie onderzoeksperiode, maar het was ook vaak afzien als er weer een hele dag voorbij was gegaan zonder één volledig assessment te hebben kunnen afnemen. Heel veel dank voor jullie hulp.

Aram Clements, David Doornbos, Lotna Kleczewski, Kate Piotrowska en Lotte Wanschers. Jullie hebben met jullie masterscripties belangrijke bijdragen geleverd aan mijn onderzoek, dank daarvoor.

Arjan Bos, Anita Eerland en Inge van Seggelen-Damen.

Dank dat jullie als supervisors van de Open Universiteit van mijn bachelor en master scripties mij op het idee hebben gebracht om een promotieonderzoek te starten.

Leo Ligthart.

Je me hebt mij als supervisor van mijn stage in het kader van de master klinische psychologie geïntroduceerd - maar vooral geïnspireerd - in het vakgebied forensische psychologie. Veel dank voor je vertrouwen en begeleiding.

De aio's en onderzoekers van de Politieacademie dank ik voor hun feedback en gezelligheid tijdens de discussiebijeenkomsten en als ik aanwezig was op de Politieacademie. Monique The-Wiltink, dank je wel voor de praktische ondersteuning in de afgelopen vier jaar. Roel Holvast, dank dat ik deel mag uitmaken van het Team Onderzoek. 
Furthermore, I would like to thank all colleagues from the Department of Clinical Psychological Science of Maastricht University. During several meetings in the past four years, your genuine interest in my research has been incredibly inspiring, supporting, and encouraging. Thank you so much for that!

Roel Boon, Andy Griffiths, Milee Herweijer, Hendrien Kaal, Sandra Kooij, Geralda Odinot, Imke Rispens, Jannie van der Sleen, Sophie Vanbelle, Dorris van der Vocht en Fiona de Vos.

Heel erg bedankt voor jullie adviezen en hulp.

En last but not least...

... ben ik mijn Sjoerd heel veel dank verschuldigd. Ondanks dat je wel eens mopperde als ik avond na avond tot laat met mijn 'werkstukje' - zoals jij het vaak plagend noemde - bezig was, heb je mij altijd onvoorwaardelijk gesteund. Je bent mijn steun en toeverlaat. Je ziet, het is me gelukt, mijn werkstuk is af. 


\section{On my first day of work,}

just after entering the room,

an older police detective told me:

"Just forget about everything you

learned at the Police Academy,

because I will teach you how to

properly conduct police investigations

and interrogations."

Young police detective, Bachelor in Criminal Investigation of the Netherlands Police Academy,

Amsterdam Police Force (2016) 


\section{Curriculum Vitae}


After graduating high school in 1996, I was selected for the Executive Master of Tactical Policing (Leergang Tactisch Management) at the Police Academy of the Netherlands, which I graduated from in 2000. Subsequently, I worked at different police departments in Amsterdam, Breda, Eersel, and Tilburg, in different ranks and positions. In 2007, I started a Bachelor's study Psychology at the Open University of the Netherlands next to my job. Five years later I earned a Bachelor's degree in Psychology. My Bachelor's thesis was selected for an oral presentation at the Dutch Student Research Conference in 2012, Utrecht University, the Netherlands. In July 2013, I obtained a Master's degree in Clinical Psychology at the Open University of the Netherlands. During my Bachelor's and Master's studies, I enrolled in several additional courses on neuropsychology, law, and management at Tilburg University and the Open University of the Netherlands. In January 2014, I started a PhD research project at Maastricht University and the Police Academy of the Netherlands under the supervision of Prof. Corine de Ruiter, PhD (Full Professor of Forensic Psychology at Maastricht University), and Nicolien Kop, PhD (Professor of Applied Sciences at the Police Academy of the Netherlands). In May 2016, I rejoined the Amsterdam police force as a senior police officer. Since October 2018, I work as a researcher at Team Research of the Police Academy of the Netherlands, but occasionally I can still be found as a police officer in the city centre of Amsterdam. 
